\title{
MINERAÇÃO DE DADOS, SIG E ANÁLISE MULTICRITÉRIO COMBINADOS PARA O PLANEJAMENTO DE REDES CICLOVIÁRIAS URBANAS
}

Tese apresentada à Escola de Engenharia de São Carlos da Universidade de São Paulo, como parte dos requisitos para a obtenção do título de Doutor em Ciências no Programa de Pós-Graduação em Engenharia de Transportes.

Área de concentração: Planejamento e Operação de Sistemas de Transporte.

Orientador: Prof. Titular Antônio Nélson Rodrigues da Silva

SÃO CARLOS

2016 
AUTORIZO A REPRODUÇÃO TOTAL OU PARCIAL DESTE TRABALHO, POR QUALQUER MEIO CONVENCIONAL OU ELETRÔNICO, PARA FINS DE ESTUDO E PESQUISA, DESDE QUE CITADA A FONTE.

Guerreiro, Thais de Cássia Martinelli

Mineração de dados, SIG e análise multicritério combinados para o planejamento de redes cicloviárias urbanas / Thais de Cássia Martinelli Guerreiro; orientador Antônio Nélson Rodrigues da Silva. São Carlos, 2016.

Tese (Doutorado) - Programa de Pós-Graduação em Engenharia de Transportes e Área de Concentração em Planejamento e Operação de Sistemas de Transporte -Escola de Engenharia de São Carlos da Universidade de São Paulo, 2016.

1. Mineração de dados. 2. SIG. 3. Análise multicritério. 4. Planejamento de redes cicloviárias. 5. Ciclistas potenciais. I. Título. 
FOLHA DE JULGAMENTO

Candidata: Engenheira THAIS DE CASSIA MARTINELLI GUERREIRO.

Título da tese: "Mineração de dados, SIG e análise multicritério combinados para o planejamento de redes cicloviárias urbanas"

Data da defesa: 24/10/2016.

Comissão Julgadora:

Prof. Titular Antônio Nélson Rodrigues da Silva (Orientador)

(Escola de Engenharia de São Carlos/EESC)

Profa. Dra. Cira Souza Pitombo

(Escola de Engenharia de São Carlos/EESC)

Prof. Dr. Rui António Rodrigues Ramos

(Universidade do Minho/Portugal)

Dra. Janice Kirner Providelo

(Pós-Doutoranda/CAPES)

Profa. Dra. Anna Beatriz Grigolon

(University of Twente/Holanda)
Resultado:

APROVADA

APROVADA

.

APROVADA

APROVADA

¿PPOVDDA

Coordenadora do Programa de Pós-Graduação em Engenharia de Transportes:

Prof. Associada Ana Paula Camargo Larocca

Presidente da Comissão de Pós-Graduação:

Prof. Associado Luis Fernando Costa Alberto 

Dedico este trabalho ao meu pai José Sanches Guerreiro (In Memorian), meu maior amigo e incentivador ao longo de todos estes anos 



\section{AGRADECIMENTOS}

A Deus, não só pelas condições físicas e psicológicas em minha vida, mas por me proporcionar crescer e estudar em uma cidade onde encontrei todas as oportunidades para tal. Enquanto tantos colegas vêm de tão longe para estudar, poder fazer isso praticamente dentro de casa realmente é um privilégio para poucos.

À minha família, por sempre me apoiar e, na maioria das vezes, entender a minha ausência em vários momentos. Ao meu pai, por ter me dado a oportunidade de estudar e sempre me apoiar, nunca cobrando nada em troca. Onde estiver, só queria que soubesse que realmente não tenho palavras para agradecer.

Ao professor Antônio Nélson, não só por ser um excelente profissional, sempre ético, coerente e paciente, mas também por ser uma excelente pessoa, me orientando e ajudando a crescer muito ao longo deste anos.

À banca de qualificação, Prof ${ }^{\underline{a}}$ Cira Pitombo e Prof. Rui Ramos, pelas sugestões para a complementação deste trabalho.

Ao Pedro, por sempre acreditar em mim, me incentivar e apoiar em todos os momentos. Quando se tem ao lado quem lhe ajuda a perseverar, a caminhada fica mais leve.

Aos professores do Departamento de Engenharia Civil da Universidade Federal de São Carlos (DECiv/UFSCar): Itamar Lorenzon, Rochele Ribeiro, Marcelo Takeda, Marcos Ferreira e Archimedes Raia Jr., pelo apoio, compreensão e incentivo.

À Luciana Pizzo, pela oportunidade de iniciar na docência.

Àqueles que sempre me apoiaram com palavras de incentivo: Cida Cris, Marco Antônio, Alexandre Seixas, Roberta Grau e Maria Eugênia.

Aos colegas de orientação: Carlos Prado, Peolla Stein, Conrado Plaza, Gláucia Maia, Thiago Ramos, Angélica Meireles, Leonardo Cadurin e Javier Mahechan. 
Aos colegas de departamento: Rafael Bizerra (GV!), Elaine Ribeiro, Tiago Torquato, Renaude Carneiro, Francisco Roza de Moraes, Fabio Vieira, pelos momentos de descontração.

Aos "Pilateiros das 18h30", pelas sessões de risoterapia e Pilates.

Às funcionárias do STT: Heloisa e Beth, sempre auxiliando nas questões burocráticas. À Magaly, Sabrina e Ana, pela amizade e descontração. Ao Toco, pelo auxílio na área de informática e ao Paulinho, pela amizade.

A todos aqueles que, ao longo destes anos, em algum momento me apoiaram, mas que por esquecimento e não por desmerecimento, não foram citados. 
"Disciplina é a ponte que liga nossos sonhos às nossas realizações." Pat Tillman 



\section{RESUMO}

GUERREIRO, T. C. M. G. Mineração de dados, SIG e análise multicritério combinados para o planejamento de redes cicloviárias urbanas. 2016. 131p. Tese (Doutorado). Escola de Engenharia de São Carlos, Universidade de São Paulo, São Carlos, 2016.

A bicicleta é vista hoje como uma alternativa para melhorar a mobilidade urbana de forma sustentável. Apesar disto, os procedimentos de planejamento disponíveis para o desenvolvimento de infraestruturas cicloviárias ainda não estão totalmente consolidadas. Sendo assim, este estudo visa desenvolver e aplicar um método objetivo para o planejamento de redes cicloviárias com base na mineração de dados desagregados de origem-destino, em recursos de SIG e de técnicas de análise multicritério. É sugerida a realização de três etapas: a) identificação, a partir do perfil de usuários reais, de usuários potenciais, b) planejamento de propostas de redes cicloviárias, e c) comparação entre as redes propostas e as definidas pelo poder municipal, considerando os usuários reais e potenciais e critérios de custos e benefícios. Como resultado positivo, o uso de dados desagregados permitiu mensurar e analisar a proximidade dos usuários às redes, a quantidade de pessoas atendidas e a identificação dos usuários potenciais. Além disso, a análise com base em critérios de custo e de benefício foi capaz de indicar, por exemplo, que a rede cicloviária existente $(\mathrm{RCE})$ na cidade considerada como estudo de caso (São Carlos, $\mathrm{SP}$, Brasil) não serve adequadamente os usuários, quando comparado às redes propostas.

Palavras-chave: Transporte Sustentável. Planejamento Cicloviário. Dados Desagregados. Geoprocessamento. Ciclistas Potenciais. 



\section{ABSTRACT}

\section{GUERREIRO, T. C. M. G. Data mining, GIS and multicriteria analysis}

combined for planning urban cycling networks. 2016. 131p. Thesis (Ph.D.). Engineering School of São Carlos, University of São Paulo, São Carlos, 2016.

Cycling is seen nowadays as an alternative to improve urban mobility in a sustainable way. Nevertheless, the planning procedures available for developing cycling infrastructures are not yet fully consolidated. This study aims at the development and application of an objective method for planning cycling networks based on data-mining of disaggregated origindestination data, GIS resources and multicriteria analysis techniques. The method involves basically three steps: a) an identification of potential users based on real users' profiles, b) planning of proposed cycling networks, and c) a comparison, considering real and potential users, as well as cost-benefit criteria, between the proposed networks and those actually developed by the municipality. As a positive outcome, the use of disaggregated data allows not only a reasonable estimate of the number of people served by the networks, but also a detailed analysis of their proximity to that infrastructure and an identification of potential users. Also, the analysis based on cost-benefit criteria was able to show, for example, that the existing cycling network (ECN) of the city taken as a case study (São Carlos, SP, Brazil) does not properly serve the users, when compared to the proposed networks.

Keywords: Sustainable Transport. Bicycle Planning. Disaggregated Data. Geoprocessing. Potential Cyclists. 



\section{LISTA DE FIGURAS}

Figura 2.1: Possibilidade de configuração de ciclofaixas 29

Figura 2.2: Tipo de infraestrutura cicloviária, de acordo com volume e velocidade permitida dos veículos motorizados. 30

Figura 3.1: Representação esquemática dos procedimentos propostos . 59 Figura 4.1: Redes cicloviárias existente (RCE) e projetada $(R C P)$ da cidade de São Carlos

Figura 4.2: Esquema com as quatro variáveis principais formadas pela árvore dos

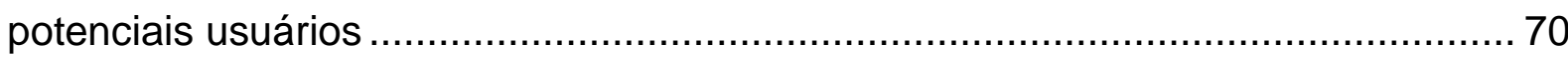

Figura 4.3: Árvore de Decisão - Amostra de treinamento .................................... 72

Figura 4.4: Árvore de Decisão - Amostra de teste .............................................. 73

Figura 4.5: Resultado na forma tabular do SPSS Statistics - adaptado .................. 77

Figura 4.6: Probabilidade do uso de bicicleta - Usuários potenciais ........................ 78

Figura 4.7: Localização geográfica (origens e destinos) - Usuários potenciais ........ 80

Figura 4.8: Distribuição dos motivos das viagens - usuários reais ......................... 82

Figura 4.9: Georreferenciamento de origens e destinos das viagens por bicicleta e um exemplo de quatro rotas possíveis a partir de um ponto de origem .................. 83 Figura 4.10: Contabilização do número de possíveis rotas sobrepostas em cada

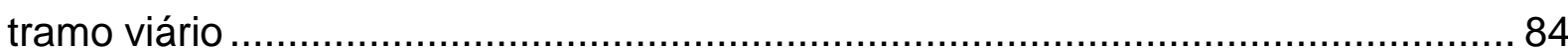

Figura 4.11: Identificação do número de rotas sobrepostas nos tramos viários ....... 86 Figura 4.12: Exemplo de avaliação do perfil topográfico - ponto específico no tramo viário (a) Rua São Joaquim (b) Rua Rui Barbosa ........................................... 87 Figura 4.13: Exemplo de avaliação do perfil topográfico - extensão do trecho(a) Rua São Joaquim (b) Rua Rui Barbosa ........................................................... 88 Figura 4.14: Rede de rotas cicloviárias propostas .......................................... 89

Figura 4.15: Exemplo de construção de banda ao redor de uma rede traçada ........ 91 Figura 4.16: Exemplo de construção de banda ao redor de uma das redes traçada, considerando os setores censitários .......................................... 92 Figura 4.17: Georreferenciamento dos estabelecimentos comerciais e industriais e escolas.

Figura 4.18: Normalização de custos e benefícios das redes estudadas - Usuários reais

Figura 4.19: Normalização de custos e benefícios das redes estudadas - Usuários potenciais. 101 



\section{LISTA DE TABELAS}

Tabela 2.1: Modelos de demanda de viagens por bicicleta................................... Tabela 2.2: Relação de estudos que identificaram os potenciais usuários limite da extensão das viagens 12

Tabela 2.3: Fatores que influenciam o uso da bicicleta nos deslocamentos diários .15 Tabela 2.4: Infraestrutura cicloviária prevista para algumas capitais brasileiras ......21 Tabela 2.5: Relação dos estudos e respectivas variáveis e métodos para o planejamento de redes cicloviárias .23

Tabela 2.6: Critérios selecionados para avaliação de redes cicloviárias....................32

Tabela 3.1: Descrição das etapas que constituem o método utilizado ......................57 Tabela 4.1: Relação entre classe socioeconômica e renda média familiar máxima $(R \$)$. .66

Tabela 4.2: Tipo de variável utilizada no minerador de dados .68

Tabela 4.3: Extensão das viagens realizadas de acordo com o modo - Usuários potenciais 79

Tabela 4.4: Variáveis calculadas para avaliação das redes cicloviárias propostas e as definidas pelo poder público municipal - Usuários reais/usuários potenciais .......93 Tabela 4.5: Comparação direta de critérios de custos e benefícios - Usuários reais/usuários potenciais .97

Tabela 4.6: Limites considerados para normalização dos resultados - análise de sensibilidade. .98 



\section{LISTA DE ABREVIATURAS}

ABRACICLO: Associação Brasileira dos Fabricantes de Motocicletas, Ciclomotores, Motonetas, Bicicletas e Similares

ABRADIBI: Importação e Exportação de Bicicletas, Peças e Acessórios

AD: Árvore de Decisão

ANTP: Associação Nacional dos Transportes Públicos

BBC: British Broadcasting Corporation

BHTRANS: Empresa de Transportes e Trânsito de Belo Horizonte

CART: Classification and Regression Trees

CHAID: CHi-squaredAutomatic Interaction Detection

CTB: Código de Trânsito Brasileiro

DENATRAN: Departamento Nacional de Trânsito

EESC: Escola de Engenharia de São Carlos

EUA: Estados Unidos da América

FHWA: Federal Highway Administration

GEIPOT: Empresa Brasileira de Planejamento de Transportes

GPS: Global Positioning System

IBGE: Instituto Brasileiro de Geografia e Estatística

IDU: Instituto de Desarrollo Urbano

IMPLAN: Instituto Municipal de Planeación Urbana

IPI: Imposto sobre Produtos Industrializados

IPPUC: Instituto de Pesquisa e Planejamento Urbano de Curitiba

MDTA : Metro-Dade Transit Agency

MD: Mineração de Dados

MTMC: Modelo Transteórico de Mudança Comportamental

NCHRP: National Cooperative Highway Research Program

PL: Projeto de Lei

PlanMob BH : Plano de Mobilidade Urbana de Belo Horizonte

PNAD: Pesquisa Nacional por Amostra de Domicílios

PGV's : Polos Geradores de Viagens

QUEST: National Cooperative Highway Research Program

SIG : Sistema de Informação Geográfica

SMAC: Secretaria Municipal de Meio Ambiente

SR: Sensoriamento Remoto

TRB: Transportation Research Board

UNICEP: Centro Universitário Central Paulista

UFSCar: Universidade Federal de São Carlos

USP: Universidade de São Paulo 



\section{SUMÁRIO}

\section{INTRODUÇÃO}

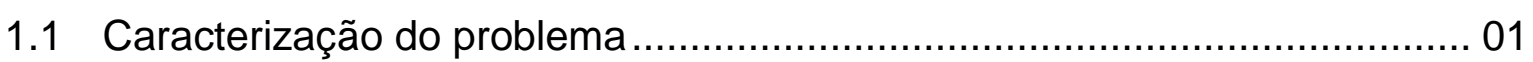

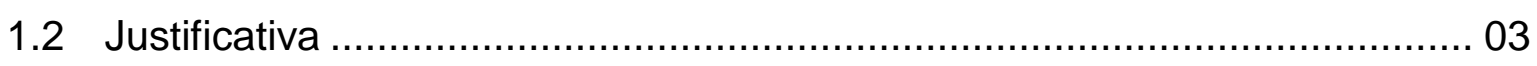

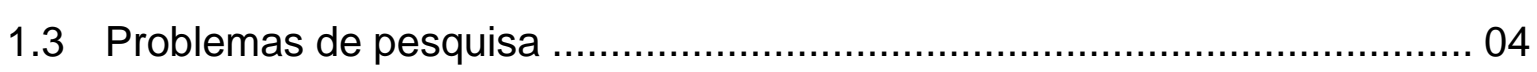

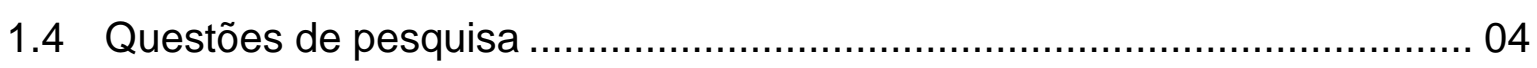

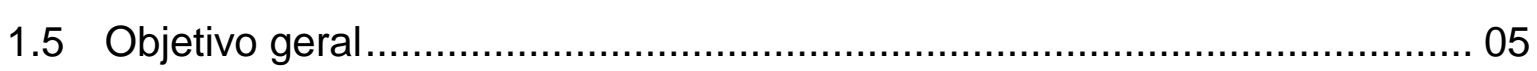

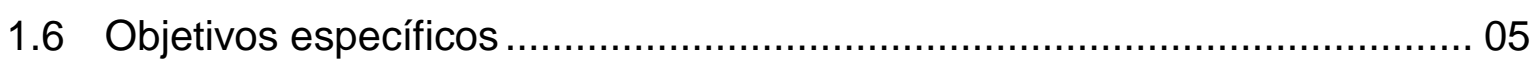

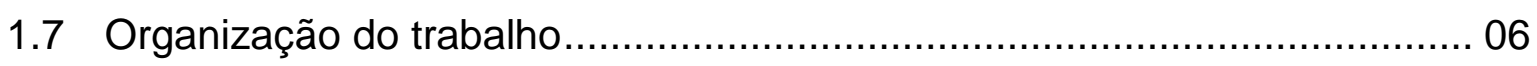

\section{REVISÃO BIBLIOGRÁFICA}

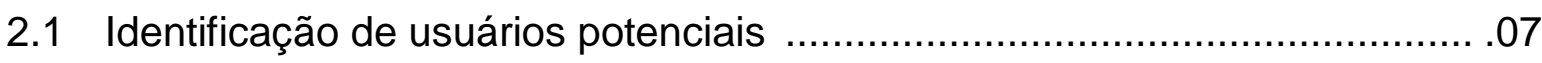

2.2 Fatores que influenciam a utilização da bicicleta nos deslocamentos diários

2.3 Panorama das redes cicloviárias no Brasil ............................................. 18

2.4 Planejamento de redes cicloviárias....................................................... 22

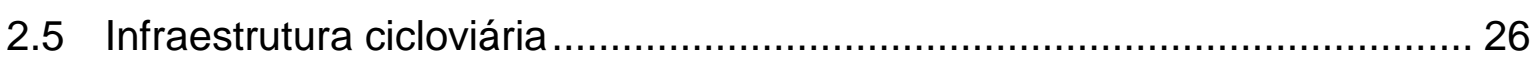

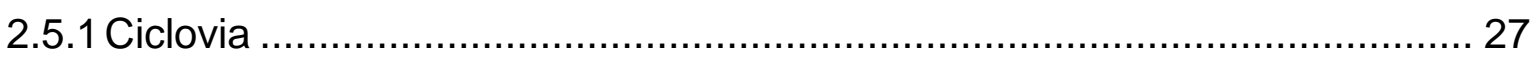

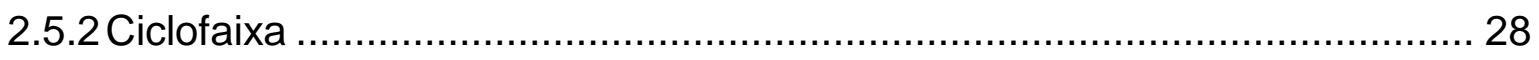

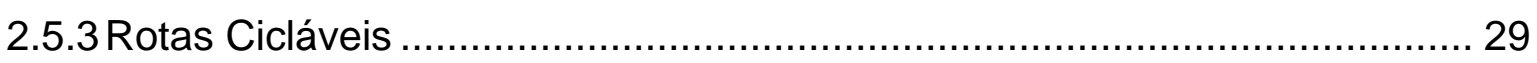

2.5.4 Vias e passeios com tráfego compartilhado ........................................... 29

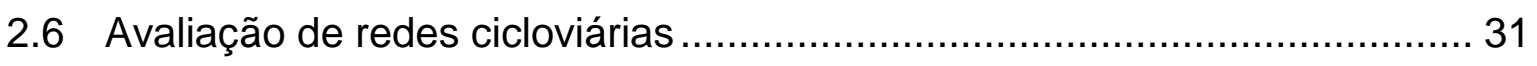

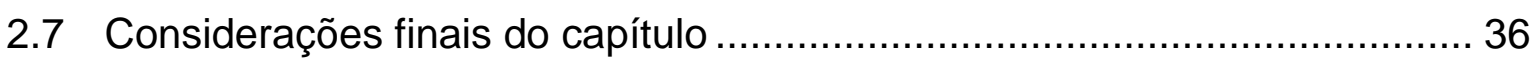

\section{MATERIAIS E MÉTODO}

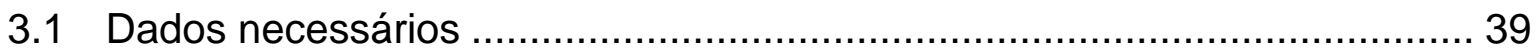

3.2 Identificação dos usuários potenciais ......................................................... 41

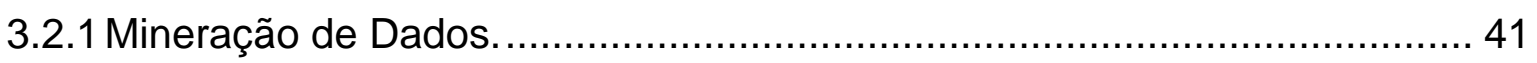

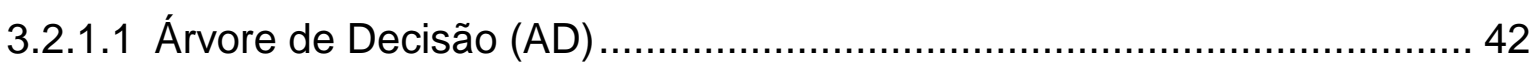

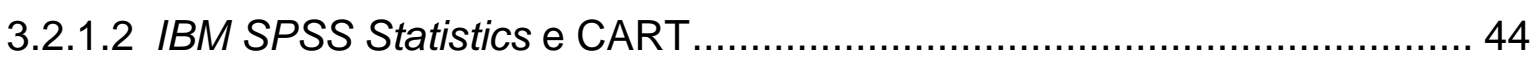

3.2.1.3 Aplicação da técnica no estudo em questão ....................................... 49

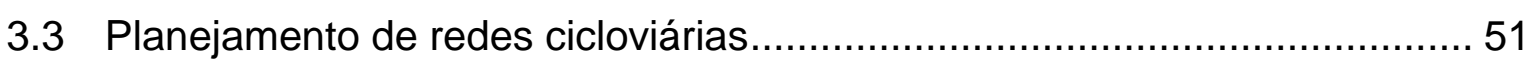




\section{APLICAÇÃO DO MÉTODO EM ESTUDO DE CASO}

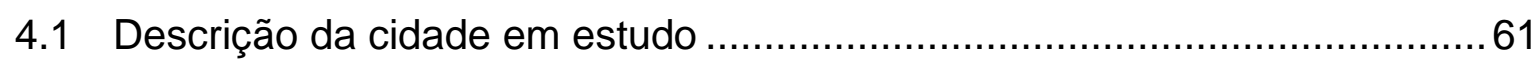

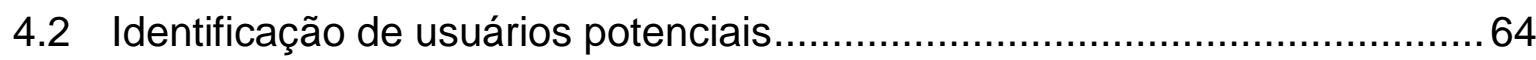

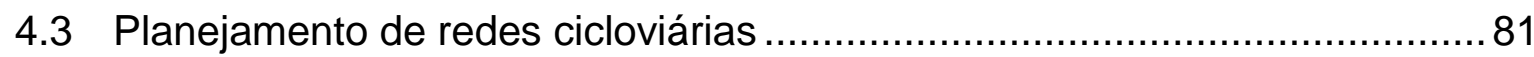

4.4 Comparação entre as redes cicloviárias ...................................................90

\section{CONCLUSÕES E RECOMENDAÇÕES}

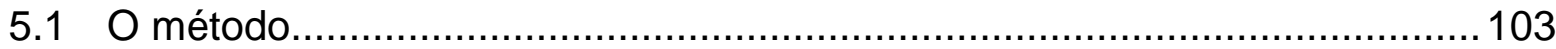

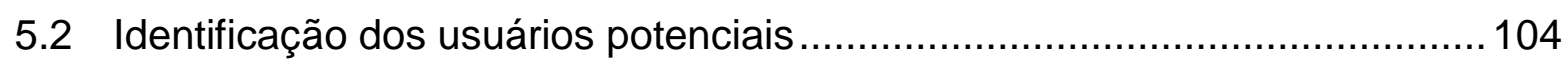

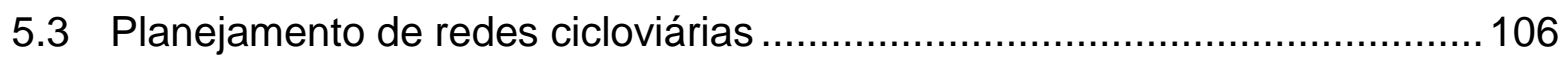

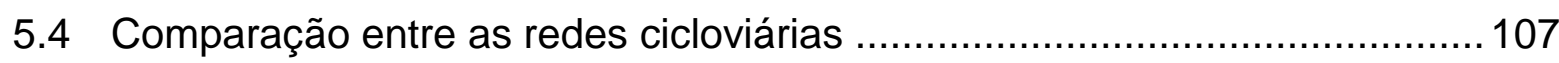

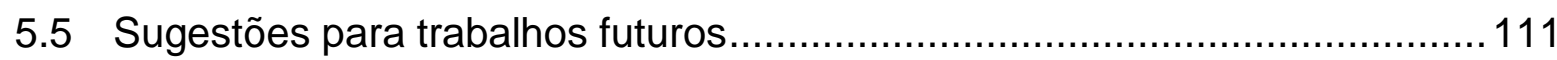

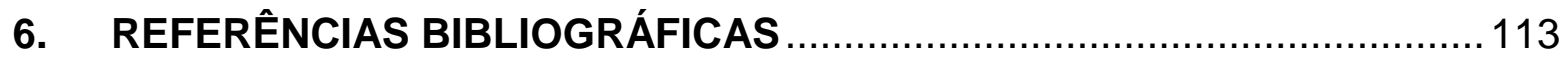




\section{INTRODUÇÃO}

De forma a entender o que este estudo propõe, neste capítulo é apresentada uma introdução sobre o mesmo. Para tanto e de forma a contextualizar o tema, é apresentada uma caracterização do problema estudado e as justificativas para realização desta pesquisa. Além disso, também são apresentados os problemas e as questões de pesquisa pertinentes a este tema, os objetivos do trabalho (geral e específicos) e a forma como o mesmo está organizado.

\subsection{Caracterização do problema}

Nos últimos cem anos, o sistema de mobilidade no Brasil vem sofrendo grandes transformações. Há sessenta anos, o principal meio de locomoção era o transporte a pé e por bicicleta e as cidades estavam concentradas em pequenos núcleos. Com o advento da indústria automobilística a partir da década de 1950, associada a outras modificações estruturais na sociedade brasileira, verificou-se uma grande expansão urbana (muitas vezes realizada sem planejamento global) e um aumento e valorização cada vez mais evidentes do uso do transporte motorizado individual. De acordo com estudo realizado por Morais et al. (2012), considerando dados da Pesquisa Nacional por Amostra de Domicílios (PNAD) para o ano de 2009, quase metade dos domicílios brasileiros (47\%) possuíam automóveis ou motocicletas. Mais especificamente, entre 2008 e 2009, o percentual de domicílios que apresentavam um destes dois modos de transporte subiu de $45,2 \%$ para $47,0 \%$, com previsão de elevação acentuada.

Com núcleos urbanos cada vez mais distantes dos locais de emprego e de serviço, ausência ou ineficiência de programas voltados à implantação de infraestrutura para o transporte coletivo e para os deslocamentos não motorizados, as distâncias e os tempos de deslocamento ainda continuam aumentando. Nas principais regiões metropolitanas (RMs) do Brasil (Distrito Federal, Curitiba, Salvador, Belo Horizonte, Porto Alegre, Rio de Janeiro, São Paulo, Fortaleza, Recife e Belém, conforme IBGE, 2010), o tempo de deslocamento entre residência e trabalho de cerca de $50 \%$ dos trabalhadores é inferior a 30 minutos. Já fora destas 
regiões, o percentual é de quase $80 \%$ (Morais et al., 2012). Todo este quadro leva a uma insustentabilidade da cidade, verificada pela elevação dos níveis de poluição atmosférica, alto consumo de recursos naturais, segregação dos espaços urbanos, elevado número de acidentes de trânsito e um aumento cada vez maior da imobilidade urbana (Benicchio, 2012).

Apenas como exemplo, com base em dados de 438 municípios brasileiros com população acima de 60.000 habitantes, houve, entre os anos de 2003 e 2013, um aumento de $28,3 \%$ na emissão de poluentes do efeito estufa decorrentes do uso dos automóveis (ANTP, 2015). Para o ano de 2014, o custo estimado dos acidentes de trânsito nas cidades brasileiras foi igual a $R$ \$ 10 bilhões (IPEA, 2015).

Para tentar minimizar cada vez mais os impactos negativos desta expansão desenfreada e insustentável das cidades, o governo federal vem regulamentando dispositivos em forma de lei visando à melhoria da mobilidade urbana.

Com a regulamentação da Lei no 10.257/2001 (BRASIL, 2001), denominada Estatuto da Cidade, todos os municípios com mais de 20.000 habitantes ficaram obrigados a executar um Plano Diretor e aqueles com mais de 500.000 habitantes, um plano de transporte urbano integrado e compatível com o Plano Diretor. Ainda assim, somente com a regulamentação da Lei no 12.587/2012 (BRASIL, 2012), conhecida como Lei da Mobilidade Urbana, é que as diretrizes da Política Nacional de Mobilidade Urbana foram consolidadas, exigindo que os municípios com mais de 20.000 habitantes realizassem o Plano de Mobilidade Urbana, contemplando ações que priorizem os modos não motorizados e contribuindo para a redução do quadro de insustentabilidade característico das cidades brasileiras médias e grandes.

Ainda, para o estado de São Paulo, no ano de 2014 foi sancionada a Lei no 15318, que institui a "Política de Mobilidade Sustentável e Incentivo ao Uso da Bicicleta e dá Outras Providências" (São Paulo, 2014). Além de incentivar o uso da bicicleta como meio de transporte, visando à redução do uso do automóvel, esta lei também tem como objetivo estimular a ligação entre as cidades, através de redes cicloviárias seguras e adequadas aos deslocamentos. 


\subsection{Justificativa}

Mesmo havendo dispositivos que obrigam os municípios a priorizarem ações para os modos sustentáveis (a pé e bicicleta), somente a instituição da lei não é suficiente para estimular o uso da bicicleta como alternativa de transporte. É necessário garantir segurança, conforto e rapidez aos deslocamentos por este modo, o que, em muitos casos, exige a criação e implantação de novas infraestruturas. O planejamento de infraestruturas condizentes com as localizações dos usuários e com as características urbanas e de tráfego ainda é, no entanto, uma prática não consolidada nas prefeituras do Brasil, em parte porque faltam métodos claros e objetivos para tal.

Somente planejar uma rede cicloviária também não é suficiente. É necessário ter conhecimento sobre a eficácia do atendimento das mesmas (sejam elas existentes ou propostas) aos seus usuários (reais ou potenciais). Uma rede mal planejada, que não atende aos pontos de interesse dos usuários, além de ser um exemplo de desperdício de dinheiro público, pode também tornar-se ineficaz, contribuindo eventualmente para o aumento do número de acidentes envolvendo ciclistas.

Uma forma de medir a eficácia do atendimento das redes cicloviárias é, por exemplo, através da análise de vários critérios de custos e benefícios comuns às redes consideradas (análise multicritério).

Tanto o planejamento de redes cicloviárias como as medidas da eficácia de seu atendimento podem também subsidiar a implantação de um sistema de apoio à decisão voltado aos transportes sustentáveis. Além disso, a localização das redes cicloviárias próximas aos terminais e à rede de transporte público pode possibilitar uma maior integração entre estes dois modos de transporte, possibilitando um aumento das viagens realizadas sem a utilização de veículos motorizados individiuais e contribuindo para uma cidade mais sustentável. 


\subsection{Problemas de pesquisa}

$\mathrm{Na}$ maioria das cidades brasileiras o procedimento prático de emprego mais simples e direto de planejamento de novas redes cicloviárias ainda é o desenho da rede de forma exploratória. Em muitas situações, este método pode ser considerado falho, pois considera os dados da população associados a setores censitários. O principal problema deste procedimento reside no fato de que os dados de população obtidos desta maneira são extremamente agregados, o que a princípio já introduz dois problemas. O primeiro é o viés associado ao problema de agregação de dados conhecido como "falácia ecológica", que advém do fato de se admitir implicitamente que a população considerada esteja distribuída de forma absolutamente homogênea em cada setor censitário, o que em geral não acontece na realidade. Além disso, o uso de dados agregados não permite analisar as características dos indivíduos e a sua proximidade à rede, dificultando um melhor entendimento sobre a relação existente entre proximidade e propensão ao uso da bicicleta por parte dos mesmos (Dill e Carr, 2003).

O segundo problema é o fato de que não se identifica, nesta população, os usuários do modo cicloviário, sejam eles usuários efetivos ou potenciais. Usuários efetivos podem ser definidos como os usuários reais que já utilizam a bicicleta em seus deslocamentos diários. Já usuários potenciais são aqueles que utilizam outro modo de transporte que não a bicicleta, mas que podem, dado o seu perfil, vir a utilizá-la em seus deslocamentos.

\subsection{Questões de Pesquisa}

Diante deste panorama, este estudo visa responder a algumas questões que podem ser levantadas na busca de um melhor entendimento sobre a identificação dos usuários potenciais do modo bicicleta e de como as redes cicloviárias podem ser planejadas e avaliadas:

- Como identificar potenciais usuários sem dispor de questionários de preferência declarada ou revelada?

- Como planejar redes cicloviárias utilizando dados desagregados de população? 
- Quais critérios devem ser considerados ao avaliar redes cicloviárias propostas e como compará-las com a infraestrutura existente?

Para responder a estas perguntas foi desenvolvido um método que contempla um objetivo geral, mais amplo e voltado ao planejamento de redes cicloviárias, e objetivos específicos, relacionados à identificação dos usuários potenciais e às redes estudadas. O método proposto foi aplicado em uma cidade brasileira de porte médio e que contém uma infraestrutura cicloviária incipiente,

\subsection{Objetivo geral}

O objetivo geral deste estudo é desenvolver um método objetivo para planejamento de redes cicloviárias, considerando usuários reais e potenciais.

\subsection{Objetivos específicos}

Como objetivos específicos, que em grande medida se sobrepõem à proposta metodológica, têm-se:

- Identificação de usuários potenciais do modo bicicleta, através da utilização de um minerador de dados;

- Proposta de procedimento para planejamento de redes cicloviárias, utilizando SIG (Sistema de Informação Geográfica) e critérios préestabelecidos;

- Estabelecimento de critérios de custo e benefício comuns às redes estudadas;

- Comparação entre a utilização de dados agregados e desagregados de população para avaliação de redes cicloviárias;

- Comparação entre redes cicloviárias propostas neste estudo e as definidas pelo poder público (existente e proposta) de uma cidade de porte médio, através de uma análise multicritério. 


\subsection{Organização do trabalho}

Para a realização deste estudo, além deste capítulo introdutório, são propostos cinco capítulos, cada qual abordando itens fundamentais para consolidação do mesmo.

No "Capítulo 2 - Revisão bibliográfica" é apresentada a fundamentação teórica para o desenvolvimento deste estudo, apresentando estudos realizados no Brasil e no exterior. Os materiais utilizados e as etapas necessárias para se atingir o objetivo proposto são apresentadas no "Capítulo 3 - Materiais e método". No "Capítulo 4 - Aplicação do método em estudo de caso" são apresentados todos os resultados obtidos, visando atingir os objetivos traçados no "Capítulo 1 - Introdução". As conclusões obtidas e as sugestões para trabalhos futuros são apresentados no "Capítulo 5 - Conclusão". Por fim, as referências bibliográficas que serviram de base para a fundamentação deste trabalho são apresentadas no "Capítulo 6 - Referências bibliográficas". 


\section{REVISÃO BIBLIOGRÁFICA}

Para a fundamentação dos conceitos abordados nesta tese, este capítulo versa sobre os pontos principais relacionados com o estudo apresentado. Baseando-se na literatura consultada foi possível elencar seis temas principais referentes ao estudo apresentado. Tais temas são tratados nesta revisão e podem ser divididos em: i) identificação de usuários potenciais do modo bicicleta; ii) fatores que influenciam a utilização da bicicleta nos deslocamentos diários; iii) panorama das redes cicloviárias no Brasil; iv) planejamento de redes cicloviárias; v) infraestrutura cicloviária, e vi) critérios de avaliação de redes cicloviárias. Ao final do capítulo, também são apresentadas algumas considerações finais acerca dos temas apresentados.

\subsection{Identificação de usuários potenciais}

$\mathrm{Na}$ literatura de transportes, algumas abordagens podem ser empregadas para a determinação da previsão de demanda de viagens por bicicleta. Ao realizar esta previsão e dependendo dos tipos de dados envolvidos (agregados ou desagregados), pode ser possível também estimar quais serão os usuários potenciais. Em trabalho desenvolvido por Turner et al. (1997) são apresentados alguns modelos (Tabela 2.1) que utilizaram a estrutura de modelagem tradicional em transportes (modelo de quatro etapas), ou seja, modelos que contemplaram as etapas de geração e distribuição de viagens, escolha modal e alocação das viagens (escolha das rotas). Ainda de acordo com Turner et al. (1997) embora estes modelos possam apresentar uma razoável margem de erro, podem apresentar uma melhoria na deficiência existente nas ferramentas de previsão de demanda. 
Tabela 2.1: Modelos de demanda de viagens por bicicleta - Turner et al. (1997)

\begin{tabular}{|c|c|c|}
\hline Modelo (ano) & Variáveis de entrada & Método \\
\hline $\begin{array}{l}\text { Rhode Island Pre-ISTEA } \\
\text { Study (1982) }\end{array}$ & $\begin{array}{l}\text { - Dados do censo de } 1980 \\
\text { - Zonas de tráfego } \\
\text { - Infraestrutura cicloviária } \\
\text { existente (ciclovia/ciclofaixa) }\end{array}$ & $\begin{array}{l}\text { Estimativa da demanda } \\
\text { cicloviária entre as cidades } \\
\text { de Bristol e Providence para } \\
\text { os anos de } 1980 \text { e } 2000\end{array}$ \\
\hline $\begin{array}{l}\text { Metro-Dade Transit Agency } \\
\text { Bikes-on-Bus Program } \\
\text { (MDTA) (1995) }{ }^{2}\end{array}$ & $\begin{array}{l}\text { - Dados de localização dos } \\
\text { indivíduos (usuários ciclistas e } \\
\text { não ciclistas) } \\
\text { - Dados do censo de } 1990\end{array}$ & $\begin{array}{l}\text { Através da junção dos dados } \\
\text { sobre setores censitários } \\
\text { com alta demanda de } \\
\text { viagens de bicicleta com o } \\
\text { trajeto das linhas de ônibus, } \\
\text { selecionaram-se as linhas } \\
\text { que poderiam atrair os } \\
\text { ciclistas, possibilitando a } \\
\text { integração entre os modos }\end{array}$ \\
\hline $\begin{array}{l}\text { Comparison of Dade } \\
\text { County Demand Models } \\
(1995)^{3}\end{array}$ & $\begin{array}{l}\text { - Dados de acidentes } \\
\text { envolvendo ciclistas }\end{array}$ & $\begin{array}{l}\text { Derivado do modelo anterior, } \\
\text { com a inclusão de novos } \\
\text { dados }\end{array}$ \\
\hline $\begin{array}{l}\text { Ridgway's Demand } \\
\text { Modeling Techniques for } \\
\text { Bicycles (1995) } 4\end{array}$ & $\begin{array}{l}\text { - Dados socioeconômicos } \\
\text { - Dados de uso do solo }\end{array}$ & $\begin{array}{l}\text { Estimativa das viagens } \\
\text { realizadas por bicicleta para } \\
\text { cada zona considerada da } \\
\text { cidade de Berkeley (modelo } \\
\text { Logit multinominal). Através } \\
\text { do modelo gravitacional foi } \\
\text { possível distribuir as viagens } \\
\text { entre as zonas }\end{array}$ \\
\hline $\begin{array}{l}\text { North Central Texas } \\
\text { Council of Governments' } \\
\text { Bicycle Needs Index } \\
(1996)^{5}\end{array}$ & $\begin{array}{l}\text { - Dados do censo de } 1990 \\
\text { - Dados de uso do solo } \\
\text { - Revisão da literatura } \\
\text { - Análise de regressão }\end{array}$ & $\begin{array}{l}\text { Desenvolvimento de um } \\
\text { índice para identificar as } \\
\text { zonas de tráfego com alto } \\
\text { uso da bicicleta e } \\
\text { infraestrutura adequada }\end{array}$ \\
\hline $\begin{array}{l}\text { Landis's Latent Demand } \\
\text { Score }(1996)^{6}\end{array}$ & $\begin{array}{l}\text { - Localização de PGV's }{ }^{8} \text { e } \\
\text { suas respectivas áreas de } \\
\text { influência } \\
\text { - Classificação de cada } \\
\text { segmento da via de acordo } \\
\text { com a proximidade aos } \\
\text { PGV's considerados } \\
\text { - Modelo gravitacional } \\
\text { probabilístico }\end{array}$ & $\begin{array}{l}\text { Estimativa da demanda } \\
\text { latente (potencial) de } \\
\text { viagens de bicicleta em uma } \\
\text { rede viária }\end{array}$ \\
\hline $\begin{array}{l}\text { Goldsmith's Study of } \\
\text { Seattle's Pine Street } \\
\text { Bicycle Lanes (19--) }\end{array}$ & $\begin{array}{l}\text { - Dados do censo da cidade } \\
\text { de Seattle } \\
\text { - Pesquisa de preferência } \\
\text { declarada }\end{array}$ & $\begin{array}{l}\text { Estimativa do número de } \\
\text { novas viagens que poderiam } \\
\text { ser realizadas por bicicletas } \\
\text { e a redução de emissões de } \\
\text { poluentes, além da previsão } \\
\text { dos efeitos de instalação de } \\
\text { uma infraestrutura para } \\
\text { bicicletas sobre as viagens } \\
\text { realizadas pelos veículos de } \\
\text { turismo }\end{array}$ \\
\hline
\end{tabular}

Fonte: ${ }^{1}$ Rhode Island (1982), ${ }^{2}$ Center for Urban Transportation Research (1995), Epperson et al. (1995), ${ }^{4}$ Ridgway (1995), ${ }^{5}$ Department of Environmental Resources (1996), ${ }^{6}$ Landis (1996) e ${ }^{7}$ Goldsmith (19--) ${ }^{8}$ Polos Geradores de Viagens 
Além dos modelos apresentados por Turner et al. (1997), Rodrigues da Silva et al. (2012) descrevem outras duas abordagens que também podem ser utilizadas para a previsão de demanda por bicicletas.

- Modelo desenvolvido pelo TRB (NCHRP, 2006): através de dados censitários de vários estados americanos, foi possível obter equações que resultaram no percentual de adultos que utilizaram a bicicleta em seus deslocamentos diários em relação ao percentual de viagens por motivo trabalho. As equações foram obtidas para 15 regiões metropolitanas e 34 estados dos Estados Unidos e 65 zonas nas cidades de Minneapolis e St. Paul;

- Metodologia desenvolvida para Tomar, Portugal (Rodrigues da Silva, 2012): considerando informações de localização dos polos geradores de viagens da cidade de Tomar, visa fornecer um valor de potencial de procura de cada segmento da rede viária, utilizando bicicleta. O valor de potencial de procura é função do tempo de viagem entre cada polo (produtor e atrator) e função do motivo da viagem. Quanto maior o valor de potencial de um determinado segmento da rede viária, maior a sua importância para os deslocamentos por bicicleta.

Alguns dos modelos apresentados utilizaram dados agregados para suas estimativas. Entretanto, muitas vezes modelos agregados têm baixo poder explicativo das variáveis consideradas. Justamente pelo fato de considerar dados agregados, isto faz com que algumas variáveis sejam mascaradas por outras, não sendo possível identificar suas variações dentro da população considerada. Isto muitas vezes pode levar a interpretações que não condizem com a realidade estudada, prejudicando o resultado final do estudo (FHWA, 1999).

Uma forma de contornar estes problemas com dados agregados é a realização de pesquisas de preferência declarada ou revelada. A pesquisa de preferência revelada é baseada em escolhas reais dos indivíduos, já a declarada é baseada nas opiniões dos entrevistados a respeito de um modo de transporte que ainda não tenha sido utilizado. Para tanto, cenários hipotéticos são criados e apresentados aos entrevistados para a identificação de suas opiniões (Ortúzar e 
Willumsen, 2011). De acordo com as respostas obtidas é possível identificar, por exemplo, a opinião do entrevistado com relação à bicicleta e sua possível utilização nas viagens diárias, ou seja, identificar um usuário potencial.

Em geral, apenas identificar o usuário potencial não é suficiente. É necessário também ter conhecimento sobre suas localizações e principais destinos das viagens realizadas. Sem estas informações pode haver dificuldade em verificar se as redes cicloviárias, existentes ou projetadas, atendem aos seus desejos de deslocamento.

Muitos estudos têm utilizado questionários de preferência declarada ou revelada aplicados à população que se pretende estudar para identificar os usuários potenciais do modo bicicleta. Um exemplo são os estudos realizados em campi universitários, que se constituem em grandes polos geradores de viagens com pico de viagens, em geral, coincidentes com os picos do tráfego do sistema viário urbano (Bertazzo et al., 2012). Dentre os autores que têm se dedicado a estudar este tema, destacam-se Akar e Clifton (2009), Stein (2013), Wang et al. (2014), Hamer et al. (2015) e Marins et al. (2015).

Ainda com relação aos campi universitários, Guerreiro et al. (2013), e Thiesen e Vieira (2013) utilizaram outras formas de identificar os usuários potenciais. No primeiro estudo, usuários potenciais foram classificados como aqueles cujas origens estavam contidas em bandas de largura iguais a 100, 200, 300 e 400 metros ao redor da rede cicloviária de um campus universitário proposta por Guerreiro e Rodrigues da Silva (2013). Ressalta-se que os dados das origens das viagens foram provenientes da pesquisa realizada por Stein (2013).

Já no segundo estudo (Thiesen e Vieira, 2013), os usuários potenciais foram definidos baseando-se em pesquisa bibliográfica realizada pelos autores e considerando dados desagregados de uma pesquisa origem-destino. Para tanto, foram definidos como indivíduos com idade inferior a 55 anos, que percorreram distância máxima de bicicleta inferior a $6,00 \mathrm{~km}$ e distância máxima até uma estação de aluguel de bicicletas igual a 400,00 metros. 
Considerando a cidade como um todo, notadamente no Brasil poucos são os estudos realizados considerando dados (agregados ou desagregados) referentes aos deslocamentos de pelo menos uma parcela representativa da população total, e a possibilidade de identificação dos usuários potenciais de bicicleta. Principalmente com relação ao uso de dados desagregados provenientes de pesquisas origemdestino, nota-se uma escassez de estudos, podendo ser justificada pela sua complexidade de elaboração, bem como o custo associado. O custo previsto da pesquisa origem-destino realizada na cidade de Curitiba, por exemplo, é de $R \$ 6,3$ milhões para uma população entrevistada aproximada de 56.000 pessoas, ou seja, um custo por pessoa superior a $\mathrm{R} \$ 110,00$ (CBN Curitiba, 2016).

Alguns autores têm estudado o deslocamento da população ao longo da cidade, entretanto nem sempre utilizando dados de uma pesquisa origem-destino aplicada a toda população urbana, mas sim apenas em uma fração dela, muitas vezes considerando alguns polos geradores de viagens. Dentre estes autores estão, por exemplo, Ortúzar et al. (2000), Macket (2001), Bergström e Magnusson (2003), Dill e Voros (2007) e Wooliscroft e Ganglmair-Wooliscroft (2014).

Considerando uma parcela da população, a identificação de potenciais usuários também foi obtida através do estabelecimento de um determinado valor limite da extensão das viagens realizadas por outros modos, como pode ser verificado nos estudos listados na Tabela 2.2. 
Tabela 2.2: Relação de estudos que identificaram os potenciais usuários - limite da extensão das viagens

\begin{tabular}{lc}
\hline \multicolumn{1}{c}{ Autor (ano) } & $\begin{array}{c}\text { Limite da extensão das } \\
\text { viagens }\end{array}$ \\
\hline Walcyng (1997) & 5,00 \\
Gärling et al. (2000) & 3,50 \\
Mackett (2001) & 8,00 \\
Loukopoulos e Gärling (2005) & 4,10 \\
\hline Rastogi (2010) & 1,25 \\
\hline Larsen et al. (2013) & 2,00 \\
\hline Thiesen e Vieira (2013) & 6,00 \\
\hline Ruiz e Barnabé (2014) & 4,00 \\
\hline
\end{tabular}

De acordo com a maioria dos estudos apresentados na Tabela 2.2, viagens com extensão inferior a $5,00 \mathrm{~km}$ foram consideradas como as que poderiam ser realizadas por bicicletas. Para estas, consequentemente, poderia ser possível a identificação dos usuários potenciais (desde que os dados fosses desagregados).

Outra forma de obter os usuários potenciais é através da identificação do estágio de mudança de comportamento em que eles se encontram. A identificação deste estágio pode ser obtida através da aplicação do Modelo Transteórico de Mudança Comportamental (MTMC) (Prochaska e Di Clemente, 1984) à população que se pretende estudar. Para Prochaska e Di Clemente (1982, 1983), a mudança de comportamento do indivíduo não ocorre de forma abrupta, mas sim ao longo de estágios até a consolidação de um novo hábito. Os estágios podem ser classificados em: i) pré-contemplação, ii) contemplação, iii) preparado para a ação, iv) ação, v) manutenção e, vi) recaída. A aplicação do MTMC contribui apenas para identificar em qual estágio o indivíduo se encontra, uma vez que a mudança propriamente dita ocorre somente a partir da vontade de cada indivíduo (Grau, 2015).

Especificamente com relação à mudança de comportamento quanto ao ciclismo, alguns autores aplicaram este método com o objetivo de investigar em qual estágio do comportamento os indivíduos entrevistados se encontraram. Como exemplo, citam-se os estudos realizados por Nkurunziza et al. (2012), Mutrie et al. 
(2002), Shannon et al. (2006), Rose e Marfurt (2007), Gatersleben e Appleton (2007), Grau (2015), Thigpen et al. (2015) e Parkes et al. (2016).

As respostas provenientes de questionários de preferência declarada, revelada e do estágio de mudança de comportamento em que os entrevistados se encontram, se baseiam no comportamento do entrevistado. Muitas vezes estas respostam podem, no entanto, não condizer com o comportamento real do indivíduo. Isto pode ocorrer porque o entrevistado não respondeu com honestidade à pergunta realizada ou mesmo porque, na prática, optou por ter uma ação diferente da que foi informada quando questionado a respeito, visto a possibilidade de passagem de tempo entre a realização da pesquisa e a ação realizada. Louviere et al. (2000) afirmam que algumas áreas do conhecimento e alguns indivíduos apresentam uma forte resistência ao uso de questionários de preferência declarada, seja quando aplicado no meio acadêmico ou comercial, uma que vez que há dúvida sobre a efetividade de captura das preferências reais dos indivíduos.

Além disso, em muitos casos a realização de pesquisas de preferência declarada ou revelada pode ser de alto custo, uma vez que envolve a necessidade de treinamento dos entrevistadores, além de maior tempo de coleta e processamento destas informações. Para muitos órgãos públicos, sobretudo em cidades de menor porte e com menores recursos financeiros, estas particularidades podem tornar a realização destas pesquisas completamente inviável.

Uma alternativa à identificação dos usuários potenciais que não a realização de questionários de preferência declarada, revelada e do uso do MTMC é a utilização de mineradores de dados aplicados aos dados desagregados obtidos, por exemplo, em uma pesquisa origem-destino domiciliar. $O$ uso de mineradores de dados é válido, sobretudo, nos casos nos quais os dados de viagens já foram coletados e tabulados e a realização de uma nova pesquisa para identificar, na população entrevistada, os usuários potenciais, torna-se muito difícil.

Diante do exposto, com exceção do trabalho desenvolvido por Guerreiro et al. (2013), verifica-se que na literatura consultada não são apresentadas alternativas à obtenção da identificação dos potenciais usuários que não a utilização de 
questionários. Pretende-se com esta tese apresentar mais uma forma de realizar esta identificação, para tanto se baseando na utilização de uma técnica de mineração de dados aplicada a dados desagregados da população. Maiores detalhes sobre esta técnicas serão apresentados no "Capítulo 3 -Materiais e Método".

\subsection{Fatores que influenciam a utilização da bicicleta nos deslocamentos diários}

Considerando o modo bicicleta, Pezzuto e Sanches (2004) afirmam a necessidade de conhecimento da importância atribuída aos fatores que influenciam o seu uso, de maneira que as políticas públicas e programas de incentivo atendam também aos usuários potenciais.

De acordo com a bibliografia consultada, vários são os fatores que podem influenciar a utilização da bicicleta nos deslocamentos diários. Tal como preconizado por FHWA (1992), os fatores podem ser objetivos (ambientais e de características de infraestrutura) e subjetivos (relacionados à percepção do ciclismo pelos indivíduos).

Independente de a viagem ser realizada por motivo trabalho ou por qualquer outro motivo, os fatores abordados neste subitem podem influenciar positiva ou negativamente a sua realização. Ou seja, podem contribuir para o maior ou menor uso da bicicleta, tanto pelos usuários que utilizam a bicicleta regularmente (que podem vir a utilizá-la com maior frequência), como por aqueles que a utilizam esporadicamente ou que simplesmente não a utilizam.

Alguns dos fatores que influenciam a utilização da bicicleta nos deslocamentos diários são apresentados na Tabela 2.3, com base na bibliografia consultada. 


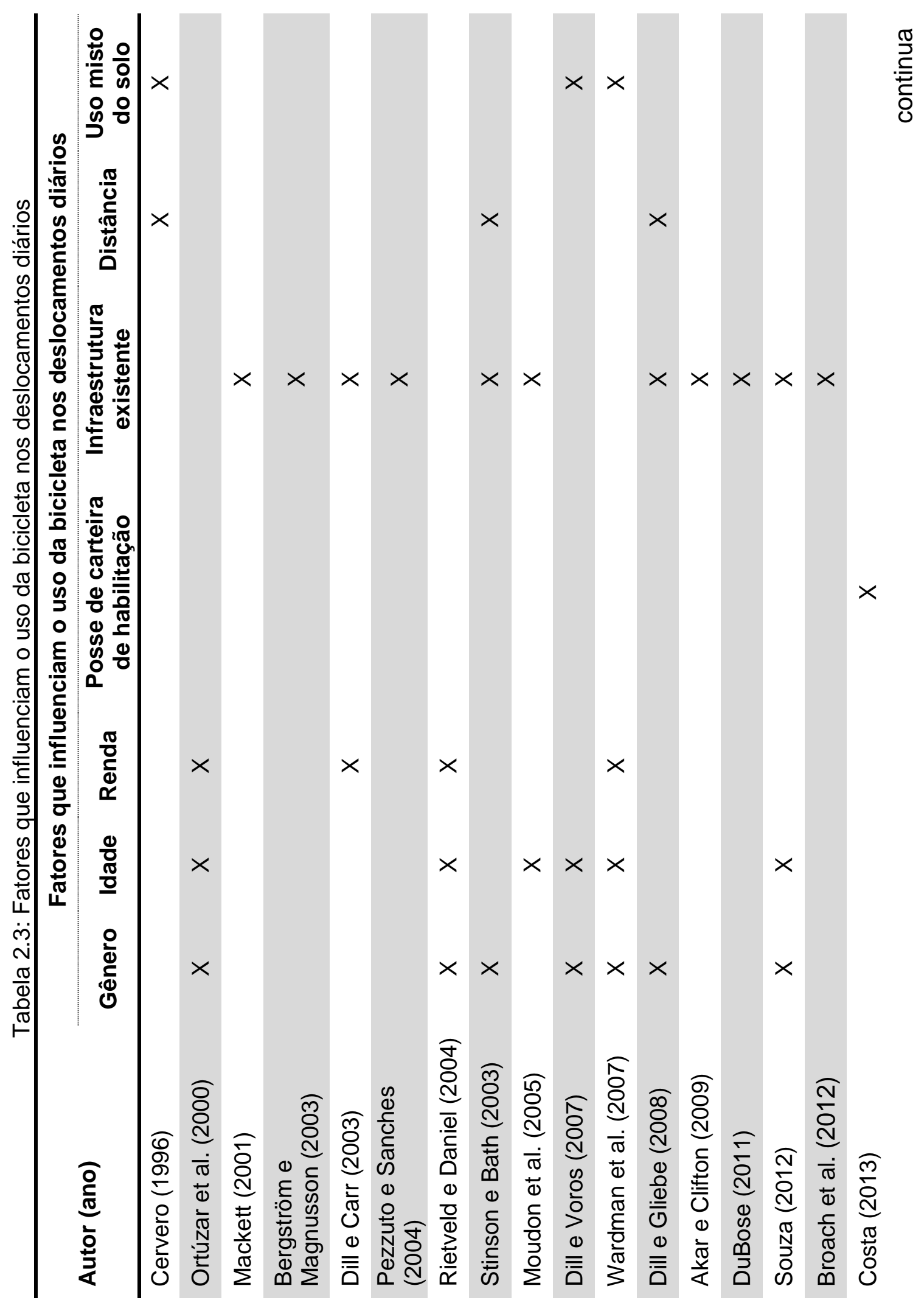




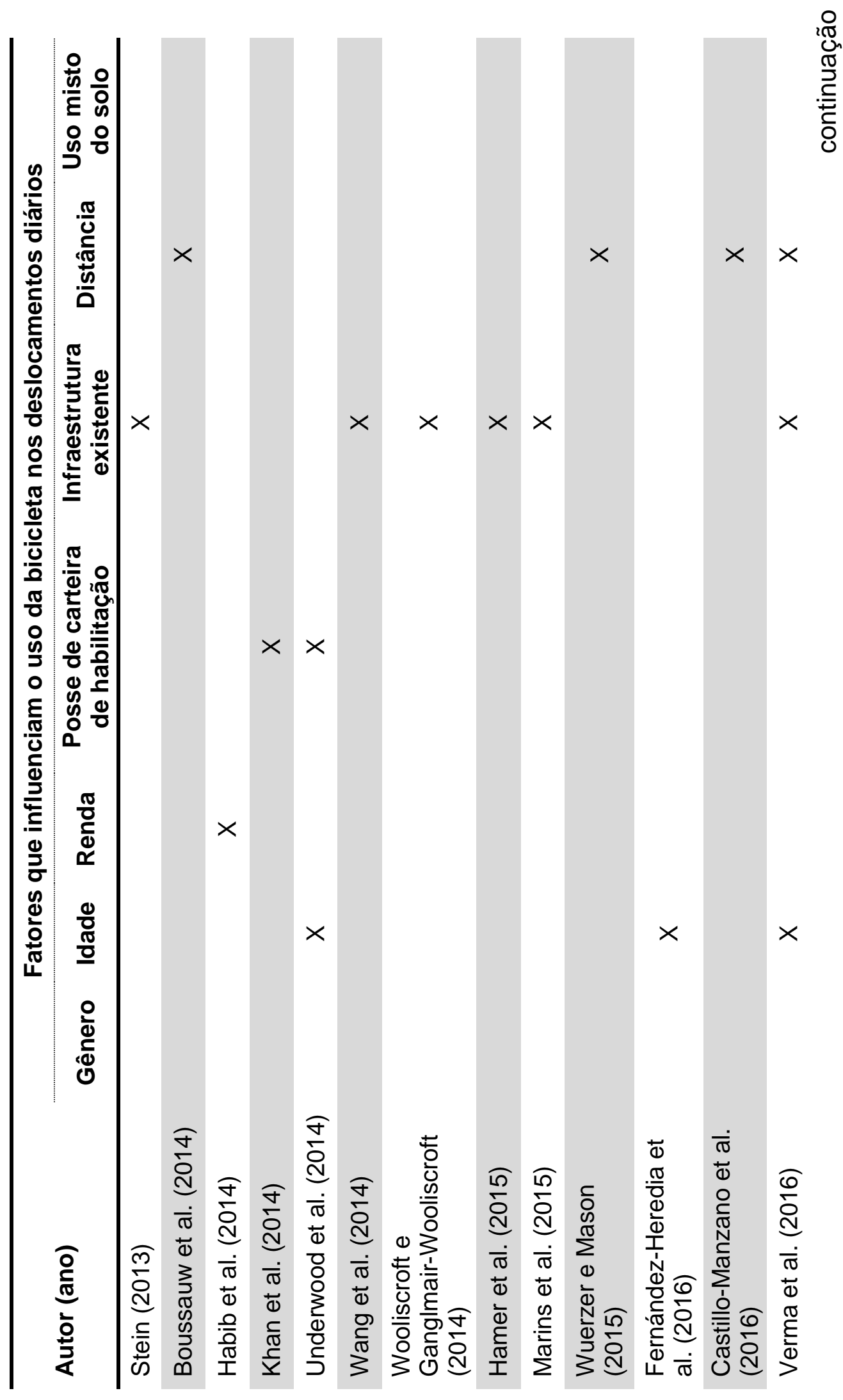




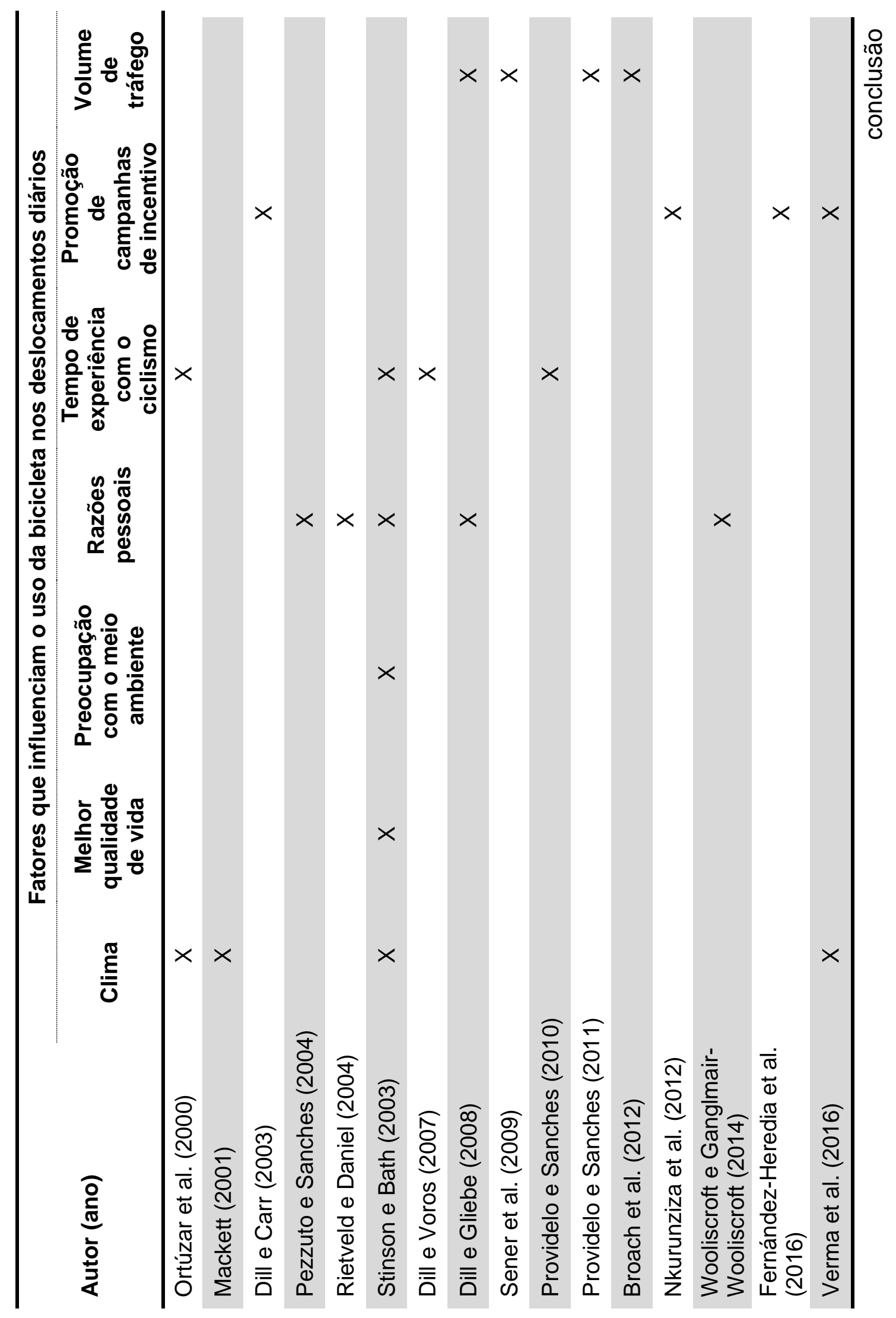


Conforme apresentado na Tabela 2.3, a presença de infraestrutura é o fator que mais contribui para o uso da bicicleta nos deslocamentos diários. Por outro lado, razões pessoais como o uso de roupas adequadas às atividades profissionais em contraposição à atividade de pedalar, podem contribuir negativamente para o uso da bicicleta.

Características socioeconômicas, como por exemplo, idade, gênero e renda, podem contribuir positiva ou negativamente para o uso da bicicleta. Considerando os estudos apresentados, pessoas mais jovens se mostraram mais dispostas a utilizar a bicicleta, sobretudo pessoas do sexo masculino. Por outro lado, as mulheres mostraram menor tendência ao uso da bicicleta, muitas vezes por serem mais vulneráveis à ocorrência de assaltos no período noturno (Rietveld e Daniel, 2004). Com relação à renda, há controvérsias quanto à sua influência no uso da bicicleta. Para Wardman et al. (2007), indivíduos com renda mais alta tendem a usar mais este modo de transporte, já para Ortúzar et al. (2000) e Habib et al. (2014), pessoas com renda mais baixa demonstraram maior tendência ao uso.

A partir do conhecimento dos fatores que influenciam o uso da bicicleta como modo regular de transporte, torna-se mais fácil identificar quais são as variáveis que podem ser consideradas ao utilizar um minerador de dados para a identificação dos usuários potenciais. É necessário ressaltar que, em alguns casos, nem todos os fatores podem ter sido levantados, uma vez que os mesmos dependem de pesquisas que já foram realizadas.

\subsection{Panorama das redes cicloviárias no Brasil}

Notadamente nos países da América Latina, através da execução de Planos Diretores de Ciclovia, recentemente a construção de redes cicloviárias vem adquirindo importância para o poder público, uma vez que podem ajudar a reduzir os problemas de mobilidade urbana e os associados aos problemas ambientais. $\mathrm{Na}$ cidade de Bogotá, na Colômbia, foi prevista a construção de 301 quilômetros de ciclovias, além do tratamento de cruzamentos perigosos para o trânsito de bicicletas, integração com outros sistemas de transporte, estacionamentos com serviços complementares, etc. (IDU, 2014). Em Santiago, Chile, para o ano de 2032 estão 
previstos 952 quilômetros de ciclovias distribuídas nos 34 municípios da região metropolitana (Plataforma Urbana, 2015). De acordo com o plano elaborado para a cidade de San Pedro Garza Garcia, no México, até 2030 estão previstos 110 quilômetros de ciclovias conectando todo o município (Implan, 2012). Já para o Peru, até o ano de 2035 estão previstos aproximadamente $885 \mathrm{~km}$ de ciclovias na região metropolitana de Lima - Callao (Peru, 2014).

Ainda assim, em muitos países a bicicleta ainda é vista apenas como um modo de transporte associado ao lazer. Neste caso, o ciclismo não está associado a uma questão de demanda derivada, mas sim visto apenas como uma atividade que gera prazer e que não é utilizada para a realização de outras atividades (Rietveld e Daniel, 2004). Neste contexto, a bicicleta não é vista como um modo de transporte utilizado nos deslocamentos das viagens diárias e importante do ponto de vista do planejamento da circulação, mas sim apenas utilizada, muitas vezes, nos finais de semana.

Especificamente com relação ao Brasil, o país nunca teve um plano cicloviário abrangente em nível nacional. Desde a década de 1950 a bicicleta está associada à prática de esportes e às atividades de lazer, sendo que muitas vezes também está associada a um produto voltado para o público infantil. Neste cenário, a posse de um automóvel está associada a um elevado status social, enquanto a de uma bicicleta, frequentemente, a uma posição inferior na sociedade, tal qual uma posição de segunda classe (Medeiros e Duarte, 2013).

A partir da década de 1980 e até os anos 2000, ao mesmo tempo em que as propagandas de bicicleta passaram a ser mais frequentemente veiculadas na televisão, o governo também passou a investir e dar subsídios cada vez maiores para as indústrias automotivas, ajudando a aumentar a taxa de motorização do país. De acordo com dados do DENATRAN - Departamento Nacional de Trânsito (2015), entre os anos 2000 e 2005 foi registrado um aumento da frota de automóveis no país igual a $31,73 \%$, sendo que no quinquênio seguinte, 2005-2010, o aumento foi igual a 41,35\% (DENATRAN, 2015). No caso da população, entre 2000 e 2005 o aumento registrado foi igual a 6,62\%, enquanto que entre 2005 e 2010, 5,48\% (IBGE, 2015). Considerando a produção de bicicletas, no primeiro quinquênio foi 
registrada uma queda de $6,52 \%$ e, no segundo, um aumento igual a $15,12 \%$ (ABRACICLO, 2012; ABRADIBI, 2015). Ou seja, enquanto foi constatado um aumento constante da frota de automóveis, o mesmo não pode ser dito com relação à frota de bicicletas.

Além de toda a questão política envolvida, a carga tributária aplicada sobre o preço de aquisição de uma bicicleta nova, em comparação ao automóvel, também pode ser um desestímulo ao seu uso. Atualmente, enquanto o imposto embutido no preço de automóveis novos gira em torno de $30 \%$, para bicicletas esta porcentagem ultrapassa os $70 \%$. Caso este imposto embutido no preço de venda de bicicletas (equivalente ao Imposto sobre Produtos Industrializados - IPI) fosse reduzido em $10 \%$, poderia haver um aumento de $11 \%$ no consumo formal, possibilitando que uma maior parcela da população conseguisse adquirir uma bicicleta (Vá de Bike, 2014).

Algumas ações, ainda incipientes, no campo legislativo, começaram a ser elaboradas na tentativa de desonerar o preço de venda das bicicletas, bem como de promover cada vez mais sua inserção nos deslocamentos urbanos. Como exemplos citam-se os Projetos de Lei (PL) (portanto ainda não consolidados como lei): no 4997/2013, que propõe eliminar a alíquota sobre o IPI para bicicletas; no 6474/2009, que institui o Programa Bicicleta Brasil; № 6418/2013, que permite 0 uso do vale-transporte para o custeio de transporte do empregado por meio de bicicletas; e n 6724/2013, que propõe a instituição do "Vale-Bicicleta" (Câmara dos Deputados, 2014).

Além dos PL's mencionados acima, a única lei de âmbito federal que trata especificamente do tema é a Lei oㅡ 12.587/2012 (Brasil, 2012), que obriga cidades com mais de 20.000 habitantes a executarem o Plano de Mobilidade Urbana, contemplando assim a melhoria da infraestrutura cicloviária. A obediência a esta lei já pode ser verificada em algumas cidades brasileiras, notadamente capitais com mais de 500 mil habitantes. Nestas cidades, os Planos de Mobilidade Urbana já contemplam a previsão de infraestruturas cicloviárias para os próximos anos, tal como apresentado na Tabela 2.4. 
Este avanço na elaboração de diretrizes para a construção de infraestrutura cicloviária vem sendo, em grande parte, cobrado por movimentos cicloativistas cada dia mais presentes nas cidades. Desde o ano 2002 estes movimentos vêm exigindo das autoridades políticas não apenas um debate sobre a inserção da bicicleta nos deslocamentos urbanos, mas também o comprometimento com a efetiva realização de ações que promovam o uso da bicicleta. Um exemplo foi a última campanha para prefeito da cidade de São Paulo, na qual os cinco candidatos a prefeito participaram de ações envolvendo a bicicleta (BBC, 2015).

Tabela 2.4: Infraestrutura cicloviária prevista para algumas capitais brasileiras

\begin{tabular}{|c|c|c|}
\hline Capital & $\begin{array}{l}\text { Ano de } \\
\text { conclusão }\end{array}$ & Infraestrutura prevista \\
\hline Curitiba $^{1}$ & 2016 & $\begin{array}{c}\text { Recuperação de } 127 \text { km de malha cicloviária e } \\
\text { implantação de } 300 \mathrm{~km} \text { de vias cicláveis (90 km - } \\
\text { ciclorotas, } 80 \mathrm{~km} \text { - vias calmas, } 130 \mathrm{~km} \text { - ciclovias, } \\
\text { ciclofaixas e passeios compartilhados) }\end{array}$ \\
\hline Rio de Janeiro ${ }^{2}$ & 2016 & $\begin{array}{c}450 \mathrm{~km} \text { de ciclovias, bicicletários e sistema de aluguel } \\
\text { de bicicletas }\end{array}$ \\
\hline $\begin{array}{l}\text { Brasília e } \\
\text { arredores }^{3}\end{array}$ & 2020 & $600 \mathrm{~km}$ de ciclovias \\
\hline Belo Horizonte ${ }^{4}$ & 2020 & $\begin{array}{c}335 \mathrm{~km} \text { - ciclovias e ciclofaixas e bicicletários e } \\
\text { paraciclos }\end{array}$ \\
\hline Fortaleza $^{5}$ & 2020 & $232 \mathrm{~km}$ - ciclovias e ciclofaixas \\
\hline Porto Alegre ${ }^{6}$ & 2022 & $\begin{array}{l}490 \mathrm{~km} \text { (ciclovias, ciclofaixas, vias de tráfego } \\
\text { compartilhado) e bicicletários, paraciclos e paradouros }\end{array}$ \\
\hline $\begin{array}{l}\text { Recife e região } \\
\text { metropolitana } 7\end{array}$ & 2024 & $\begin{array}{c}346 \mathrm{~km} \text { - ciclovias, ciclofaixas e ciclorotas (municipais } \\
\text { e interurbanas) }\end{array}$ \\
\hline São Paulo ${ }^{8}$ & 2030 & $\begin{array}{c}1.600 \mathrm{~km} \text { de ciclovias e ciclofaixas, além de estruturas } \\
\text { cicloviárias em } 20 \text { pontes, } 30 \text { viadutos, } 50 \text { passarelas, } \\
12 \text { ciclopassarelas, } 4 \text { passagens subterrâneas e um } \\
\text { sistema de compartilhamento de bicicletas }\end{array}$ \\
\hline
\end{tabular}

Fonte: 'IPPUC (2013), ${ }^{2}$ SMAC (2010), ${ }^{3}$ Brasília (2010), ${ }^{4}$ BHTRANS (2012), ${ }^{5}$ Ceará Agora (2016), ${ }^{6}$ Ferrari (2008), ${ }^{7}$ Infraestrutura Urbana (2014) e ${ }^{8}$ Prefeitura do Município de São Paulo (2015)

Infelizmente, no entanto, vários dos trechos construídos muitas vezes estão localizados em pontos com baixa demanda, tanto real quanto potencial, como também não estão conectados entre si e resultam apenas em uma bandeira política da gestão municipal vigente, não contribuindo para a segurança e rapidez dos deslocamentos realizados por bicicletas. Uma das razões para este cenário pode ser 
a carência, ou a não adoção, de estudos ou diretrizes para a construção de um plano diretor de mobilidade contemplando redes cicloviárias, sobretudo a falta de métodos claros e objetivos para tal.

As redes cicloviárias devem, preferencialmente, ser implantadas com base em estudos preliminares, notadamente aqueles contendo as origens e os destinos das viagens, além da necessidade de também haver conhecimento de como essas redes devem ser planejadas. Para tanto, na próxima seção são apresentados alguns estudos que relatam quais foram os principais dados, ferramentas e métodos utilizados para o planejamento das redes cicloviárias apresentadas.

\subsection{Planejamento de redes cicloviárias}

Especificamente com relação aos métodos de planejamento de redes cicloviárias, alguns estudos com diferentes abordagens vêm sendo desenvolvidos ao longo dos anos. Muitos deles consideram a utilização de Sistemas de Informação Geográfica (SIG's), de ferramentas de simulação e/ou uma avaliação de diversos critérios considerados importantes para o planejamento e escolha da melhor rede. Outros consideraram modelos ou algoritmos matemáticos para o planejamento das redes. Os modelos estudados estão resumidos na Tabela 2.5. 
Tabela 2.5: Relação dos estudos e respectivas variáveis e métodos para o planejamento de redes cicloviárias

\begin{tabular}{|c|c|c|c|}
\hline Autor (ano) & País & Variáveis de entrada & Método \\
\hline $\begin{array}{l}\text { Huang e Ye } \\
\text { (1995) }\end{array}$ & $\begin{array}{l}\text { Estados } \\
\text { Unidos }\end{array}$ & $\begin{array}{l}\text { - Dados agregados de } \\
\text { população (setores } \\
\text { censitários) e de emprego } \\
\text { - Tempo de viagem } \\
\text { - Tráfego de automóveis } \\
\text { - Declividade (entre } 0,4 \% \text { e } \\
5,0 \% \text { ) } \\
\text { - Condições da superfície de } \\
\text { rolamento }\end{array}$ & $\begin{array}{l}\text { Modelo gravitacional } \\
\text { associado a SIG para } \\
\text { desenvolvimento de } \\
\text { procedimento de } \\
\text { seleção de vias para } \\
\text { definição de rotas } \\
\text { cicloviárias }\end{array}$ \\
\hline $\begin{array}{l}\text { Aultman-Hall et } \\
\text { al. (1997) }\end{array}$ & Canadá & $\begin{array}{l}\text { - Dados desagregados de } \\
\text { origem e destino } \\
\text { - Comprimento da viagem } \\
\text { - Hierarquia viária (arterial, } \\
\text { coletora e local) } \\
\text { - Passagem por pontes } \\
\text { - Uso de vias de trânsito } \\
\text { rápido }\end{array}$ & $\begin{array}{l}\text { Comparação entre as } \\
\text { rotas reais informadas } \\
\text { pelos usuários e as } \\
\text { rotas traçadas pelo } \\
\text { SIG (ArcINFO) }\end{array}$ \\
\hline $\begin{array}{l}\text { Hyodo et al. } \\
(2000)\end{array}$ & Japão & $\begin{array}{l}\text { - Dados desagregados de } \\
\text { origem e um único destino } \\
\text { - Largura da via }\end{array}$ & $\begin{array}{l}\text { Definição de um } \\
\text { modelo de escolha da } \\
\text { rota de bicicleta, } \\
\text { utilizando algoritmo de } \\
\text { caminho mínimo } \\
\text { (modelo matemático) }\end{array}$ \\
\hline Kirner (2006) & Brasil & $\begin{array}{l}\text { - Dados desagregados de } \\
\text { origem e destino (dois } \\
\text { PGV's considerados como } \\
\text { destinos) } \\
\text { - Georreferenciamento dos } \\
\text { dados } \\
\text { - Vias utilizadas pelos } \\
\text { ciclistas entrevistados }\end{array}$ & $\begin{array}{l}\text { Identificação das vias } \\
\text { potenciais para uso da } \\
\text { bicicleta, através da } \\
\text { definição de área de } \\
\text { influência ao redor dos } \\
\text { dois PGV's, associada } \\
\text { às linhas de desejo } \\
\text { entre as origens e } \\
\text { destinos (TransCAD) e } \\
\text { às informações das } \\
\text { vias utilizadas }\end{array}$ \\
\hline $\begin{array}{l}\text { Menghini et al. } \\
\text { (2010) }\end{array}$ & Suíça & $\begin{array}{l}\text { - Dados desagregados de } \\
\text { origem e destino, obtidos } \\
\text { através de GPS } \\
\text { - Malha urbana } \\
\text { georreferenciada } \\
\text { - Informações sobre vias } \\
\text { recomendadas para } \\
\text { bicicletas }\end{array}$ & $\begin{array}{l}\text { Comparação entre as } \\
\text { rotas reais (GPS) e } \\
\text { rotas traçadas na } \\
\text { simulação multiagente } \\
\text { aplicada a cada par } \\
\text { origem-destino }\end{array}$ \\
\hline
\end{tabular}




\begin{tabular}{|c|c|c|c|}
\hline Autor (ano) & País & Variáveis de entrada & Método \\
\hline $\begin{array}{l}\text { Rybarczyk e Wu } \\
\text { (2010) }\end{array}$ & $\begin{array}{l}\text { Estados } \\
\text { Unidos }\end{array}$ & $\begin{array}{l}\text { - Dados agregados de } \\
\text { população } \\
\text { - Localização } \\
\text { georreferenciada de } \\
\text { parques, escolas } \\
\text { - Mapa viário urbano }\end{array}$ & $\begin{array}{l}\text { Planejamento de uma } \\
\text { rede cicloviária através } \\
\text { da estimativa da } \\
\text { demanda potencial } \\
\text { para cada segmento } \\
\text { viário, considerando a } \\
\text { população, parques e } \\
\text { escolas contidos } \\
\text { dentro de uma banda } \\
\text { de } 200,00 \text { metros } \\
\text { traçada ao redor dos } \\
\text { segmentos viários }\end{array}$ \\
\hline Hsu e Lin (2011) & China & $\begin{array}{l}\text { - Dados agregados de } \\
\text { população (setores } \\
\text { censitários) e zonas de } \\
\text { tráfego } \\
\text { - Mapa viário urbano }\end{array}$ & $\begin{array}{l}\text { Planejamento de uma } \\
\text { rede cicloviária a partir } \\
\text { do traçado do caminho } \\
\text { mínimo entre as } \\
\text { origens e destinos, } \\
\text { considerando o } \\
\text { algoritmo Floyd- } \\
\text { Warshall }\end{array}$ \\
\hline $\begin{array}{l}\text { Broach et al. } \\
\text { (2012) }\end{array}$ & $\begin{array}{l}\text { Estados } \\
\text { Unidos }\end{array}$ & $\begin{array}{l}\text { - Dados desagregados de } \\
\text { origem e destino, obtidos } \\
\text { através de GPS } \\
\text { - Comprimento da rota } \\
\text { - Declividade da via (máxima } \\
\text { igual a } 6,0 \% \text { ) } \\
\text { - Volume de tráfego }\end{array}$ & $\begin{array}{l}\text { Comparação entre as } \\
\text { rotas reais (GPS) e } \\
\text { rotas traçadas } \\
\text { utilizando algoritmo de } \\
\text { caminho mínimo } \\
\text { (ArcGIS) (vinte } \\
\text { possibilidades de } \\
\text { traçado entre cada par } \\
\text { origem-destino) }\end{array}$ \\
\hline $\begin{array}{l}\text { Mesbah et al. } \\
(2012)\end{array}$ & Austrália & $\begin{array}{l}\text { - Rede hipotética contendo } \\
15 \text { origens e } 2 \text { destinos } \\
\text { - Características do tráfego e } \\
\text { do sistema viário }\end{array}$ & $\begin{array}{l}\text { Utilização de um } \\
\text { algoritmo genético } \\
\text { para escolha da rede } \\
\text { cicloviária ótima }\end{array}$ \\
\hline Neri (2012) & Brasil & $\begin{array}{l}\text { - Localização } \\
\text { georreferenciada de PGV's } \\
\text { (escolas, teatros, bibliotecas, } \\
\text { parques, terminal de } \\
\text { transporte urbano) } \\
\text { - Hierarquia viária } \\
\text { - Características da rede } \\
\text { viária } \\
\text { - Mapa viário urbano }\end{array}$ & $\begin{array}{l}\text { Metodologia para o } \\
\text { planejamento de uma } \\
\text { rede potencial } \\
\text { cicloviária, } \\
\text { considerando a } \\
\text { avaliação de } \\
\text { parâmetros } \\
\text { (relacionados a } \\
\text { aspectos econômicos, } \\
\text { sociais, de espaço } \\
\text { público e urbanismo) } \\
\text { para os eixos viários } \\
\text { considerados }\end{array}$ \\
\hline & & & continuação \\
\hline
\end{tabular}




\begin{tabular}{|c|c|c|c|}
\hline Autor (ano) & País & Variáveis de entrada & Método \\
\hline Larsen (2013) & Canadá & $\begin{array}{l}\text { - Dados desagregados de } \\
\text { origem e destino } \\
\text { - Mapa viário urbano } \\
\text { - Dados de acidentes com } \\
\text { ciclistas } \\
\text { - Conectividade dos } \\
\text { segmentos viários }\end{array}$ & $\begin{array}{l}\text { Locação de } \\
\text { infraestrutura } \\
\text { cicloviária a partir do } \\
\text { traçado de caminho } \\
\text { mínimo entre os pares } \\
\text { origem-destino, } \\
\text { considerando rotinas } \\
\text { de caminho mínimo } \\
\text { entre os pares } \\
\text { (ArcGIS) e } \\
\text { informações obtidas } \\
\text { juntos aos usuários }\end{array}$ \\
\hline Lin e Yu (2013) & China & $\begin{array}{l}\text { - Dados agregados de } \\
\text { origem e destino } \\
\text { - Continuidade dos caminhos } \\
\text { - Tipos de infraestrutura que } \\
\text { poderiam ser implantadas }\end{array}$ & $\begin{array}{l}\text { Desenvolvimento de } \\
\text { modelo matemático } \\
\text { para definição de } \\
\text { redes cicloviárias, } \\
\text { considerando a } \\
\text { minimização do risco e } \\
\text { do impacto das redes } \\
\text { cicloviárias no tráfego } \\
\text { e a maximização do } \\
\text { conforto e da cobertura } \\
\text { da rede }\end{array}$ \\
\hline $\begin{array}{l}\text { Guerreiro e } \\
\text { Rodrigues da } \\
\text { Silva (2013) }\end{array}$ & Brasil & $\begin{array}{l}\text { - Dados desagregados de } \\
\text { origem e destino } \\
\text { - Mapa do sistema viário }\end{array}$ & $\begin{array}{l}\text { Definição de uma rede } \\
\text { cicloviária } \\
\text { considerando quatro } \\
\text { possibilidades de } \\
\text { caminho mínimo entre } \\
\text { cada par origem- } \\
\text { destino (TransCAD) e } \\
\text { um determinado valor } \\
\text { de viagens por tramo } \\
\text { viário }\end{array}$ \\
\hline $\begin{array}{l}\text { Milakis e } \\
\text { Athanasopoulos } \\
(2014)\end{array}$ & Grécia & $\begin{array}{l}\text { - Dados agregados de } \\
\text { origem e destino } \\
\text { (estabelecimentos } \\
\text { comerciais, escritórios, } \\
\text { escolas e locais para lazer) } \\
\text { - Dados do Plano Diretor de } \\
\text { Atenas sobre hierarquia } \\
\text { viária ao redor dos PGV's } \\
\text { considerados } \\
\text { - Matriz OD }\end{array}$ & $\begin{array}{l}\text { Definição de vários } \\
\text { cenários de redes } \\
\text { cicloviárias, } \\
\text { considerando uma } \\
\text { banda de largura igual } \\
\text { a } 1500 \text { metros ao redor } \\
\text { dos principais eixos } \\
\text { viários conectando os } \\
\text { PGV's considerados e } \\
\text { de informações obtidas } \\
\text { junto aos ciclistas }\end{array}$ \\
\hline $\begin{array}{l}\text { Segadilha } \\
(2014)\end{array}$ & Brasil & $\begin{array}{l}\text { - Dados desagregados de } \\
\text { origem e destino, obtidos } \\
\text { através de GPS } \\
\text { - Condições da superfície de } \\
\text { rolamento } \\
\text { - Hierarquia viária }\end{array}$ & $\begin{array}{l}\text { Comparação entre as } \\
\text { rotas reais (GPS) e } \\
\text { rotas traçadas por } \\
\text { rotina de caminho } \\
\text { mínimo (TransCAD) } \\
\text { para cada par origem- } \\
\text { destino }\end{array}$ \\
\hline
\end{tabular}


De uma forma geral, os estudos apresentados consideraram a declividade e o mapa viário do local de estudo (como também a hierarquia viária) para o planejamento de redes cicloviárias. Não obstante, a presença de dados agregados ou desagregados mostrou-se fundamental para qualquer possibilidade de traçado de caminho entre os pares considerados. Ressalta-se que 0 uso de dados desagregados permite maior refinamento quanto à localização dos indivíduos, pois é possível ter informações exatas da respectiva posição geográfica (latitude e longitude).

Especificamente com relação ao método para o planejamento de redes cicloviárias, em muitos estudos foram utilizadas rotinas de caminho mínimo traçadas entre os pares origem-destino, inclusive a consideração de apenas uma possibilidade de traçado entre os pares (exceção feita ao estudo realizado por Broach et al., 2012). Nos estudos realizados comparando rotas traçadas através de rotinas de caminho mínimo presentes nos software utilizados e as obtidas via GPS, Aultman-Hall et al. (1997) apontaram a inexistência de grandes diferenças dos traçados realizados. Já para Menghini et al. (2010) e Segadilha (2014), algumas diferenças foram verificadas, mas não tão expressivas. De qualquer forma, a utilização de rotinas de caminho mostrou-se útil para identificar os possíveis caminhos a serem percorridos entre cada par origem-destino, inclusive com a utilização de SIG's específicos para tal (ArcINFO, ArcGIS e TransCAD).

\subsection{Infraestrutura cicloviária}

Alguns dos itens de infraestrutura considerados necessários para as viagens sustentáveis têm sido discutidos por vários autores, tais como Litman et al. (2002), Rodríguez e Joo (2004), Crow (2007), Zahran et al. (2008) e Heinen et al. (2011). Especificamente com relação à Litman et al. (2002), estes descreveram as características da demanda e os diferentes tipos de infraestrutura que podem ser utilizadas nos deslocamentos por bicicleta. Complementarmente, Crow (2007) enfatizou os elementos principais para o desenvolvimento de uma rede cicloviária: coesão, direitura (no original, "directness"), segurança, conforto e atratividade. 
De acordo com o Código de Trânsito Brasileiro (Brasil, 1997), a circulação de bicicletas pode ocorrer nos bordos da pista de rolamento, sempre no mesmo sentido de circulação permitido para a via e com preferência à circulação dos veículos automotores. Tais deslocamentos apenas deverão ser realizados nos bordos da pista, no entanto, caso não haja ciclovia, ciclofaixa ou acostamento.

Para GEIPOT (2001) a estruturação de uma determinada área do território destinada à circulação de bicicletas, esteja ela dentro do município, do estado ou do país, pode ser dividida em três sistemas distintos:

a) Sistema Cicloviário Compartilhado: a bicicleta circula em vias com baixo volume de tráfego motorizado e elevado nível de segurança. As vias podem ser adaptadas ou não à circulação de bicicletas, constituindo assim rotas cicláveis;

b) Sistema Cicloviário Preferencial: a bicicleta circula em espaços exclusivos, tais como ciclovias e ciclofaixas, sendo que as vias participantes devem ter sido adaptadas conforme as medidas moderadoras de "traffic calming";

c) Sistema Cicloviário de Uso Misto: combina trechos de vias compartilhados entre bicicleta e tráfego motorizado e vias exclusivas para bicicleta. É o sistema que apresenta maior facilidade para implantação nas cidades, visto sua maior flexibilidade em relação aos outros dois sistemas.

Considerando estes sistemas, sejam separados ou em conjunto, seus componentes podem ser divididos em:

\subsubsection{Ciclovia}

De acordo com Código de Trânsito Brasileiro (Brasil, 1997), ciclovia pode ser definida como uma pista separada fisicamente do tráfego automotor, na qual é permitido somente o tráfego de ciclos (veículo de duas rodas movido à propulsão humana). Rodrigues da Silva et al. (2012) propõem uma definição mais ampla: além de permitir somente a circulação de bicicletas (tráfego segregado), normalmente a ciclovia é mais elevada do que a faixa de rolamento destinada aos demais veículos, pode estar localizada tanto ao longo do canteiro central, como também nas calçadas, e pode possuir uma configuração independente do sistema viário. 
Pode ser unidirecional ou bidirecional, sendo a largura efetiva dependente do volume de tráfego contabilizado em uma hora. No caso das pistas unidirecionais, a largura efetiva varia entre 2,00 e 6,00 metros e no caso das pistas bidirecionais, entre 2,50 e acima de 6,00 metros (GEIPOT, 2001).

\subsubsection{Ciclofaixa}

Diferentemente da Ciclovia, a Ciclofaixa é parte integrante da pista destinada ao tráfego motorizado, entretanto é exclusiva para a circulação de ciclos (Brasil, 1997). De acordo com GEIPOT (2001), pode ser separada da pista de rolamento por sinalização horizontal e/ou dispositivos delimitadores, deve ser sempre unidirecional, possuir largura efetiva mínima de $1,20 \mathrm{~m}$ e, na aproximação dos cruzamentos, quando possível, ser canalizada.

Há quatro possibilidades de configuração de ciclofaixa (Figura 2.1), todas dependentes da possibilidade ou não de existência de estacionamento junto ao meio fio. A mais recomendada (posição no 1) é aquela na qual a ciclofaixa localiza-se junto ao meio fio, no bordo direito de uma via onde é proibido o estacionamento de automóveis ao longo de sua extensão. Na segunda posição a ciclofaixa situa-se entre o bordo do meio fio (ao lado da calçada) e a faixa de estacionamento. Outra configuração possível (posição no 3 ) estabelece a ciclofaixa entre a faixa de estacionamento e a faixa de rolamento presentes na via. Tanto a posição no 2 como a no 3 expõem os ciclistas a um risco eminente de acidentes, seja devido às operações de embarque e desembarque dos veículos estacionados, seja devido à entrada e saída dos carros das vagas de estacionamento. A última posição (posição no 4) é indicada para vias que apresentam sobrelargura da faixa de rolamento, permitindo que a bicicleta se acomode na faixa excedente, aumentando a segurança do ciclista. 


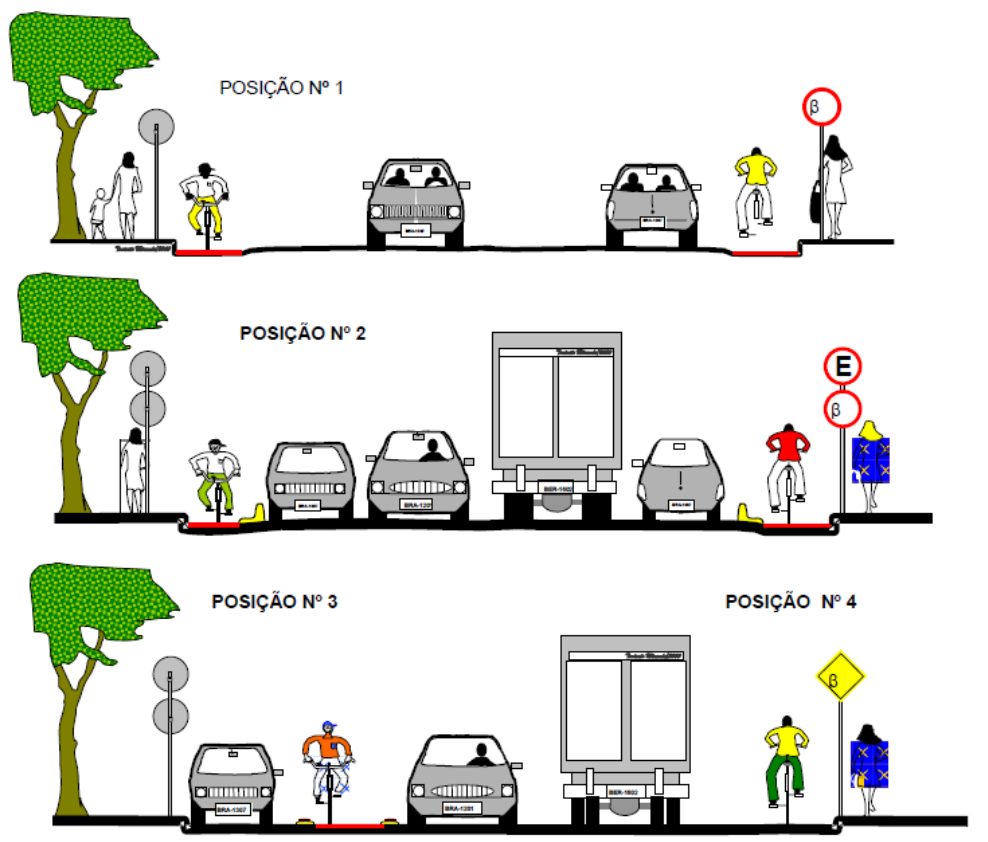

Figura 2.1: Possibilidade de configuração de ciclofaixas. Fonte: GEIPOT (2001)

\subsubsection{Rotas Cicláveis}

Podem ser definidas como caminhos existentes no campo ou na cidade e constituídos por segmentos viários ou espaços e trilhas naturais. Dependendo das condições de organização do espaço, do caminho, da infraestrutura (natural ou artificial) podem ser divididas em rotas cicláveis naturais ou especiais (GEIPOT, 2001).

\subsubsection{Vias e passeios com tráfego compartilhado}

Em muitas cidades brasileiras é verificada a predominância de vias locais. Isto acontece devido ao padrão da malha viária urbana, o qual é constituído basicamente por vias que se cruzam a cada 100 ou 150 metros. Se por um lado esta configuração favorece maior conectividade entre as vias que formam a malha, por outro lado pode conduzir a vias com larguras insuficientes para a implantação de ciclovias ou ciclofaixas. Como alternativa, tem-se vias nas quais o tráfego é compartilhado entre automóveis e bicicletas, e, sendo baixa a velocidade dos veículos, na maioria das vezes a convivência entre os modos não se constitui em um obstáculo ao uso diário da bicicleta. Desde que haja uma hierarquia entre as vias, à medida que os usuários de bicicleta distanciam-se de suas origens torna-se cada vez mais necessário a presença de vias exclusivas para ciclistas, uma vez que maiores são os volumes de 
tráfego e os valores das velocidades praticadas, além de maiores riscos de manobras bruscas de conversão. Na Figura 2.2 são apresentadas as possibilidades de infraestrutura cicloviárias, de acordo como volume de tráfego e a velocidade permitida para a via.

Em alguns casos, também é possível compartilhar com segurança e tranquilidade o espaço dedicado ao ciclista com cadeirantes e pedestres, através da implantação de "Ciclo Redes" (GEIPOT, 2001).

Outra possibilidade de infraestrutura para bicicleta é a execução de passeio compartilhado com pedestres. Para tanto, primeiramente deve ser considerado como um passeio para os pedestres (mais frágeis quando comparados aos ciclistas), não devendo apresentar qualquer separação física entre os dois grupos de usuários e apresentar sinalização indicando o compartilhamento entre pedestres e ciclistas (Ministério das Cidades, 2007).

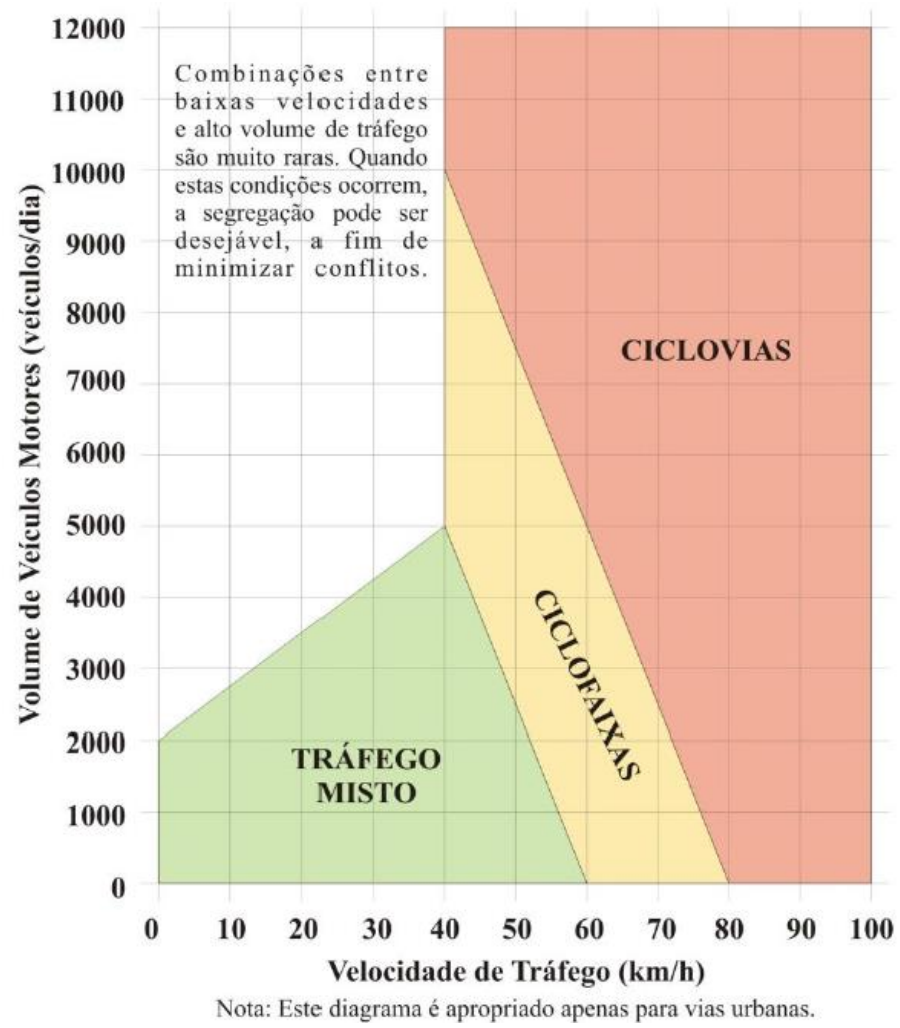

Figura 2.2: Tipo de infraestrutura cicloviária, de acordo com volume e velocidade permitida dos veículos motorizados. Fonte (elaborado por Neri (2012), a partir de LTSA (2004)) 
De acordo com o gráfico da Figura 2.2, a velocidade igual a $40 \mathrm{~km} / \mathrm{h}$ corresponde à velocidade limítrofe para a mudança de infraestrutura considerando variável o volume de veículos motores. Considerando o conceito de Tráfego Calmo (do inglês, Traffic Calming), que estabelece a velocidade de $30 \mathrm{~km} / \mathrm{h}$ como uma velocidade segura para pedestres e ciclistas e que permite a redução da severidade dos acidentes, o gráfico da Figura 2.2 poderia ser ajustado para uma velocidade limítrofe igual a $30 \mathrm{~km} / \mathrm{h}$. Esta mudança se aplicaria inclusive ao Brasil, onde a redução do número de acidentes e de sua gravidade têm se tornado uma grande preocupação.

\subsection{Avaliação de redes cicloviárias}

Independentemente do tipo de infraestrutura cicloviária presente na rede existente é necessário ter conhecimento sobre a eficácia do atendimento que ela fornece aos seus usuários, sejam eles reais ou potenciais. Esta eficácia pode ser medida, por exemplo, através da realização de várias etapas, tal como proposto por LTSA - Land Transport Safety Authority (2004): i) avaliação das necessidades, ii) realização de auditorias, e iii) revisão das condições de ciclabilidade das redes cicloviárias. Outra forma de avaliar redes cicloviárias é através do estabelecimento e avaliação de critérios que sejam comuns a todas as redes estudadas, tal como verificado pelos autores apresentados na Tabela 2.6.

O formato da malha urbana também é um fator que pode interferir na continuidade da rede cicloviária. À medida que se tem bairros com um padrão de ruas no formato de grelhas e quarteirões pequenos, maior é a conectividade entre os pontos da rede, o que pode não ser obtido no caso de haver quarteirões de grandes extensões e com ruas no formato de cul-de-sacs (Dill e Gliebe, 2008). A configuração de grelha associada à existência de quarteirões de tamanho pequeno e interseções com preferência ao ciclista reduz o número de paradas, melhorando o desempenho da rede. 


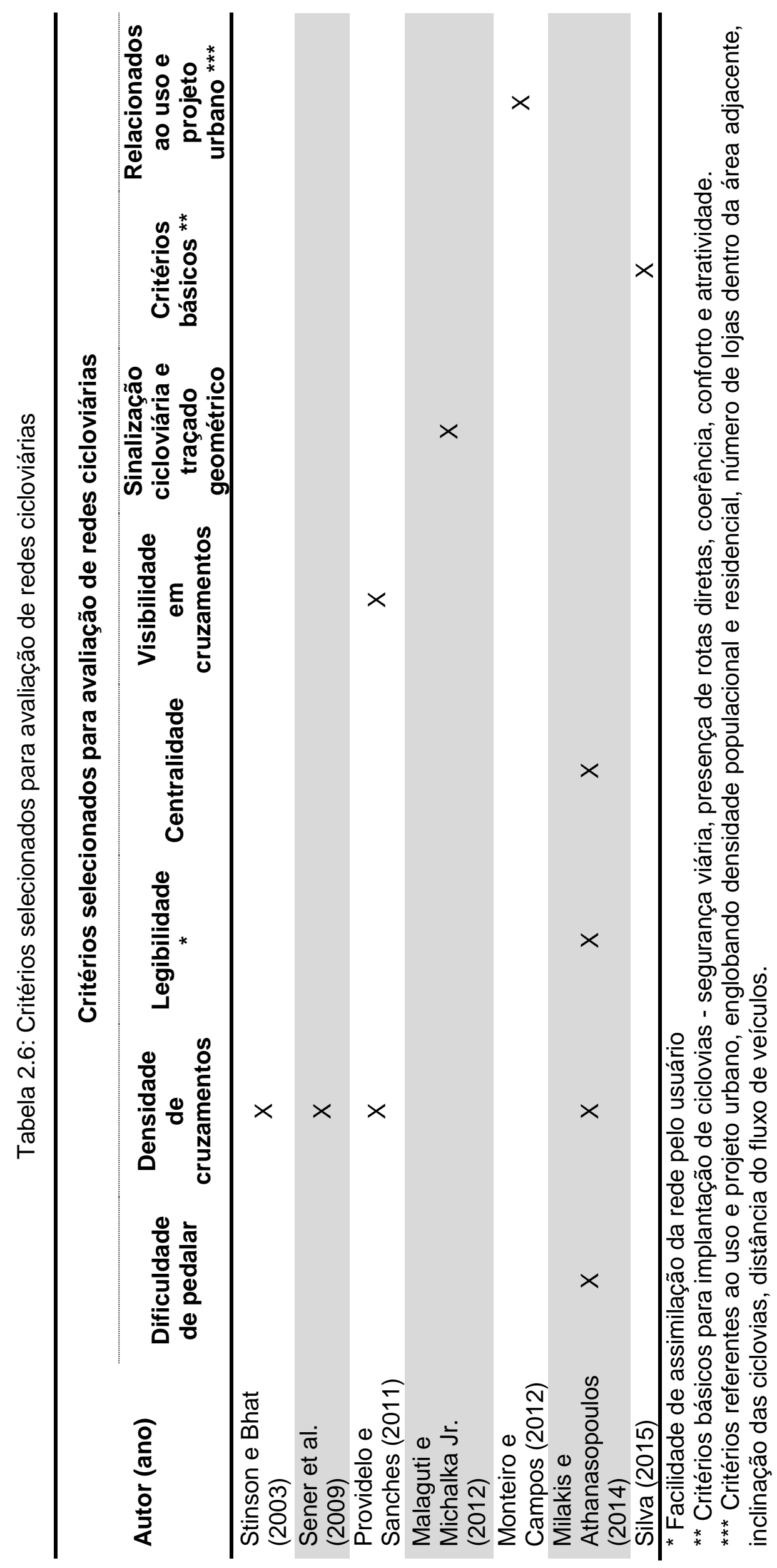


A avaliação do nível de serviço da rede cicloviária também pode ser um fator a ser considerado em um processo de comparação entre redes propostas ou mesmo no caso da análise de uma única rede, tal como apresentado nos estudos realizados por LTSA (2004), Kirner (2006) e por Rybarczyk e Wu (2010). No primeiro estudo, para a avaliação são consideradas características típicas do tráfego de veículos e a probabilidade do uso de determinado tipo de infraestrutura. Em Kirner (2006), o modelo de Dixon (1996) foi aplicado a cada segmento das vias mais utilizadas pelos ciclistas entrevistados, de modo a classificar cada via em um determinado nível de serviço. Já o terceiro estudo, utilizou a técnica de análise exploratória de dados (ou ESDA, de Exploratory Spatial Data Analysis, na sigla original em inglês) aplicada no nível do vizinho mais próximo, obtendo o nível de serviço dos segmentos viários com demanda potencial para o uso da bicicleta.

Outros autores também realizaram a avaliação de redes cicloviárias (Hopkinson e Wardman, 1996, Flügel et al., 2015, Gössling e Choi, 2015, Yi et al., 2011). Para tanto, admitiram critérios de custos e benefícios que puderam ser contabilizados economicamente, tais como custos associados a transporte, acidentes, consumo de combustível, emissão de poluentes e benefícios associados à redução do uso de medicamentos, redução da deterioração do pavimento, redução de congestionamentos, dentre outros.

Ao realizar a avaliação de redes cicloviárias é necessário também considerar a proximidade destas aos elementos estruturantes da cidade. Em muitas situações, estes elementos correspondem a empreendimentos que produzem e atraem um grande número de viagens ao longo do dia, sendo definidos como PGV's (estabelecimentos comerciais, indústrias, postos de saúde, escolas, pontos de lazer (parques, teatros, museus, etc.). Notadamente com relação às escolas, estas podem ser definidas como um dos pontos estruturantes mais importantes da cidade. As escolas, principalmente aquelas com ensino fundamental, são locais onde as crianças aprendem valores que irão contribuir para a formação da sua moral. Do ponto de vista do planejamento dos transportes, quanto mais houver atividades voltadas à valorização do respeito aos pedestres e ciclistas, do uso da bicicleta nos deslocamentos diários, maior é a probabilidade do uso efetivo da bicicleta por estes 
indivíduos, podendo conduzir a uma mudança de hábito que valorize a adoção de transportes sustentáveis.

Notadamente estudantes até 14 anos correspondem à parcela estudantil mais vulnerável no trânsito. Isto ocorre devido às características próprias desta faixa etária, dentre elas: visão periférica e percepção áudio-motora não totalmente desenvolvidas, baixa estatura e desatenção (DENATRAN, 2008). Estas características, aliadas à execução de uma rede cicloviária nas proximidades das escolas, pode não somente ajudar a incutir nos jovens a importância da realização das viagens utilizando modos de locomoção sustentáveis, como também contribuir para a redução do número de acidentes de trânsito envolvendo estudantes, para a redução do volume de tráfego e de congestionamentos, e para um aumento do tempo dedicado às atividades físicas e da disposição dos estudantes (deixando-os mais alertas), além da prevenção de doenças como a obesidade (Bicycle Network, 2014).

Em alguns casos, as variáveis a serem analisadas podem estar associadas a fatores positivos ou negativos, sendo esta classificação dependente do contexto no qual é realizado o estudo. Por exemplo, em estudo realizado por Rybarczyk e Wu (2010), as variáveis associadas aos fatores positivos corresponderam à população e ao número de escolas, parques e centros comerciais. Quanto maior o valor obtido, maior a demanda, portanto maior a possiblidade do uso da bicicleta. Por outro lado, a ocorrência de crimes foi uma variável associada a um fator negativo, sendo que quanto maior o valor obtido, menor a demanda potencial. Sendo assim, os autores construíram uma função linear para normalizar as variáveis, de acordo com o fator associado:

$$
\begin{gathered}
x_{i}^{\prime}=\frac{\left(x_{i}-x_{\min }\right)}{x_{\max }-x_{\min }} \text { para as variáveis associadas aos fatores positivos } \\
x_{i}^{\prime}=\frac{\left(x_{\max }-x_{i}\right)}{x_{\max }-x_{\min }} \text { para as variáveis associadas aos fatores negativos }
\end{gathered}
$$

Onde, $\mathrm{x}_{\mathrm{i}}$ : valor original da variável 


$$
\begin{aligned}
& \mathrm{X}_{\min } \text { : mínimo valor da variável } \\
& \mathrm{X}_{\text {max }} \text { : máximo valor da variável }
\end{aligned}
$$

Através deste processo é possível transformar todos os valores para uma mesma escala, tornando possível a agregação entre eles. Ao realizar a normalização, devem ser considerados os valores máximo e mínimo da variável que se pretende normalizar, de tal forma que o valor procurado fique dentro deste intervalo. Com os resultados da normalização, quando possível, a construção de um gráfico contendo todos os valores obtidos entre 0 e 1 pode ajudar o entendimento da relação existente entre eles, contribuindo para uma análise mais direta da situação. 


\subsection{Considerações finais do capítulo}

De acordo com a revisão bibliográfica apresentada, muitos são os estudos voltados à identificação dos usuários potenciais. Entretanto, estes estudos, em sua maioria, utilizam questionários aplicados a uma parcela da população, muitas vezes somente a que frequenta o polo gerador estudado. Desta forma, não é possível ter conhecimento sobre a localização dos demais indivíduos que poderiam ser usuários potenciais, comprometendo, portanto, ações voltadas ao estabelecimento de uma rede cicloviária eficaz em toda a cidade. Como alternativa a esta situação, o uso de mineradores pode ser uma opção promissora, sobretudo quando os dados já foram coletados.

Por outro lado, é necessário ter conhecimento sobre quais são os fatores que influenciam os deslocamentos por bicicleta. O desconhecimento dos mesmos, mesmo havendo uma base de dados sólida sobre as informações dos indivíduos entrevistados (por exemplo, informações socioeconômicas), pode comprometer os resultados, uma vez que variáveis importantes não foram explicitamente definidas. Tal desconhecimento por ser explicado pela forma como o questionário foi montado, pela atitude do entrevistador no momento da realização da pesquisa e pela replicação de questionários em populações com características sociais e culturais diferentes entre si. Mesmo assim, de acordo com a bibliografia consultada, de uma forma geral, em países onde a cultura pelo uso da bicicleta ainda não está consolidada, nota-se que qualquer incremento na melhoria das condições de infraestrutura (por exemplo), automaticamente gera uma maior sensação de segurança aos usuários entrevistados, contribuindo para o maior uso da mesma.

Com relação à execução de redes cicloviárias no Brasil, notadamente em cidades com mais de 500.000 habitantes verificam-se planos cicloviários voltados à execução de grandes extensões de redes. Mesmo assim, ainda são poucos os estudos desenvolvidos para o planejamento das redes. Tais redes podem ser concebidas utilizando vários métodos e ferramentas e considerando vários critérios, muitas vezes estes dependentes dos dados disponíveis no momento da realização da pesquisa. Além disso, em muitos estudos apresentados, foram utilizados dados 
agregados de população, seja ela concentrada em setores censitários, seja em PGV's. Como já dito anteriormente, isto pode comprometer o entendimento dos deslocamentos dos demais indivíduos da cidade, uma vez que muitas vezes não são suficientemente representativos dos mesmos.

Em nenhum dos estudos apresentados sobre o planejamento de redes cicloviárias foi constatada a contabilização do número de viagens em cada tramo viário. Muitas vezes apenas identificar que o tramo viário é um local de passagem de caminho mínimo pode não ser suficiente. É necessário ter conhecimento se esse tramo é fundamental ou não para o possível deslocamento da população. Isto pode ser verificado através da análise de toda a malha viária urbana associada à contabilização de viagens por tramo (quanto maior o número de viagens, maior a importância do tramo viário nos deslocamentos utilizando bicicleta). Ainda com relação aos estudos envolvendo o planejamento de redes cicloviárias, a utilização de rotinas de caminho mínimo, através de ferramentas presentes nos SIG's utilizados, mostrou-se útil para a previsão das vias que poderiam ser utilizadas pelos ciclistas em seus deslocamentos.

Comparando a quantidade de estudos acerca de planejamento de redes cicloviárias com os voltados para a avaliação das redes, nota-se uma diferença entre a quantidade dos mesmos. De qualquer forma, foi possível identificar quais foram os critérios considerados e como eles foram relacionados entre si, sobretudo quando há uma diferença entre as ordens de grandezas existentes.

A partir do material apresentado, este capítulo procurou fornecer a fundamentação teórica para a formulação e aplicação do método aqui desenvolvido e para a análise dos resultados, sendo possível compará-los com os estudos apresentados, conforme constatado nos próximos capítulos. 


\section{MATERIAIS E MÉTODO}

De forma a atingir os objetivos propostos neste estudo, sugere-se primeiramente a obtenção dos dados necessários. Posteriormente, as etapas sugeridas são: i) identificação dos usuários potenciais, a partir do perfil dos usuários reais, ii) planejamento de redes cicloviárias (redes propostas), iii) comparação entre as redes cicloviárias propostas e as definidas pelo poder municipal, considerando os usuários reais e potenciais, estratégias de avaliação e critérios objetivos de custos e benefícios. No que diz respeito aos materiais utilizados, o foco se concentra nos programas de computador destinados à tarefas específicas, como é apresentado na etapa de identificação dos usuários potenciais.

\subsection{Dados necessários}

Para o desenvolvimento de um método objetivo para o planejamento e comparação de redes cicloviárias como aqui proposto, alguns itens podem ser considerados fundamentais. Esses itens estão relacionados às informações exatas de localização das origens e dos destinos das viagens e dos polos geradores referentes à cidade em estudo, às características da malha viária urbana e das redes cicloviárias estudadas e aos dados dos setores censitários oficiais. Os itens considerados foram:

a. Dados desagregados de uma Pesquisa Origem-Destino (O/D), contendo a localização geográfica (coordenadas de latitude e longitude) dos pontos de origem e destino das viagens, além de dados socioeconômicos dos entrevistados e informações das viagens realizadas;

b. Localização geográfica (coordenadas de latitude e longitude) de importantes polos geradores de viagens;

c. Malha viária urbana georreferenciada, contendo nome dos logradouros, sentido das vias e pontos de interseções;

d. Base de dados do IBGE contendo as populações dos setores censitários georreferenciados da cidade em estudo;

e. Extensão das redes cicloviárias;

f. Extensão das viagens realizadas utilizando as redes cicloviárias em estudo (dado obtido durante o processo). 
As localizações das origens e dos destinos das viagens realizadas podem ser obtidas, por exemplo, através de uma Pesquisa O/D, preferencialmente domiciliar. Como é praticamente impossível coletar dados de viagens de toda a população de uma cidade, através de uma amostra da população, a Pesquisa O/D possibilita que sejam coletadas informações acerca do comportamento das viagens realizadas, bem como características socioeconômicas dos indivíduos entrevistados. Estas informações podem ser consideradas representativas da população, desde que coletadas em toda a mancha urbana, portanto englobando as diferentes classes socioeconômicas e seus respectivos padrões de deslocamento, e com valores representativos do ponto de vista estatístico.

A localização exata de determinados PGV's e as características da malha viária urbana podem ser obtidas através de consulta aos órgãos municipais responsáveis pela sua manutenção e operação (por exemplo, Secretaria Municipal de Habitação) em formato físico (plantas de localização impressas) ou digital (arquivos shapefile, por exemplo).

Os dados referentes aos setores censitários do IBGE (por exemplo, localização e população residentes) podem ser obtidos direta e gratuitamente da plataforma do próprio órgão e já corretamente georreferenciados.

Para que seja possível realizar o correto georreferenciamento das informações de localização geográfica das origens e dos destinos das viagens e dos polos geradores, bem como o planejamento de redes cicloviárias e consequente contabilização dos itens referentes às mesmas e às viagens consideradas, sugerese a utilização de SIG's, preferencialmente voltados à área de transportes (SIG-T). Dentre os exemplos de SIG que podem ser utilizados, destacam-se TransCAD, Quantum GIS, ArcGIS, entre outros.

Posteriormente à aquisição dos dados necessários, sugere-se a realização das três etapas citadas anteriormente e detalhadas na sequência. 


\subsection{Identificação dos usuários potenciais}

Para a identificação dos usuários potenciais sugere-se a utilização de uma técnica de mineração de dados aplicada a dados desagregados de uma pesquisa origem-destino. Algumas características desta técnica são apresentadas a seguir.

\subsubsection{Mineração de dados}

Ao longo dos anos, uma grande quantidade de dados de diferentes tipos passou a ser coletada e armazenada. Ao mesmo tempo, com o advento da

tecnologia, computadores cada vez mais compactos e velozes passaram a apresentar maior capacidade de processamento destes dados coletados. Técnicas tradicionais de processamento de dados deixaram de ser suficientes para o tratamento da grande quantidade de dados obtidos, sendo necessário o desenvolvimento de novas alternativas.

Dentre estas alternativas, surgiu um conjunto de técnicas denominado Mineração de Dados (Data Mining). Este conjunto de técnicas cumpre basicamente duas tarefas: i) prever valores desconhecidos ou futuros de uma variável (por exemplo, probabilidade de uso de determinado modo de transporte), a partir de outras variáveis e, ii) encontrar padrões que estão ocultos com o objetivo de descrever os dados, permitindo sua interpretação (Breiman et al., 1984). Em função destas características, possibilita o delineamento de ações no campo estratégico do planejamento, sendo aplicada em diferentes áreas do conhecimento, como por exemplo: astronomia, bioengenharia, desenvolvimento de sistemas inteligentes, economia, engenharia de alimentos, geografia, medicina, meio ambiente, oceanografia, semântica, tecnologia da informação, zootecnia, dentre outras (conforme Schuh et al., 2015, Teoh et al., 2016, Englund et al., 2016, Hui et al., 2011, Caballero et al., 2016, Maia et al., 2016, El Naqa et al., 2010, Pourtaghi et al., 2016, Williamson et al., 2015, Ristoski e Paulheim, 2016, Gonzalez et al., 2008, Rodrigues et al., 2013, respectivamente).

Especificamente com relação à área da engenharia de transportes, algumas técnicas de Mineração de Dados (MD) vêm sendo utilizadas para a realização de modelagem de demanda de transportes, uma vez que possuem uma estrutura mais 
flexível do que os modelos tradicionais, como o modelo Logit. A utilização de métodos matemáticos ou estatísticos pelos modelos tradicionais conduz às suposições sobre a descoberta das relações existentes entre variáveis dependentes e independentes. Essas suposições, por exemplo, podem ser relacionadas à distribuição da probabilidade de determinada variável.

Através do uso de técnicas de $\mathrm{MD}$, a descoberta da relação entre estas variáveis se torna mais fácil, uma vez que os algoritmos utilizados são mais flexíveis e permitem um melhor entendimento entre elas, além da possibilidade de reconhecimento dos padrões existentes (Xie et al., 2003).

De acordo com Bispo (1998), as principais técnicas de MD utilizadas são: Lógica Nebulosa, Redes Neurais Artificiais, Árvores de Decisão, Algoritmos Genéticos, Regras de Indução, Vizinho mais Próximo e Visualização.

Nesta tese será dado um enfoque especial à Árvore de Decisão (AD), uma vez que foi a técnica escolhida para a identificação dos usuários potenciais.

\subsubsection{1 Árvore de Decisão (AD)}

Esta técnica possui este nome por apresentar uma estrutura semelhante a uma árvore, contendo uma raiz e vários ramos (intermediários e finais). À raiz é atribuído o nome de nó raiz (ou nó pai), o qual contém os dados originais. Os ramos intermediários são denominados de nós intermediários (ou nós filhos) e o ramo final, ou seja, aquele a partir do qual não há outro ramo, é denominado de nó terminal ou folha. Os dados originais são divididos em subgrupos com características homogêneas segundo a variável dependente considerada, obedecendo a regras hierárquicas de decisão (do tipo: "Se....então...") (Breiman et al., 1984).

Talvez a característica mais importante da $A D$ seja a capacidade de representar processos complexos de tomada de decisão na forma de processos mais simples, resultando em maior facilidade de interpretação dos resultados. Pode ser definida como um gráfico acíclico, seguindo uma única direção, e apresentando as seguintes características (Safavian e Landgrebe, 1991): 
- Há um único nó denominado raiz, o qual contém todos os dados de entrada;

- Há um único caminho da raiz para cada nó;

- Há uma hierarquia entre os nós, composta por nós pai e filhos, sendo estes subdivisões dos primeiros;

- Os nós terminais (folhas) são aqueles que não apresentam subdivisão (não apresentam nós filhos);

- No caso de dois nós terminais apresentarem ao menos uma classe em comum, diz-se que os nós apresentam uma sobreposição de classes.

As Árvores de Decisão vêm sendo utilizadas em diversas áreas com resultados satisfatórios, como nos estudos de Stojanova et al. (2006), Kheir et al. (2008), Xie et al. (2003), Rasouli e Timmermans (2014), Caballero et al. (2016), dentre outros. De acordo com Borges (2013), a AD possui algumas características que possibilitam o seu uso:

- Precisão: apresenta habilidade para avaliar ou prever corretamente classes, agrupamentos, regras;

- Velocidade: configuradas todas as variáveis, seu uso é imediato e o processamento das informações é rápido;

- Robustez: consegue avaliar e prever corretamente os padrões investigados, mesmo com a presença de valores ausentes nos dados;

- Escalabilidade: capacidade de construir modelos eficientes a partir de grandes volumes de dados;

- Interpretabilidade: capacidade de fornecer interpretações fáceis ao operador.

Para que seja possível realizar a divisão dos dados originais (contidos no nó raiz) segundo regras hierárquicas, dando origem a vários subgrupos, é necessário utilizar determinados algoritmos. Alguns algoritmos utilizados para obter as AD's são: C4.5 (Quinlan, 1993), CHAID (Kass, 1980) e CART (do inglês, Classification and Regression Tree, conforme Breiman et al., 1984). Este último será detalhado no próximo subitem, tendo em vista o seu uso nesta pesquisa em particular. 


\subsubsection{IBM SPSS Statistics e CART}

Neste trabalho optou-se por utilizar o software IBM SPSS Statistics versão 24, uma vez que o mesmo contém um módulo específico para mineração de dados. Além disso, este software estava disponível no Departamento de Engenharia de Transportes da Escola de Engenharia de São Carlos (EESC) e possibilitou a identificação dos usuários potenciais por meio da probabilidade do uso da bicicleta pelos mesmos, baseando-se na identificação do perfil (ou padrão) dos usuários reais, o qual foi obtido através da técnica de Árvores de Decisão. Este software foi também utilizado em outros estudos da área (Silva, 2006, Isler e Pitombo, 2014, Pitombo e Costa, 2015, Santos, 2015, Pitombo e Guimarães, 2016 e Lindner et al., 2017), apresentando resultados satisfatórios.

Tanto a variável dependente (chamada de variável resposta) como a variável independente (variável de previsão) podem assumir valores categóricos ou numéricos. Variáveis com valores categóricos são aquelas cujos valores não apresentam nenhuma ordem natural entre si, ao passo que variáveis numéricas são aquelas cujos valores são números reais (inteiros ou não), podendo haver uma hierarquia entre as mesmas. Dependendo do tipo de variável dependente, a $A D$ pode assumir dois tipos de distribuição. Para variáveis numéricas têm-se árvores de regressão e distribuições normais (gaussianas). Para variáveis categóricas, árvores de classificação (tratadas como modelos de probabilidade) e com distribuições multinomiais.

Uma vez que a variável dependente é categórica, a árvore resultante é tratada como um modelo de probabilidade, na qual o desvio é empregado como critério de divisão. Neste tipo de árvore, a impureza é mensurada através do índice Gini:

$$
\operatorname{GINI}(t)=-2 \sum_{j}[p(j \mid t)]^{2}
$$

Onde:

$p(j \mid t)$ : frequência relativa da classe $j$ no nó $t$ 
O algoritmo CART no IBM SPSS Statistics versão 24 considera a minimização do índice Gini como critério de partição e valores de aprimoramento para a escolha das variáveis explicativas (valores de corte).

As variáveis também podem ser medidas em três níveis distintos e de acordo com os valores recebidos. Às variáveis categóricas é atribuído o nível de medida "Nominal", uma vez que este nível representa categorias que não estão associadas a nenhum ranking, tais como regiões da cidade, classes de solos, códigos postais, etc.

Por sua vez, às variáveis numéricas podem ser atribuídos os níveis de medida "Ordinal" ou "Escala". Variáveis medidas sob a forma "Ordinal" apresentam valores associados a alguma classificação (ranking) e que resultam em um ordenamento dos valores, como, por exemplo, o nível de satisfação do cliente (1 - satisfeito, 5 - insatisfeito), o grau de preferência do usuário por determinado modo de transporte, etc. Variáveis medidas sob a forma "Escala" apresentam valores que podem ser classificados de acordo com um intervalo numérico, sendo possível a comparação entre eles dentro destes intervalos.

A determinação dos níveis de medida das variáveis é importante, uma vez que afeta a divisão dos dados originais em subgrupos. Uma atribuição inadequada de um nível de medida a uma variável, seja ela dependente ou independente, pode levar a resultados inadequados e, consequentemente, análises inadequadas das AD's geradas (IBM, 2016).

O IBM SPSS Statistics permite a utilização de quatro algoritmos para realizar o crescimento da AD: i) CHAID, ii) CHAID exaustivo, iii) CART e iv) QUEST. Especificamente com relação ao algoritmo CART, considerado para esta pesquisa, ele é composto basicamente por nós e regras de divisões binárias. A partir da aplicação de regras de divisão ao conjunto inicial dos dados, os subgrupos são obtidos e, consequentemente, os nós (intermediários e finais). As regras de divisão envolvem as variáveis independentes escolhidas (categórica e numérica) e os respectivos valores (Breiman et al., 1984). 
Por exemplo, se a variável independente for categórica, a representação se dá na forma:

- $x_{i} \in\{\mathrm{A}, \mathrm{B}\}$

Se for numérica (por exemplo, "idade") e apresentar um dos valores como sendo 14,1, uma regra de divisão possível pode ser:

- Idade $<14,5$

Para as variáveis independentes categóricas existem $2^{(k-1)}-1$ possíveis divisões, onde $k$ corresponde ao número de categorias possíveis para a variável independente. Já, para as variáveis independentes numéricas com $k$ valores ordenados, existem $k-1$ divisões possíveis.

Em cada etapa para a formação da árvore, ao realizar cada divisão dos dados originais o algoritmo CART utiliza uma única variável. Esta variável é escolhida como sendo a que possui maior poder de segregação dos dados, possibilitando a formação do grupo mais homogêneo, sendo esta condição a utilizada pelo algoritmo em cada subetapa para a formação de novos nós filhos (por exemplo, dentro do nó terminal todos os registros apresentam o mesmo valor para a variável dependente). Deste modo, as variáveis são analisadas individual e separadamente, não possibilitando a ocorrência de multicolinearidade (Pitombo, 2007).

Basicamente, o algoritmo CART considera dois critérios possíveis para selecionar a melhor divisão dos dados, de acordo com a homogeneidade:

- Critério de Twoing: as variáveis dependentes são agrupadas em duas subclasses, sendo que as divisões são realizadas de forma a obter a melhor separação entre os grupos;

- Critério de Gini: as subdivisões são originadas de tal forma a maximizar a homogeneidade dos nós filhos com relação às variáveis dependentes. Desta forma, é possível reduzir as impurezas na divisão dos nós estabelecendo valores mínimos para tal (Breiman et al., 1984). 
De acordo com Breiman et al. (1984), ao se comparar os dois critérios citados quando aplicados em vários conjuntos de dados, as divisões de Gini são as melhores, portanto, geralmente é preferível o uso do critério de Gini.

Uma vez que a árvore gerada pode ser muito grande, com muitos nós intermediários, é possível limitar o crescimento da AD através do estabelecimento da profundidade máxima da árvore e do número mínimo de casos observados em cada nó terminal. O estabelecimento da profundidade máxima permite limitar o número de níveis em que os dados originais podem ser divididos, considerando as variáveis independentes selecionadas. O IBM SPSS Statistics automaticamente apresenta duas opções para a determinação da profundidade:

- Considerando os algoritmos de crescimento: para CHAID, três níveis, e para CART e QUEST, cinco níveis;

- Personalizada, no qual é possível estabelecer o número de níveis em que os subgrupos são divididos. Ressalta-se que quanto maior 0 número de níveis, maior o número de subdivisões dos grupos de variáveis.

Especificamente no caso da escolha da opção "personalizada", caso haja um conjunto inicial de dados com poucos registros, os valores padrão fornecidos pelo programa e iguais a 100 casos para nós pai e 50 casos para nós terminais podem resultar em árvores com nenhum nó abaixo do nó raiz. Neste caso, é conveniente adotar valores menores de casos observados em cada nó, de forma a produzir resultados que conduzam a análises mais próximas da realidade. Além disso, essas escolhas, que são dependentes do usuário, dependem do tamanho da amostra.

É possível validar os dados, ou seja, verificar a qualidade da estrutura da AD utilizada, considerando todas as variáveis independentes selecionadas. Através da validação é possível utilizar as AD’s geradas, de forma generalizada, em populações maiores.

O SPSS Statistics permite a validação dos dados de duas formas:

- Validação cruzada: a amostra original de dados é dividida em um número de subamostras (máximo de 25 subamostras). Em seguida são 
geradas árvores, sempre excetuando uma das subamostras geradas. Para cada árvore, o risco de erros de classificação é estimado pela aplicação da árvore para a subamostra excluída em gerá-la;

- Validação amostral: permite a geração da $A D$, utilizando uma amostra de treinamento. Também permite testar o modelo em uma amostra de teste. Ambas as amostras são separadas aleatoriamente, de acordo com os percentuais escolhidos. Este tipo de validação não deve ser usado em bases contendo um pequeno número de dados originais, pois pode produzir modelos pobres, uma vez que em algumas categorias pode haver casos insuficientes para possibilitar 0 crescimento adequado da árvore.

Sendo a variável dependente classificada como categórica, ela pode apresentar diferentes valores de categoria, sendo necessário codificar a categoria que se pretende identificar ao realizar a mineração de dados utilizando a AD. Esta codificação pode ser realizada, por exemplo, utilizando os valores 0 (zero) ou 1 (um).

Se a variável dependente que se pretende descobrir o padrão for codificada como 0 (zero), o SPSS Statistcs assume que o valor previsto (do inglês, predicted value) igual a 0 (zero) está associado à variável com boa classificação. Consequentemente, o outro valor possível (um) vai estar associado às demais categorias que não são objeto de descoberta de padrão e, portanto, são classificadas no programa como variáveis com má classificação.

Além disso, o software utilizado também permite a obtenção das probabilidades previstas da variável dependente (do inglês, predicted probability), de acordo com a codificação a ela atribuída. No caso da variável com boa classificação, a probabilidade de ocorrência da mesma é dada pelos valores contidos no campo PredictedProbability_2. Para as variáveis com má classificação, a probabilidade será o valor contido no campo PredictedProbability_1.

Através da $A D$ contida no software utilizado é possível representar a probabilidade de uso de determinado modo de transporte, tal como estudado neste trabalho. A árvore reconhece que "indivíduos homogêneos" (segundo a variável 
dependente) não necessariamente possuem a mesma decisão acerca de um modo de transporte e sim apresentam determinadas probabilidades, muitas vezes valores diferentes, para este modo.

\subsubsection{Aplicação da técnica no estudo em questão}

Os dados desagregados podem estar armazenados na forma de registros de programas específicos para gestão de bancos de dados. Antes da inserção destes dados em um minerador de dados, no entanto, faz-se necessário um tratamento dos mesmos, o que pode envolver duas etapas: i) análise de consistência dos registros e ii) correção e/ou complementação dos registros.

Na análise de consistência dos registros é necessário verificar a existência de informações contraditórias (cruzamentos formados por logradouros que não se interceptam na realidade, dados socioeconômicos incoerentes, dados incompletos de viagens, etc.) no banco de dados desagregados, para então corrigi-las ou complementá-las. Na correção e/ou complementação dos registros, é necessária a identificação do formulário de pesquisa relativo ao usuário e que contém as informações procuradas, para então sanar os problemas encontrados (correção ou complementação) diretamente no banco de dados.

Em seguida, para a inserção dos registros em um minerador de dados, sugere-se primeiramente determinar quais serão os registros a serem utilizados, uma vez que nem todos contribuem necessariamente para a identificação dos usuários potenciais. Na sequência, os mesmos podem ser exportados para uma planilha eletrônica, uma vez que isto torna mais fácil a organização das informações que serão utilizadas, e a migração destas para o minerador. Recomenda-se que as variáveis sejam escolhidas de acordo com a disponibilidade presente no formulário da pesquisa origem-destino e que possam apresentar alguma relação com o uso da bicicleta nos deslocamentos diários, tal como apresentado nos estudos de Boussauw et al. (2014), Castillo-Manzano et al. (2016) e Heinen et al. (2010), por exemplo. 
Muitas vezes o banco de dados contém registros que informam com precisão somente a localização da origem das viagens e não do destino, por exemplo. Para efeito do método proposto neste trabalho, esta informação é primordial e deve ser considerada. Entretanto, muitas vezes os próprios formulários não apresentam esta informação, seja porque não foram informadas na entrevista, seja devido à falha de preenchimento por parte do entrevistador, ou ainda porque tanto o entrevistado como o entrevistador não sabiam a localização exata do ponto de destino. Sendo assim, em muitos casos é necessário excluir estes registros da planilha eletrônica. Tal procedimento garante a integridade dos registros que estão armazenados no banco de dados original da pesquisa (por exemplo, no programa gerenciador de banco de dados) e não compromete os registros que serão inseridos no minerador.

Após a inserção dos registros em um minerador de dados, os mesmos recebem o nome de variáveis e é necessário configurá-las com relação ao tipo de categoria e à forma de medida permitida pelo minerador. Em seguida é necessário escolher uma técnica de mineração de dados que possibilite a identificação dos padrões dos usuários reais de bicicleta para a determinação dos usuários potenciais. Além disso, também é necessário que esta técnica retorne a probabilidade do uso da bicicleta pelos usuários potenciais, o que pode ser obtido utilizando a Árvore de Decisão (AD). Para que seja possível utilizá-la, o minerador requer que sejam definidas as variáveis dependente e independentes (uma vez que esta escolha irá influenciar diretamente nos resultados), as configurações dos critérios que originarão a $A D$ e a definição do algoritmo a ser usado. Especificamente com relação ao algoritmo, a partir dele é possível encontrar as variáveis independentes mais importantes dentro do banco de dados utilizado e que fornecem a máxima divisão dos dados em pequenos conjuntos homogêneos, segundo a variável dependente, e que resultam nos padrões buscados.

Realizadas as configurações das variáveis, a escolha e configuração da técnica a ser utilizada dentro do minerador de dados para a identificação dos padrões e o algoritmo associado, é necessário validar os dados inseridos na técnica de mineração. Esta validação é realizada através da determinação da porcentagem de uma amostra de treinamento e uma amostra de teste. 
Logo após esta última sequência de atividades, é possível identificar os usuários potenciais e iniciar a etapa de definição do planejamento de redes cicloviárias. Ressalta-se que os usuários potenciais foram, para fins deste estudo, os indivíduos classificados nas folhas com probabilidade maior que $15 \%$ quanto ao uso da bicicleta, mas que, de acordo com os dados da pesquisa O/D, escolheram outros modos de transporte.

\subsection{Planejamento de redes cicloviárias}

Nesta etapa é proposto um procedimento para o planejamento de redes cicloviárias (redes propostas) considerando dados desagregados da população e a contabilização dos tramos do sistema viário com maior número de possíveis rotas sobrepostas.

É necessário que os dados desagregados contenham a localização geográfica (coordenadas de latitude e longitude) dos pontos de origem e destino das viagens (exceto viagens com retorno para casa) e a malha viária urbana esteja georreferenciada e contenha o nome dos logradouros (para permitir posterior verificação de dados de elevação), sentido das vias, bem como todos os pontos de interseção. Sugere-se que as viagens com retorno para casa sejam desconsideradas, uma vez que é possível que sejam realizadas pelas mesmas vias utilizadas pelas viagens com destino ao trabalho, estudo, recreação, etc..

Os procedimentos propostos para o planejamento de redes cicloviárias são os seguintes:

i) Obtenção da base de dados desagregada e georreferenciada referente a uma pesquisa domiciliar de origens e destinos, com informações sobre os motivos das viagens;

ii) Obtenção de base de dados georreferenciada contendo a malha viária da cidade em estudo;

iii) Exclusão das viagens com retorno para casa;

iv) Utilização de recursos de SIG voltados à área de transportes (SIG-T);

v) Identificação dos pares origem-destino das viagens realizadas por bicicleta; 
vi) Identificação dos motivos das viagens realizadas por bicicleta;

vii) Para cada viagem de cada motivo, obtenção de pelo menos quatro possíveis rotas de cada origem para cada destino associado, através do emprego de rotinas de caminho mínimo disponíveis no SIG-T (no caso estudado utilizou-se o software TransCAD, mas outros programas também podem ser utilizados);

viii) Contabilização do número de possíveis rotas sobrepostas em cada tramo viário, considerando todas as viagens realizadas por bicicleta e de acordo com o respectivo motivo;

ix) Identificação de tramos do sistema viário que concentraram um número de possíveis rotas sobrepostas superior a um ou mais valores préestabelecidos;

x) Utilização de recursos computacionais que permitam a visualização da elevação do terreno, como, por exemplo, os programas Google Earth/Google Street View;

xi) Planejamento de redes cicloviárias, com base nos tramos de vias com maior número de possíveis rotas sobrepostas (item ix), no volume e sentido do fluxo de tráfego de automóveis (neste caso, sugere-se evitar vias com volume de tráfego motorizado superior a um limite predeterminado, por exemplo, 120 veículos/hora/faixa) e na topografia das vias (sugere-se evitar aclives/declives superiores a 5\%, uma vez que influenciam os deslocamentos realizados por bicicleta (GEIPOT, 2001).

Sugere-se a utilização de recursos computacionais que permitam a visualização da elevação do terreno (como o software Google Earth/Google Street View), pois através dos mesmos é em geral possível identificar a elevação de determinados trechos de vias. Isto é particularmente importante no caso em questão porque muitas vezes apenas a informação disponível da malha viária urbana não dispõe dos valores relacionados à topografia das vias, o que pode dificultar a escolha de determinado trecho viário no caso de haver dois ou mais com as mesmas características de volume e sentido do fluxo de tráfego de automóveis. 


\subsection{Comparação entre as redes cicloviárias}

Muitas vezes somente planejar redes cicloviárias não é suficiente para ter conhecimento sobre a real eficácia do atendimento fornecida por elas. Além disso, no caso de cidades que já dispõem de redes cicloviárias construídas (existentes) ou projetadas pelo poder municipal, a comparação entre elas e as redes propostas fornece um maior conhecimento sobre a situação real de atendimento vivenciado pelos usuários de bicicleta e o que pode ser melhorado.

Sendo assim, na terceira e última etapa propõe-se uma comparação entre as redes obtidas (propostas) e as definidas pelo poder municipal, considerando os usuários reais e potenciais, estes não considerados no trabalho exploratório realizado por Guerreiro et al. (2017, no prelo). Os usuários reais provêm diretamente dos dados desagregados da pesquisa $\mathrm{O} / \mathrm{D}$, ao passo que os usuários potenciais podem ser obtidos através da mineração dos dados, como apresentado na primeira etapa descrita na metodologia. Com relação às redes definidas pelo poder municipal, sugere-se que a rede cicloviária existente seja denominada de RCE e a rede cicloviária proposta, de RCP.

Recomenda-se a realização de duas estratégias de avaliação considerando uma banda com largura homogênea ao redor de todas as redes (para a qual se sugere aqui um valor de 400 metros, mas que pode ser ajustado conforme o tomador de decisão). A primeira estratégia (Avaliação I) se baseia em informações obtidas na própria pesquisa origem-destino e considerando as características das viagens realizadas, enquanto que a segunda estratégia de avaliação (Avaliação II) considera dados das redes cicloviárias e dados agregados da população fornecidos pelo IBGE - Instituto Brasileiro de Geografia e Estatística, ou seja, dados independentes da pesquisa origem-destino. Para tanto, os seguintes itens foram computados:

- Avaliação I

a) Extensão total das redes cicloviárias;

b) Total de viagens realizadas;

c) Total de origens identificadas;

d) Média das distâncias das origens das viagens até as redes; 
e) Viagens de bicicleta já existentes e cujas origens estão contidas na banda traçada;

f) Percentual da extensão total das viagens realizadas utilizando as redes estudadas (extensão das viagens realizadas dentro da rede), bem como da extensão das viagens realizadas fora da rede, para cada origem.

- Avaliação II

a) Extensão total das redes cicloviárias;

b) População (absoluta e relativa) referente aos setores censitários e contida na banda traçada.

Especificamente com relação ao percentual da extensão das viagens realizadas dentro da rede, é necessário verificar individualmente as viagens realizadas por cada indivíduo. No caso dos usuários potenciais pode haver a ocorrência de muitas viagens encadeadas, ou seja, viagens que ocorrem em sequência, muitas vezes com o ponto de destino da primeira viagem sendo igual ao ponto de origem da próxima viagem. Nestes casos, é necessário identificar precisamente quais são as origens e respectivos destinos, além de verificar e excluir as viagens com retorno para casa.

Posteriormente recomenda-se que as redes sejam comparadas considerando um número igual de critérios que sejam comuns a todas elas (análise multicritério), como, por exemplo, critérios de custo e de benefício. Estes critérios podem considerar, por exemplo, características próprias das redes cicloviárias traçadas, da malha viária urbana, das viagens realizadas, da localização exata dos pontos de origem das viagens e dos polos geradores, dentre outros fatores. Quanto maior 0 número de critérios, melhor pode ser a comparação entre as redes. Neste estudo, os critérios de custo ( $\mathrm{C} 1$ a $\mathrm{C} 6$ ) e benefícios (B1 a B6) utilizados foram os descritos a seguir.

C1. Extensão total da rede;

C2. Número de interseções, por km, ao longo da rede; 
C3. Razão entre o número de conversões e o comprimento da rota, como medida de legibilidade da rede (facilidade de assimilação da rede pelo usuário);

C4. Distância média de polos geradores de viagem significativos para o modo cicloviário até a rede - no estudo de caso considerado, refere-se à distância entre escolas (públicas e privadas) e as redes propostas;

C5. Distância média da origem das viagens até a rede - refere-se à distância percorrida por cada usuário para acessar as redes propostas;

C6. Percentual das viagens realizadas fora da rede, representada pelo percentual da extensão das viagens percorridas fora da rede para acessar 0 destino, relativamente à extensão total da rede.

B1. Percentual da origem das viagens coberto pela rede;

B2. Percentual das viagens realizadas dentro da rede, representada pelo percentual da extensão das viagens percorridas dentro da rede para acessar o destino, relativamente à extensão total da rede;

B3. Percentual de população atendida (IBGE);

B4. Percentual de escolas (públicas e privadas) atendidas pela rede;

B5. Percentual de estabelecimentos comerciais atendidos pela rede;

B6. Percentual de indústrias atendidas pela rede.

No caso dos custos C2 e C3 é imprescindível a utilização da base de dados georreferenciada da rede viária urbana, bem como o sentido das vias utilizadas.

Para os custos, quanto maior for o valor, pior é o atendimento da rede, seja devido ao maior custo de construção (C1), maior tempo de espera (C2), difícil assimilação pelo usuário (C3) e maiores distâncias percorridas pelo usuário (C4, C5 e C6). Para todos os benefícios, quanto maior o valor obtido, melhor é o atendimento realizado pela rede. Com exceção do item B2, no caso dos benefícios, os percentuais foram obtidos através da contabilização dos respectivos itens dentro da banda de largura predeterminada ao redor das redes propostas e em relação ao total de cada item. 
Complementando a comparação dos critérios, propõe-se a realização de uma análise de sensibilidade admitindo limites mínimos e máximos para cada um dos critérios de custo e benefício considerados. Através da análise de sensibilidade é possível ter conhecimento da relação entre os valores obtidos, como também do atendimento realizado pelas redes cicloviárias em estudo. A partir desta análise é possível tomar decisões acerca da alternativa das redes cicloviárias estudadas que retorna o melhor atendimento aos usuários, sejam eles reais ou potenciais.

Como os critérios de custo e de benefício podem apresentar valores com ordens de grandeza diferentes, não permitindo assim uma comparação direta entre eles, sugere-se a normalização de todos os valores obtidos, inclusive dos valores admitidos na análise de sensibilidade (por exemplo, para os benefícios o mínimo admitido foi $0 \%$ e o máximo $95 \%$ - com a normalização, 0\% recebe valor 0 e $95 \%$ valor 1). Esta normalização não prejudica a análise de sensibilidade, uma vez que mantém a proporcionalidade entre os valores considerados em cada critério. Além disso, muitas vezes a normalização pode contribuir para um melhor entendimento entre os valores obtidos, uma vez que os coloca em uma mesma ordem de grandeza.

Diante das etapas apresentadas, considerando os dados e ferramentas disponíveis, foi possível desenvolver a metodologia apresentada de forma resumida na Tabela 3.1, que aparece também representada de forma esquemática na Figura 3.1. 
Tabela 3.1: Descrição das etapas que constituem o método utilizado

\section{Identificação dos usuários potenciais}

\begin{tabular}{|c|c|}
\hline 1 & $\begin{array}{l}\text { Obtenção de base de dados desagregada e georreferenciada de uma } \\
\text { pesquisa origem-destino }\end{array}$ \\
\hline 2 & $\begin{array}{l}\text { Tratamento dos registros, através de análise de consistência e } \\
\text { correção/complementação dos mesmos }\end{array}$ \\
\hline 3 & Seleção dos registros \\
\hline 4 & Inserção dos registros em software de mineração de dados \\
\hline 5 & $\begin{array}{l}\text { Configuração das variáveis e escolha das variáveis dependente e } \\
\text { independentes no software }\end{array}$ \\
\hline 6 & Escolha da técnica de Mineração de Dados \\
\hline 7 & Escolha do algoritmo \\
\hline 8 & Identificação dos padrões dos usuários \\
\hline \multirow[t]{2}{*}{9} & $\begin{array}{l}\text { Identificação dos usuários potenciais com probabilidade maior que } 15 \% \\
\text { quanto ao uso da bicicleta (excluindo-se as viagens com retorno pra casa) }\end{array}$ \\
\hline & Planejamento de redes cicloviárias \\
\hline 1 & $\begin{array}{l}\text { Obtenção de base de dados desagregada e georreferenciada de uma } \\
\text { pesquisa origem-destino }\end{array}$ \\
\hline 2 & $\begin{array}{l}\text { Tratamento dos registros, através de análise de consistência e } \\
\text { correção/complementação dos mesmos }\end{array}$ \\
\hline 3 & Identificação das viagens \\
\hline 4 & Exclusão das viagens com retorno pra casa \\
\hline 5 & Obtenção de dados georreferenciados da rede viária urbana \\
\hline 6 & Identificação dos pares origem-destino \\
\hline 7 & Identificação dos motivos das viagens \\
\hline 8 & $\begin{array}{l}\text { Traçado de caminhos mínimos (pelo menos quatro alternativas) entre cada } \\
\text { par origem-destino }\end{array}$ \\
\hline 9 & $\begin{array}{l}\text { Contabilização das rotas sobrepostas (dadas pelos caminhos mínimos) em } \\
\text { cada tramo do sistema viário }\end{array}$ \\
\hline 10 & $\begin{array}{l}\text { Definição de limites mínimos de rotas por tramo do sistema viário a serem } \\
\text { consideradas }\end{array}$ \\
\hline 11 & $\begin{array}{l}\text { Identificação de tramos do sistema viário que concentraram um número de } \\
\text { possíveis rotas sobrepostas superior aos limites pré-estabelecidos }\end{array}$ \\
\hline 12 & Planejamento de redes cicloviárias \\
\hline
\end{tabular}




\section{Comparação entre as redes}

\begin{tabular}{cl}
1 & $\begin{array}{l}\text { Inserção, em um SIG, das redes cicloviárias obtidas na etapa anterior e as } \\
\text { existentes e projetadas pelo poder público municipal. }\end{array}$ \\
2 & $\begin{array}{l}\text { Obtenção de dados georreferenciados da rede viária urbana, de polos } \\
\text { geradores de viagens e da base de dados do IBGE }\end{array}$ \\
3 & Criação de banda (buffer) ao redor das redes consideradas \\
4 & Avaliação das redes segundo duas estratégias \\
5 & Definição e cálculo de critérios de custo e benefício comuns às redes \\
6 & $\begin{array}{l}\text { Normalização dos valores calculados de todos os critérios considerados, } \\
\text { através de planilha eletrônica }\end{array}$ \\
7 & Análise de sensibilidade \\
8 & Comparação entre as redes (análise multicritério) \\
\hline
\end{tabular}




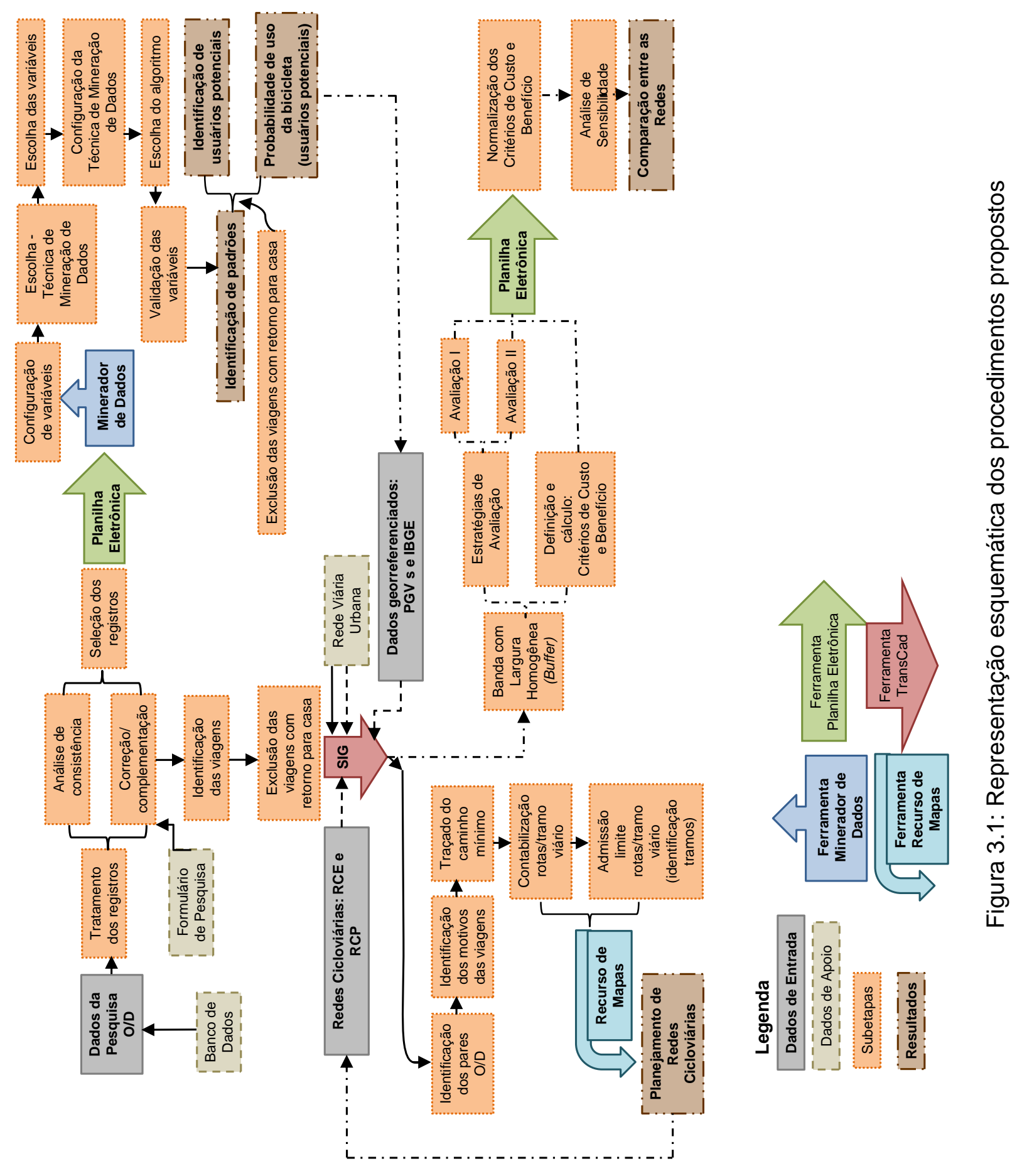




\section{APLICAÇÃO DO MÉTODO EM ESTUDO DE CASO}

O estudo apresentado foi aplicado à cidade de São Carlos, cidade de porte médio localizada no interior do estado de São Paulo. Sendo assim, inicialmente é apresentada uma descrição da cidade em estudo. Posteriormente são apresentados os resultados, seguindo a mesma sequência de etapas descritas no método.

\subsection{Descrição da cidade em estudo}

A cidade de São Carlos situa-se na região central do estado de São Paulo, a $233 \mathrm{~km}$ da capital e possui aproximadamente 242 mil habitantes (IBGE, 2016). Ao longo dos anos, tem se consolidado como um grande polo tecnológico devido à presença de duas instituições públicas de ensino e pesquisa (USP e UFSCar), uma particular (UNICEP), duas unidades da Embrapa, escolas técnicas, dois parques tecnológicos, duas incubadoras de empresas e mais de 200 empresas de base tecnológica. Todo esse contexto educacional e tecnológico faz São Carlos ser conhecida como a "Capital da Tecnologia" (São Carlos, 2011).

Ao longo dos anos, ao mesmo tempo em que São Carlos desenvolveu-se como um dos principais polos tecnológicos do estado de São Paulo, o mesmo não foi verificado com relação ao desenvolvimento do planejamento urbano e de transportes da cidade. Mesmo com a execução do Plano de Mobilidade Urbana Ambientalmente Sustentável em 2002, o qual contemplava, dentre outros itens, medidas de estímulo ao transporte não motorizado (pedestres e ciclistas), pouquíssimas diretrizes e ações neste segmento foram constatadas. Somente a partir de 2005, com a execução do Plano Diretor (Lei Municipal no 13.691/2005) (São Carlos, 2005), verificou-se o surgimento de um conjunto de diretrizes relacionadas ao crescimento da cidade e à promoção de modos de transporte sustentáveis.

A partir de então foi iniciada a construção de infraestrutura cicloviária em alguns pontos da cidade, além de estudos voltados à definição de diretrizes para implantação de novas redes cicloviárias. Como resultado, atualmente a cidade de São Carlos apresenta uma Rede Cicloviária Existente (RCE) e outra já projetada 
(denominada aqui de Rede Cicloviária Projetada - RCP), apresentando extensão de $10,53 \mathrm{~km}$ e 42,32 km, respectivamente (extensões lineares, não considerando a existência de trechos bidirecionais). De acordo com informações obtidas junto aos gestores públicos, a RCP foi projetada considerando as linhas de desejo informadas por uma comunidade de ciclistas entrevistados. Já sobre a RCE, não foram obtidas informações adicionais sobre como foi projetada. Especificamente com relação à RCE verifica-se a descontinuidade entre os vários trechos construídos, o que dificulta os deslocamentos dos usuários reais do modo bicicleta com segurança e manutenção de uma velocidade constante. Tais características podem contribuir para o pouco uso da rede existente. Os traçados das redes RCE e RCP são apresentados na Figura 4.1.

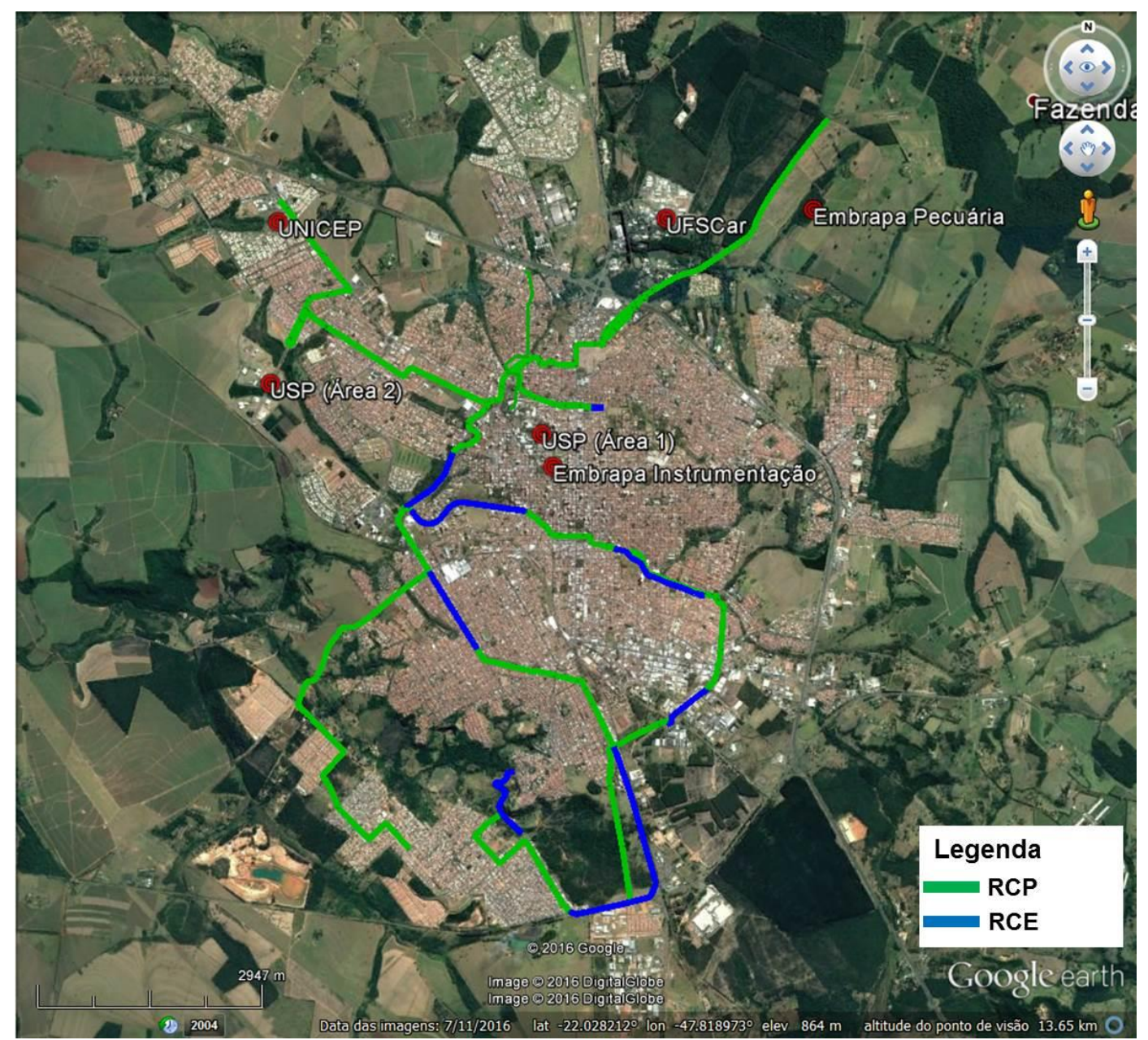

Figura 4.1: Redes cicloviárias existente (RCE) e projetada (RCP) da cidade de São Carlos

Recentemente, no ano de 2012, foi realizada a revisão do Plano Diretor de São Carlos (São Carlos, 2012) e nela esteve prevista a construção de infraestrutura 
cicloviária próxima às áreas paisagísticas de lazer e aos parques lineares e florestais. Entretanto, nem sempre os deslocamentos realizados pelos usuários frequentes de bicicleta ocorrem ao longo de áreas paisagísticas e parques (lineares e florestais), uma vez que tais áreas podem não constituir uma das rotas utilizadas pelos ciclistas. Uma forma de entender melhor a dinâmica dos deslocamentos, seja dos usuários de bicicleta, seja dos usuários dos outros modos de transporte, é através da Pesquisa OD.

Para tanto, entre os anos de 2007 e 2008 foi realizada a primeira Pesquisa OD domiciliar na cidade de São Carlos, composta por duas partes: a primeira composta por uma pesquisa domiciliar para identificação das viagens que ocorreram dentro do município e outra, denominada de cordão, para identificar as viagens que cruzaram os limites de determinada região. O total de domicílios entrevistados foi igual a 3.614 , o que representou $6 \%$ da população à época da pesquisa (Rodrigues da Silva, 2008). A pesquisa foi realizada através de uma cooperação entre duas instituições públicas de ensino superior - Universidade de São Paulo e Universidade Federal de São Carlos - e o poder público municipal. Os dados foram coletados através de formulários preenchidos por pesquisadores treinados, os quais entrevistaram a amostra da população sobre seus deslocamentos ao longo de um dia típico da semana.

Para fins de aplicação e teste do método proposto apresentados nesta tese, foram utilizados os dados provenientes da pesquisa domiciliar, os quais encontraram-se desagregados e contabilizaram 19.784 viagens. Destas, foram consideradas 11.679 viagens, uma vez que nos demais casos faltavam informações importantes (como os pontos de origem ou de destino, impossibilitando 0 georreferenciamento das mesmas). Além disso, também foram utilizados dados censitários agregados, relativos ao ano de 2010, quando a cidade abrigava 212.465 habitantes na área urbanizada (IBGE, 2015). Estes dados censitários foram provenientes da base de dados digital do IBGE, entidade da administração pública federal que é responsável por coletar, tratar, analisar e divulgar dados populacionais, econômicos e sociais de todos os municípios do Brasil, sendo a maioria destes dados georreferenciados. Tanto os dados provenientes da pesquisa origem-destino 
domiciliar como os referentes aos setores censitários são dados públicos, respeitada a privacidade dos respondentes.

Especificamente com relação aos deslocamentos realizados por bicicleta, foram consideradas, para fins deste estudo, 186 viagens, para as quais foi possível identificar os respectivos pares origem-destino e os motivos. Tais viagens referiramse às realizadas pelos usuários reais.

Para uma melhor compreensão do método proposto, a apresentação dos resultados do estudo de caso seguirá a mesma sequência de etapas descritas na metodologia (conforme Tabela 3.1 e Figura 3.1).

\subsection{Identificação de usuários potenciais}

Para a identificação dos usuários potenciais foram utilizados os registros de 11.679 viagens que apresentaram os respectivos pontos de origem e de destino. Aos registros destas viagens estavam associadas informações referentes aos usuários que as realizaram.

Desta forma, no próprio formulário de pesquisa havia campos que faziam a associação entre o número atribuído ao entrevistado e à viagem realizada por ele, de tal forma que tornasse a identificação e o entendimento das viagens possível de serem realizadas. Além das informações de origem e destino, as viagens continham informações referentes aos modos de transporte utilizado, motivo da viagem, horários de saída e chegada, tempo de caminhada (quando houve), a forma e o responsável pelo pagamento da passagem do transporte público urbano, além da condição do usuário ter servido ou não outro passageiro (no caso de utilizar automóvel nos deslocamentos).

Quanto aos usuários, foram coletadas informações socioeconômicas, tais como a posição na família, nível educacional, gênero, idade, condição econômica, informações sobre o tipo de trabalho realizado, dentre outras. Todas estas informações (viagens e usuários) foram inseridas em um programa gerenciador de 
banco de dados, para uma melhor organização e consulta do conjunto dos dados, a partir de agora individualmente denominados registros.

Antes de inserir todos os registros contidos no banco de dados em um minerador de dados, foi realizada uma etapa de tratamento dos mesmos. Nesta etapa, as inconsistências foram verificadas e corrigidas através de consulta direta aos formulários de pesquisa.

Após a correção das inconsistências e da complementação necessária de algumas informações, foram separados os registros a serem inseridos no minerador de dados. Como o objetivo foi identificar os usuários potenciais através das características dos usuários reais, nem todas as informações coletadas na Pesquisa O/D eram necessárias (por exemplo, nome, situação domiciliar ou familiar, nome do local de trabalho, etc.). Sendo assim, as informações consideradas (ou seja, os registros escolhidos do banco de dados) foram:

i) Gênero: (1) Masculino (2) Feminino;

ii) Idade;

iii) Possui Carteira de Habilitação: (1) Sim (2) Não;

iv) Estuda regularmente: (1) Não, (2) Educação infantil - Creche/Pré-Escola, (3) Ensino Fundamental - 1a a $4^{\text {a }}$ Série ou $1^{\circ}$ ao $4^{\circ}$ ano, (4) Ensino Fundamental - 5a a 8ª Série ou 5ำ ao 9aa, (5) Ensino Médio, (6) Superior/Universitário, (7) Outros;

v) Grau de instrução: (1) Não Alfabetizado (2) Pré-Escola (3) Ensino Fundamental Incompleto (4) Ensino Fundamental Completo (5) Ensino Médio Incompleto (6) Ensino Médio Completo (7) Superior Incompleto (8) Superior Completo;

vi) Condição de Renda (em Salários Mínimos): (1) Não tem Renda (2) 0.0 $2.0 \mathrm{SM}$ (3) 2.1 - 4.0 SM (4) 4.1 - 6.0 SM (5) 6.1 - 8.0 SM (6) 8.1 - $10.0 \mathrm{SM} \mathrm{(7)}$ 10.1 - 20.0 SM (8) Não Respondeu;

vii) Modo: (1) Ônibus (2) Ônibus Fretado (3) Transporte Escolar (4) Dirigindo Automóvel (5) Passageiro de Auto (6) Táxi (7) Lotação/Perua (8) Moto (9) Bicicleta (10) a Pé (11) Outros. 
Além destas informações, também foram escolhidos registros referentes à classe econômica e à distância percorrida em cada viagem, os quais não estavam contidos no banco de dados.

Especificamente com relação à classe econômica, ela foi determinada a partir das informações contidas nos registros referentes a cada categoria da condição de renda. Para tanto foi necessário cruzar os dados relativos à condição de renda (apresentados no formulário da pesquisa, em quantidade de salários mínimos) com as classes definidas pela ABEP (Associação Brasileira de Empresas de Pesquisa). De acordo com esta associação, para o ano de 2008, quando o valor do salário mínimo era igual à $R \$ 380,00$, as classes econômicas eram definidas de acordo com a renda média familiar ( $\mathrm{R} \$)$, tal como apresentado na Tabela 4.1.

Tabela 4.1: Relação entre classe socioeconômica e renda média familiar máxima $(R \$)$

Fonte: ABEP (2008)

\begin{tabular}{cc}
\hline Classe & $\begin{array}{c}\text { Renda média familiar } \\
\text { máxima (R\$) }\end{array}$ \\
\hline $\mathrm{A} 1$ & 9.733 \\
$\mathrm{~A} 2$ & 6.564 \\
$\mathrm{~B} 1$ & 3.479 \\
$\mathrm{~B} 2$ & 2.013 \\
$\mathrm{C} 1$ & 1.195 \\
$\mathrm{C} 2$ & 726 \\
$\mathrm{D}$ & 485 \\
$\mathrm{E}$ & 277 \\
\hline
\end{tabular}

Em cada categoria da condição de renda considerada na Pesquisa O/D, através do uso de planilha eletrônica, a quantidade de salários mínimos foi convertida no valor real da renda, considerando o salário mínimo igual à $R \$ 380,00$. A partir desta conversão, foi possível classificar cada categoria em uma determinada classe econômica, conforme o estabelecido pela ABEP. Por exemplo, se o indivíduo informasse o recebimento de 2 salários mínimos receberia o total de $R \$ 760,00$, portanto pertencendo à classe econômica $\mathrm{C} 1$. Ressalta-se que, de acordo com os dados coletados, não ocorreram registros contendo valores de classe $\mathrm{D}$ e $\mathrm{E}$. 
Com relação à distância, a mesma já havia sido previamente calculada entre cada par Origem/Destino e considerando rotinas de caminho mínimo presentes no software TransCAD, conforme trabalho desenvolvido por Ribeiro (2011). Cada valor de distância percorrida estava associado à respectiva viagem, realizada por determinado indivíduo, através da variável denominada "Morador Viagem". Tanto esta variável como a variável "Per_ID" foram inseridas no minerador de dados, embora não influenciassem na geração dos resultados.

Estas duas variáveis tinham como objetivo apenas a identificação dos indivíduos, por meio de um número atribuído a ele ("Per_ID"), e a identificação da sua respectiva viagem ("Morador Viagem"). Desta forma, por exemplo, ao indivíduo entrevistado de número 30 ("Per_ID" = 30) que realizou duas viagens, sendo a primeira identificada pelo número 1 e a segunda pelo número 2, o campo "Morador Viagem" recebeu os valores 301 ( $1^{\text {a }}$ viagem do usuário 30 ) e 302 (2a viagem do usuário 30).

Para a inserção dos registros anteriormente escolhidos no minerador de dados, os mesmos foram exportados do gerenciador de banco de dados para uma planilha eletrônica, de forma a tornar mais fácil a manipulação dos mesmos. Também foi necessário realizar a junção entre estes registros com a informação de distância percorrida, previamente calculada. Esta junção foi realizada considerando a variável "Morador Viagem", uma vez que esta era comum aos registros e à distância percorrida.

Ainda utilizando a planilha eletrônica, para que fosse possível diferenciar os usuários entrevistados que utilizaram a bicicleta em seus deslocamentos daqueles que utilizaram os outros modos, utilizou-se uma variável dummy. No caso dos usuários que utilizaram o modo de transporte bicicleta, a variável dummy recebeu o valor 1. Aos usuários que utilizaram os outros modos de transporte (Ônibus, Ônibus Fretado, Transporte Escolar, Dirigindo Automóvel, Passageiro de Auto, Táxi, Lotação/Perua, Moto, a Pé e outros) a variável dummy recebeu o valor 0 . Desta forma, os registros referentes à variável modo apresentaram somente os valores 0 e 1. Com relação às variáveis independentes, gênero e posse de carteira de habilitação foram consideradas binárias. Para a variável distância foram admitidos 
os valores previamente calculados e não binários. As demais variáveis independentes (estuda regularmente, grau de instrução e classe econômica) apresentaram valores que não eram binários, mas sim obtidos de acordo com a classificação utilizada no questionário da pesquisa origem-destino domiciliar.

O minerador de dados escolhido foi o IBM SPSS Statistics versão 24, uma vez que estava disponível no Departamento de Engenharia de Transportes da EESC e atendia aos requisitos necessários para a pesquisa. Além disso, cita-se a facilidade de operação e entendimento do mesmo.

Para dar início à mineração de dados foi necessário classificar as variáveis em categóricas ou em numéricas, de acordo com o tipo de informação armazenada (textos ou valores numéricos). Além disso, também foi necessário classificar as variáveis de acordo com os níveis de medida possíveis dentro do software (classes ordenadas, desordenadas ou variando dentro de um intervalo numérico). A classificação das variáveis é apresentada na Tabela 4.2.

Tabela 4.2: Tipo de variável utilizada no minerador de dados

\begin{tabular}{lcc}
\hline \multicolumn{1}{c}{ Variáveis } & Tipo de variável & Níveis de medida \\
\hline Gênero & & \\
$\begin{array}{l}\text { Possui } \mathrm{CNH}^{*} \\
\text { Classe }\end{array}$ & Categórica & Nominal \\
Modo & & \\
\hline $\begin{array}{l}\text { Estuda regularmente } \\
\text { Grau de instrução }\end{array}$ & Numérica & Ordinal \\
\hline $\begin{array}{l}\text { Idade } \\
\text { Distância }\end{array}$ & & Escala \\
\hline
\end{tabular}

Com relação ao tipo de variável, "Gênero", "Possui CNH", "Classe" e "Modo" receberam a classificação "Categórica", uma vez que os respectivos valores não apresentavam nenhuma numeração hierárquica entre si, apenas representavam uma qualidade. Com relação ao nível de medida, por apresentarem classes sem nenhum ordenamento entre si, receberam a classificação "Nominal".

As variáveis "Estuda regularmente", "Grau de instrução" e "Idade", por apresentarem categorias divididas segundo uma hierarquia numérica, receberam a classificação "Numérica". A variável "Distância", embora não apresentasse 
categorias de acordo com uma hierarquia numérica, também foi classificada como "Numérica", uma vez que retornou informações de extensão das viagens ocorridas sob a forma de números.

Com relação aos níveis de medida, as duas primeiras variáveis receberam a classificação "Ordinal”, uma vez que possuem diferentes categorias ordenadas de acordo com os valores possíveis. As duas últimas, "Idade" e "Distância", são variáveis cujos valores podem variar dentro de intervalos distintos, recebendo, portanto a classificação "Escala".

A partir da escolha da técnica Árvore de Decisão para identificar os usuários potenciais através dos padrões dos usuários reais foi necessário escolher uma variável que possibilitasse esta identificação. Sendo assim, a variável "Modo" foi escolhida como variável dependente e as demais variáveis como independentes. Além disso, o algoritmo CART (do inglês, Classification and Regression Tree) foi escolhido como o método crescente da árvore.

Para a geração da Árvore de Decisão no IBM SPSS Statistics 24 foi necessário configurar os critérios relacionados a ela. Quanto à profundidade máxima da árvore optou-se pelo modo "Automático", no qual o número máximo de níveis permitido é igual a 5, ou seja, foram feitas até 5 subdivisões dos grupos considerados relevantes a partir das variáveis independentes escolhidas. Quanto ao número de observações, foram considerados, no mínimo, 50 casos no nó pai e 25 casos no nó filho (25 observações no nó terminal). A medida de impureza considerada foi Gini, ou seja, foram obtidos grupos cada vez mais homogêneos em relação à variável dependente.

De forma a verificar a qualidade da estrutura da $A D$, foi realizada a validação dos dados. Para tanto, foi considerada uma amostra de treinamento igual a $70 \%$ e uma de teste igual a $30 \%$. Além disso, foi determinado ao minerador de dados que, para cada viagem inserida, retornasse a probabilidade do uso do modo bicicleta (variável dummy 1) e dos demais modos (variável dummy 0). 
O software utilizado gera os resultados de forma gráfica (Árvore de Decisão) e tabular. A forma gráfica apresenta cada um dos nós observados e neles o número de casos observados (e respectiva porcentagem) referentes ao modo com variável dummy 1 (bicicleta) e variável dummy 0 (outros modos). A cada subdivisão da árvore, realizada com base nas variáveis independentes consideradas, novos nós são apresentados e neles as informações referentes aos mesmos.

Os resultados de forma tabular contêm as informações referentes às variáveis, dependente e independentes, para cada um dos registros considerados, além da probabilidade do uso do modo (variável dependente) e outros itens que podem ser selecionados durante a etapa de configuração da Árvore de Decisão.

Considerando a árvore gerada, foram obtidos 17 nós, sendo 9 nós terminais (último nó da divisão). Pode-se considerar que as variáveis "Gênero", "Classe", "Possui CNH" e "Estuda Regularmente" foram as variáveis mais importantes para a obtenção da Árvore de Decisão, uma vez que a partir delas ocorreu um maior número de ramificações. Um esquema com disposição das variáveis é apresentado na Figura 4.2.

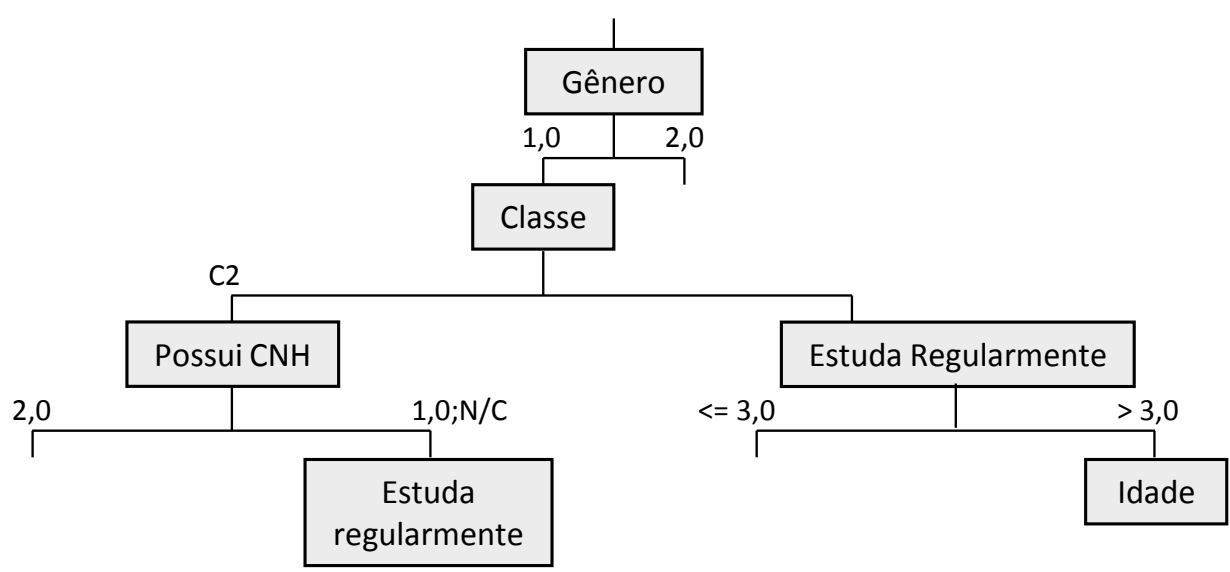

Figura 4.2: Esquema com as quatro variáveis principais formadas pela árvore dos potenciais usuários

Em uma primeira análise, observa-se que a variável "Gênero" e masculino $(1,0)$ é a determinante para o início da mineração e o que mais caracteriza as viagens realizadas por bicicleta. Outra variável diretamente relacionada ao uso deste modo é a "Classe", sendo a C2 a mais importante dentre todas as classes 
consideradas. Igualmente importante podem ser consideradas as variáveis "Possui $\mathrm{CNH}$ " e "Estuda Regularmente", sendo que somente os usuários que possuem $\mathrm{CNH}$ $(1,0)$ e os que estudam a partir do ensino fundamental podem ser considerados os característicos do uso de bicicleta. Uma análise completa da árvore gerada pode ser obtida a partir das figuras 4.3 e 4.4 , as quais demonstram as árvores geradas pelo IBM SPSS Statistics 24 para as amostras de treinamento e de teste, respectivamente. 


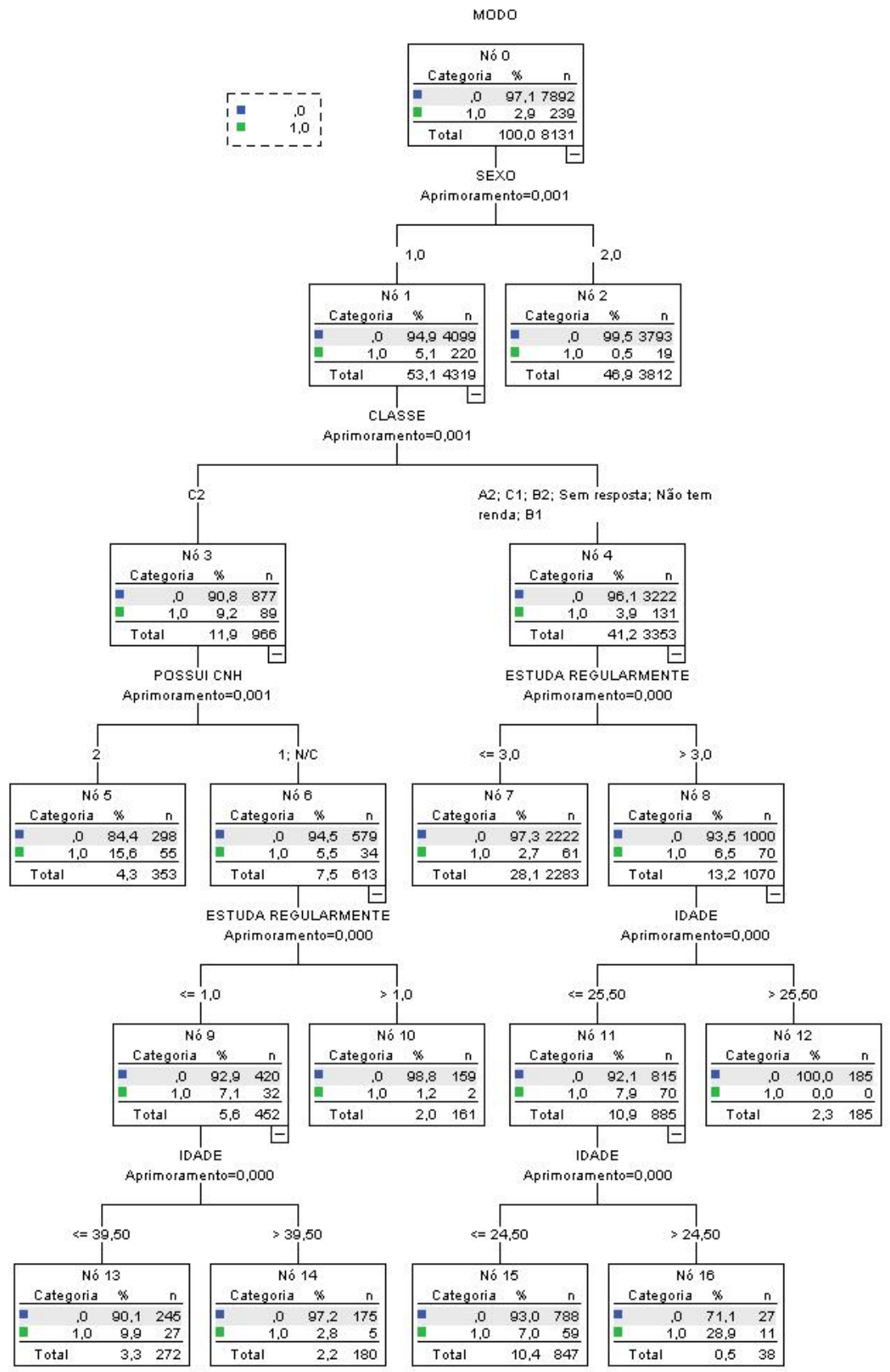

Figura 4.3: Árvore de Decisão - Amostra de treinamento OBS.: Onde se lê "sexo", leia-se "gênero" 


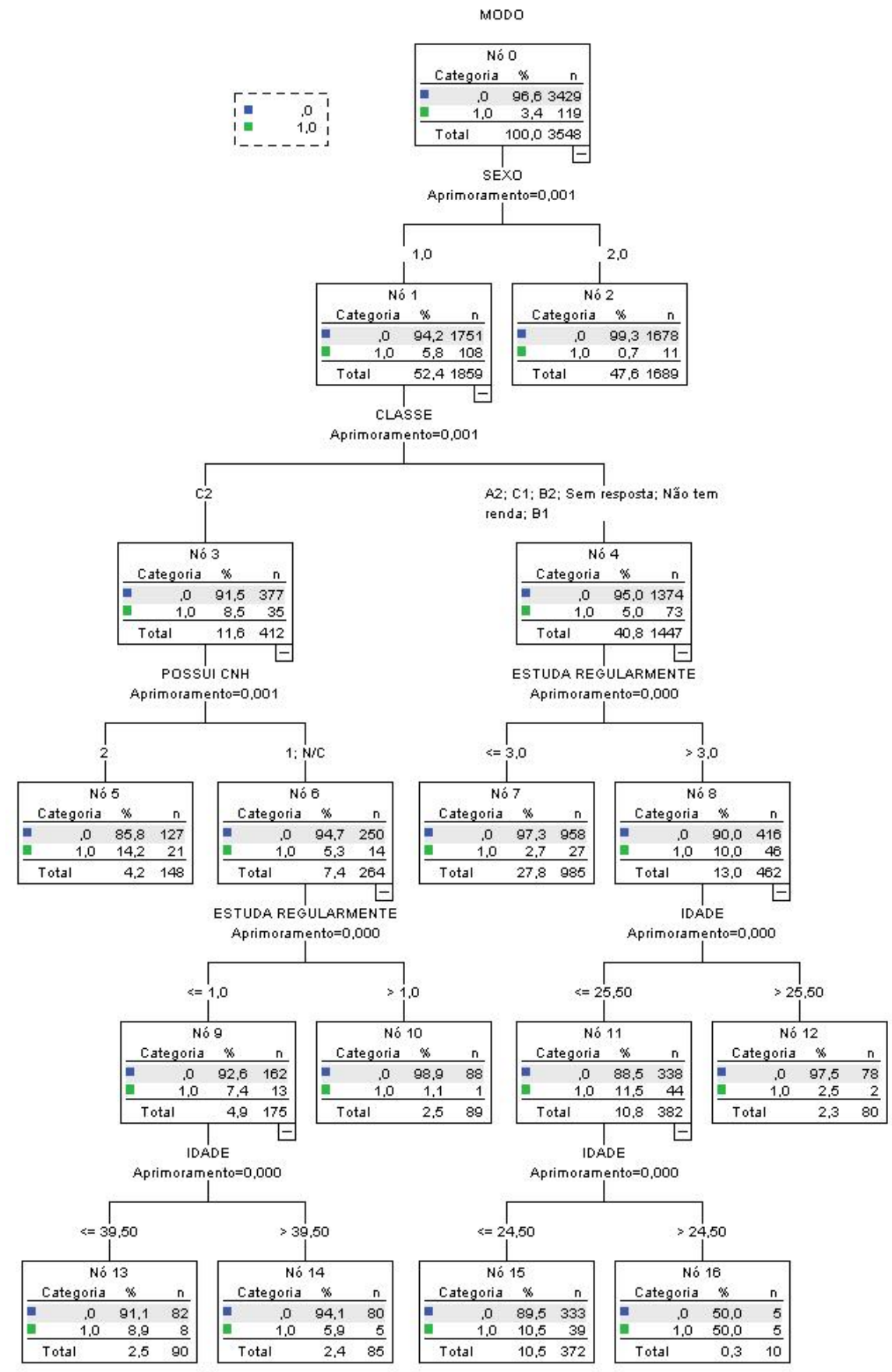

Figura 4.4: Árvore de Decisão - Amostra de teste

OBS.: Onde se lê "sexo", leia-se "gênero" 
A primeira variável de maior importância foi "Gênero", sendo que a partir da raiz a árvore se ramificou em dois grupos principais: (1) Masculino e (2) Feminino. $O$ gênero (1) Masculino foi o grupo mais relevante para a próxima divisão da árvore, que considerou a variável "Classe" como a segunda variável mais importante. A partir desta variável, dois grupos principais foram gerados: $\mathrm{C} 2$ e as demais classes (A2, B1, B2, C1, Sem resposta e Não tem renda).

Para a próxima divisão da árvore, a variável "Possui CNH" foi considerada a terceira mais relevante com relação ao grupo pertencente à classe C2 e subdividiuse no grupo que não possuía CNH ((2) Não) e no grupo que possuía CNH e aqueles que não informaram sobre a posse da mesma ((1) Sim; N/C). Para as demais classes, a variável "Estuda Regularmente" também foi considerada a terceira mais relevante e subdividiu-se somente em dois grupos:

- $\leq 3,0$ : usuários que não estudam e aqueles que estudam na Educação Infantil - Creche/Pré-Escola;

- > 3,0: usuários que estudam regularmente a partir do Ensino Fundamental $1^{\mathrm{a}}$ a $4^{\underline{a}}$ Série ou $1^{\circ}$ ao $4^{\circ}$ ano.

Em seguida foi realizada nova divisão da árvore, a partir dos grupos obtidos com as variáveis no terceiro nível da mineração. Considerando o grupo que possuía CNH (1) referente a terceira variável, o minerador obteve a variável "Estuda Regularmente" como a quarta variável mais importante para este estágio, sendo que esta se dividiu em dois grupos:

- $\leq 1,0$ : não estuda regularmente;

- $>1,0$ : demais categorias.

O grupo que não estuda regularmente $(\leq 1,0)$ foi considerando o mais relevante.

Ainda no terceiro nível da mineração, para o outro grupo que considerou os usuários que estudam regularmente a partir do Ensino Fundamental $(>3,0)$, a "Idade" foi considerada a quarta variável mais importante, sendo dividida em dois grupos: 
- $\leq 25,50$ : idade igual e inferior a 25 anos e meio;

- >25,50: idade superior a 25 anos e meio.

O grupo com idade igual ou inferior a 25 anos e meio $(\leq 25,50)$ foi considerado o mais relevante.

Por fim, para a obtenção da quinta variável foram observados os grupos considerados mais importantes com relação à quarta variável. Tanto para o grupo que não estuda regularmente $(\leq 1,0)$ como para o grupo com idade igual ou inferior a 25 anos e meio $(\leq 25,50)$, a variável "Idade" foi novamente considerada a variável mais importante para a divisão da árvore. Entretanto a idade considerada para a divisão dos grupos apresentou valores diferentes.

Relacionada ao grupo que não estuda regularmente $(\leq 1,0)$, a idade considerada foi:

- $\leq 39,50$ : idade igual e inferior a 39 anos e meio;

- $>39,50$ : idade superior a 39 anos e meio.

Com relação ao grupo com idade igual e inferior a 25 anos e meio $(\leq 25,50)$, a idade considerada foi:

- $\leq 24,50$ : idade igual e inferior a 24 anos e meio;

- $>24,50$ : idade superior a 24 anos e meio.

Tal como dito anteriormente, a mineração atingiu 5 níveis e apresentou as variáveis mais significativas com relação às características dos usuários reais de bicicleta. Dentre todas as variáveis consideradas como independentes na mineração, "Grau de instrução" e "Distância" não foram consideradas determinantes para identificar um usuário que não utiliza bicicleta e que venha a utilizá-la.

Através dos resultados obtidos verifica-se que a condição de estudar regularmente é mais importante do que o grau de instrução que o indivíduo possui. Além disso, a variável "Estuda Regularmente" foi importante para definição de dois níveis de subdivisão da árvore. Em um primeiro momento considerou os usuários que estudavam regularmente a partir da $5^{\underline{a}}$ série (no caso do grupo de usuários que 
pertenciam às demais classes econômicas que não a C2) e, em um segundo momento, aqueles usuários que não estudavam regularmente.

Considerando a terceira variável importante na construção da árvore, para os usuários que foram classificados como pertencentes à classe econômica $\mathrm{C} 2$, a posse de $\mathrm{CNH}$ foi mais importante do que a condição de estudar regularmente. Por outro lado, para os usuários classificados nas classes econômicas com maior valor de renda média familiar (classes A2, B1, B2 e C1) e aqueles que não responderam ou alegaram não possuir renda, a variável "Estuda Regularmente" foi considerada mais importante do que "Possui $\mathrm{CNH"} \mathrm{nas} \mathrm{subdivisões} \mathrm{seguintes} \mathrm{da} \mathrm{árvore.} \mathrm{Além}$ disso, a "Idade" também foi um fator importante para este grupo, aparecendo como a quarta variável mais importante.

Os resultados obtidos de forma tabular foram organizados e são apresentados na Figura 4.5. As duas primeiras colunas, "Per_ID" e "Viagem Morador", como já dito anteriormente, correspondem à identificação dos indivíduos e à identificação da viagem realizada, respectivamente. Além disto, através destes dois campos foi possível identificar, no banco de dados georreferenciados da Pesquisa $O / D$, a posição geográfica dos usuários potenciais, informação primordial para a etapa de comparação entre as redes. 


\begin{tabular}{|c|c|c|c|c|}
\hline $\begin{array}{l}\text { Col. } \\
01\end{array}$ & $\begin{array}{l}\text { Col. } \\
02\end{array}$ & $\begin{array}{l}\text { Col. } \\
03\end{array}$ & $\begin{array}{l}\text { Col. } \\
04\end{array}$ & $\begin{array}{l}\text { Col. } \\
05\end{array}$ \\
\hline Per_ID & $\begin{array}{l}\text { Viagem } \\
\text { Morador }\end{array}$ & $\begin{array}{c}\text { Predicted } \\
\text { Probability_1 }\end{array}$ & $\begin{array}{c}\text { Predicted } \\
\text { Probability_2 }\end{array}$ & Usuário \\
\hline 1 & 11 & 0,973280771 & 0,026719229 & potencia \\
\hline 1 & 12 & 0,973280771 & 0,026719229 & potencia \\
\hline 4 & 41 & 0,995015740 & 0,004984260 & real \\
\hline 4 & 42 & 0,995015740 & 0,004984260 & real \\
\hline 5 & 51 & 0,995015740 & 0,004984260 & real \\
\hline 5 & 52 & 0,995015740 & 0,004984260 & real \\
\hline 6 & 61 & 0,995015740 & 0,004984260 & real \\
\hline 6 & 62 & 0,995015740 & 0,004984260 & real \\
\hline 6 & 63 & 0,995015740 & 0,004984260 & real \\
\hline 6 & 64 & 0,995015740 & 0,004984260 & real \\
\hline 6 & 65 & 0,995015740 & 0,004984260 & real \\
\hline 7 & 71 & 0,995015740 & 0,004984260 & real \\
\hline 7 & 72 & 0,995015740 & 0,004984260 & real \\
\hline 9 & 91 & 0,995015740 & 0,004984260 & real \\
\hline 9 & 92 & 0,995015740 & 0,004984260 & real \\
\hline 9 & 93 & 0,995015740 & 0,004984260 & real \\
\hline 9 & 94 & 0,995015740 & 0,004984260 & real \\
\hline 10 & 101 & 0,995015740 & 0,004984260 & real \\
\hline 10 & 102 & 0,995015740 & 0,004984260 & real \\
\hline 10 & 103 & 0,995015740 & 0,004984260 & real \\
\hline 10 & 104 & 0,995015740 & 0,004984260 & real \\
\hline 12 & 121 & 0,972222222 & 0,027777778 & potencial \\
\hline 12 & 122 & 0,972222222 & 0,027777778 & potencia \\
\hline 12 & 123 & 0,972222222 & 0,027777778 & potencial \\
\hline 13 & 131 & 0,973280771 & 0,026719229 & potencia \\
\hline 13 & 132 & 0,973280771 & 0,026719229 & potencial \\
\hline 15 & 151 & 0,973280771 & 0,026719229 & potencia \\
\hline 15 & 152 & 0,973280771 & 0,026719229 & potencia \\
\hline 15 & 153 & 0,973280771 & 0,026719229 & potencia \\
\hline
\end{tabular}

Figura 4.5: Resultado na forma tabular do SPSS Statistics - adaptado

As colunas 03 e 04 retornam as probabilidades calculadas para os modos considerados (1-bicicleta e 0 -outros modos). A coluna 03 apresenta a probabilidade para uso do modo 1 (bicicleta) (em inglês, Predicted Probability_1) e a coluna 04, para o uso do modo 0 (outros modos) (em inglês, Predicted Probability_2). Como se necessita encontrar a probabilidade do uso da bicicleta por aqueles usuários que utilizam os outros modos, a coluna 04 (Predicted Probability_2) foi a que retornou os valores procurados. A coluna 05 retorna se 0 
indivíduo já utiliza bicicleta em seus deslocamentos, ou seja, se é um usuário real ou se apresenta probabilidade de uso superior a $15 \%$, ou seja, se um usuário potencial.

Considerando tanto a amostra de treinamento como a de teste, os valores de probabilidade do uso da bicicleta pelos usuários potenciais variaram desde $0 \%$ até $29 \%$, conforme apresentado na Figura 4.6.

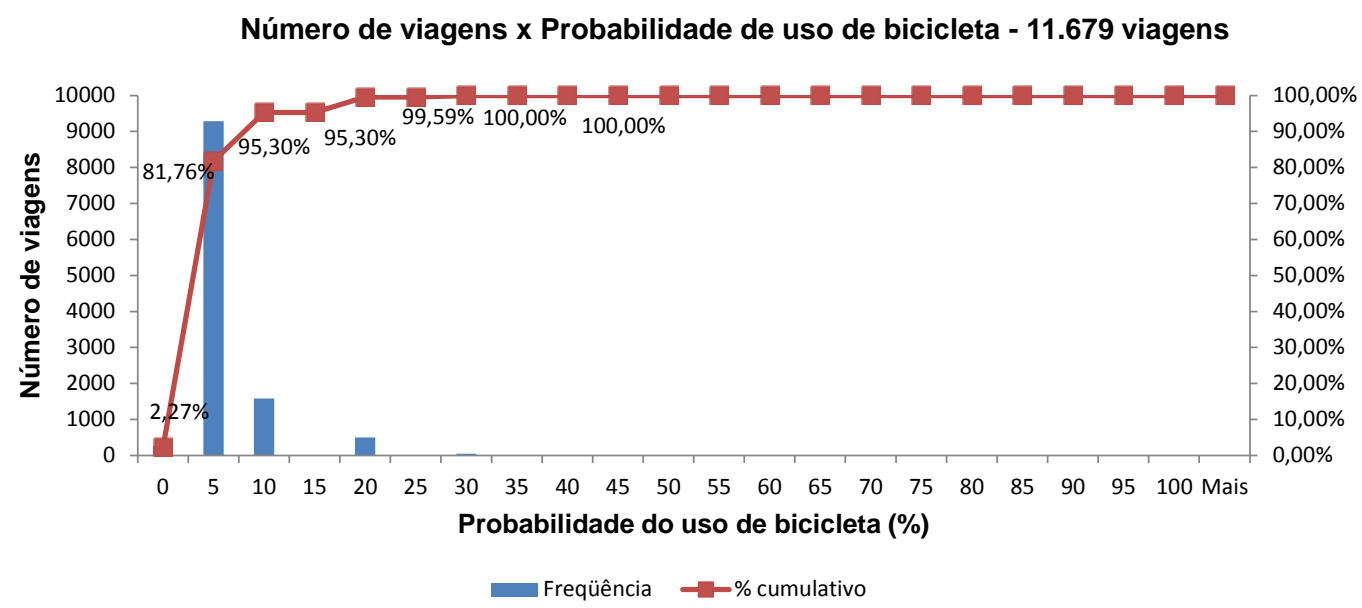

Figura 4.6: Probabilidade do uso de bicicleta - Usuários potenciais

De forma a obter uma quantidade representativa dos usuários potenciais (modo 0 ), visto que $95 \%$ do total das viagens consideradas resultaram em até $10 \%$ de probabilidade de uso da bicicleta nos deslocamentos, foram admitidos como usuários potenciais os que apresentaram probabilidade do uso da bicicleta com o valor igual ou superior a 15\% (campo Predicted Probability_2 > 15\%). Realizando este refinamento, obteve-se uma amostra igual a 456 viagens, da qual se excluíram as viagens com retorno para casa, obtendo uma amostra final de 258 viagens (das mais de onze mil viagens consideradas).

A maioria das viagens (64\%) apresentou extensão até $5,0 \mathrm{~km}$ e foram realizadas, preponderantemente, pelo modo a pé. Foi constatada apenas uma viagem acima de 10,01 km, sendo esta realizada utilizando ônibus fretado. A média da extensão das viagens realizadas foi igual a $3,93 \mathrm{~km}$, a mínima, 0,12 km e a máxima, 10,05 km. Tais informações são apresentadas na Tabela 4.3. 
Tabela 4.3: Extensão das viagens realizadas de acordo com o modo - Usuários potenciais

\begin{tabular}{|c|c|c|c|c|c|c|c|}
\hline $\begin{array}{c}\text { Distância } \\
(\mathbf{k m})\end{array}$ & Ônibus & $\begin{array}{l}\text { Ônibus } \\
\text { fretado }\end{array}$ & $\begin{array}{l}\text { Automóvel } \\
\text { (dirigindo) }\end{array}$ & $\begin{array}{c}\text { Automóvel } \\
\text { (passageiro) }\end{array}$ & $\begin{array}{c}\text { Lotação/ } \\
\text { perua }\end{array}$ & Moto & A pé \\
\hline $0-5,00$ & $\begin{array}{c}41 \\
(16 \%)\end{array}$ & $\begin{array}{c}10 \\
(4 \%)\end{array}$ & $\begin{array}{c}6 \\
(2 \%)\end{array}$ & $\begin{array}{c}19 \\
(7 \%)\end{array}$ & $\begin{array}{c}2 \\
(1 \%)\end{array}$ & $\begin{array}{c}5 \\
(2 \%)\end{array}$ & $\begin{array}{c}81 \\
(31 \%)\end{array}$ \\
\hline $5,01-10,00$ & $\begin{array}{c}33 \\
(13 \%)\end{array}$ & $\begin{array}{c}13 \\
(5 \%)\end{array}$ & $\begin{array}{c}7 \\
(3 \%)\end{array}$ & $\begin{array}{c}9 \\
(3 \%)\end{array}$ & $\begin{array}{c}1 \\
(0,4 \%)\end{array}$ & $\begin{array}{c}3 \\
(1 \%)\end{array}$ & $\begin{array}{c}11 \\
(4 \%)\end{array}$ \\
\hline $10,01-15,00$ & 0 & $\begin{array}{c}1 \\
(0,4 \%)\end{array}$ & 0 & 0 & 0 & 0 & 0 \\
\hline $\begin{array}{l}\text { Não } \\
\text { informado }\end{array}$ & $\begin{array}{c}5 \\
(2 \%)\end{array}$ & $\begin{array}{c}1 \\
(0,4 \%)\end{array}$ & 0 & $\begin{array}{c}1 \\
(0,4 \%)\end{array}$ & 0 & $\begin{array}{c}1 \\
(0,4 \%)\end{array}$ & $\begin{array}{c}8 \\
(3 \%)\end{array}$ \\
\hline \multicolumn{8}{|c|}{ Distância de viagem (km) } \\
\hline Mínima & 0,12 & & & & & & \\
\hline Média & 3,93 & & & & & & \\
\hline Máxima & 10,05 & & & & & & \\
\hline
\end{tabular}

A localização geográfica das origens e destinos dos usuários potenciais identificados na base de dados georreferenciada da pesquisa O/D é apresentada na Figura 4.7. 


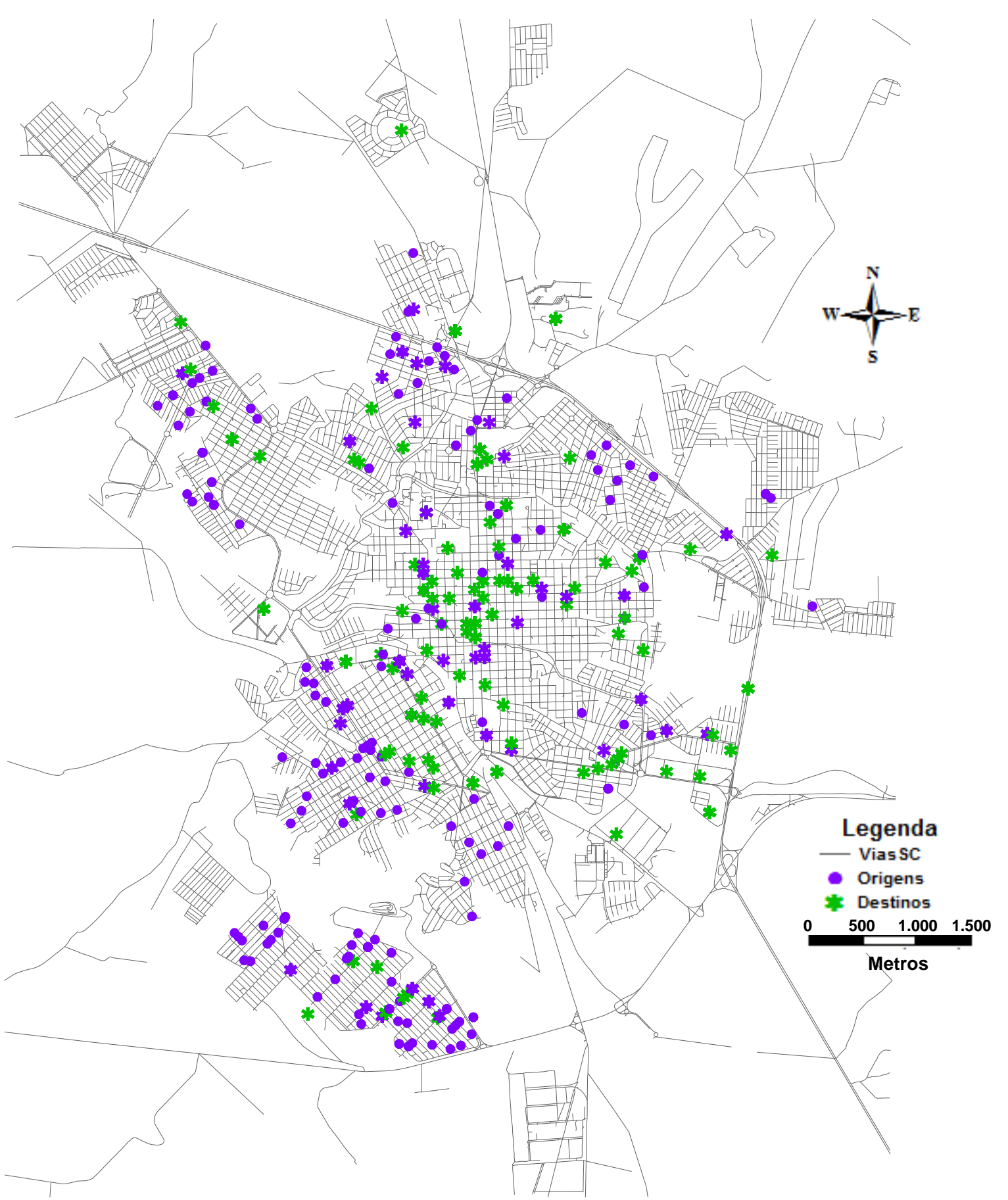

Figura 4.7: Localização geográfica (origens e destinos) - Usuários potenciais 


\subsection{Planejamento de redes cicloviárias}

Para a execução do traçado de novas redes cicloviárias, primeiramente foi necessário obter a base de dados desagregada e georreferenciada referente à pesquisa O/D realizada na cidade de São Carlos, contemplando 11.679 viagens (de um total de 19.784 viagens). Em seguida, foi necessário obter a malha viária urbana georreferenciada contendo o nome dos logradouros, sentido das vias, bem como todos os pontos de interseção. Em determinadas regiões da cidade foi necessário complementar a malha urbana através do georreferenciamento das respectivas imagens de satélite. Isto ocorreu porque em tais regiões, sejam elas mais recentes ou que apresentaram algumas modificações no sistema viário, a malha viária urbana disponível e utilizada neste trabalho não estava totalmente atualizada. Esta defasagem das informações poderia prejudicar o entendimento dos deslocamentos realizados pelos usuários reais e potenciais do modo bicicleta, prejudicando, portanto, os resultados obtidos.

Através da utilização de recursos de SIG voltados à área de transportes (SIG-T) foi possível identificar os pares origem-destino exclusivamente das viagens realizadas por bicicleta, uma vez que era o objetivo desta etapa. Além disso, também foi possível excluir as viagens com retorno para casa e identificar os motivos das viagens realizadas, resultando em186 deslocamentos.

Com relação aos motivos das viagens, o motivo "Trabalho" foi o predominante (105 viagens) e apresentou três subdivisões: "Trabalho: Indústria", "Trabalho: Comércio" e "Trabalho: Serviços", respectivamente, trabalho realizado nas indústrias, no comércio e em serviços. O motivo "Escola" foi o segundo em número de viagens (63), seguido dos motivos "Recreação", "Outros", "Saúde" e "Compras", tal como apresentado na 4.8. 


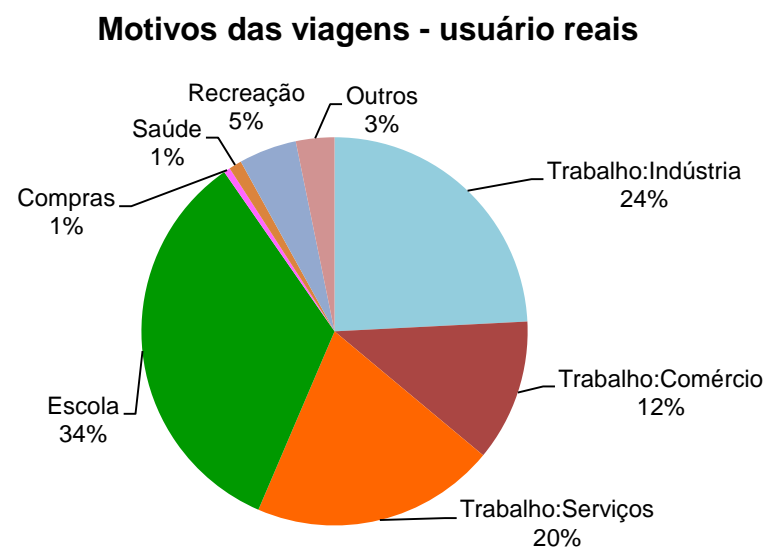

Figura 4.8: Distribuição dos motivos das viagens - Usuários reais

Para cada viagem de cada motivo foram traçadas quatro possíveis rotas entre cada origem e o respectivo destino, utilizando rotinas de caminho mínimo (utilizou-se o Sistema de Informações Geográficas TransCAD, mas outros programas podem ser utilizados), tal como apresentado no exemplo da Figura 4.9. É razoável presumir inclusive que uma destas rotas deve se aproximar do traçado real percorrido pelo respondente para o respectivo par origem-destino. 


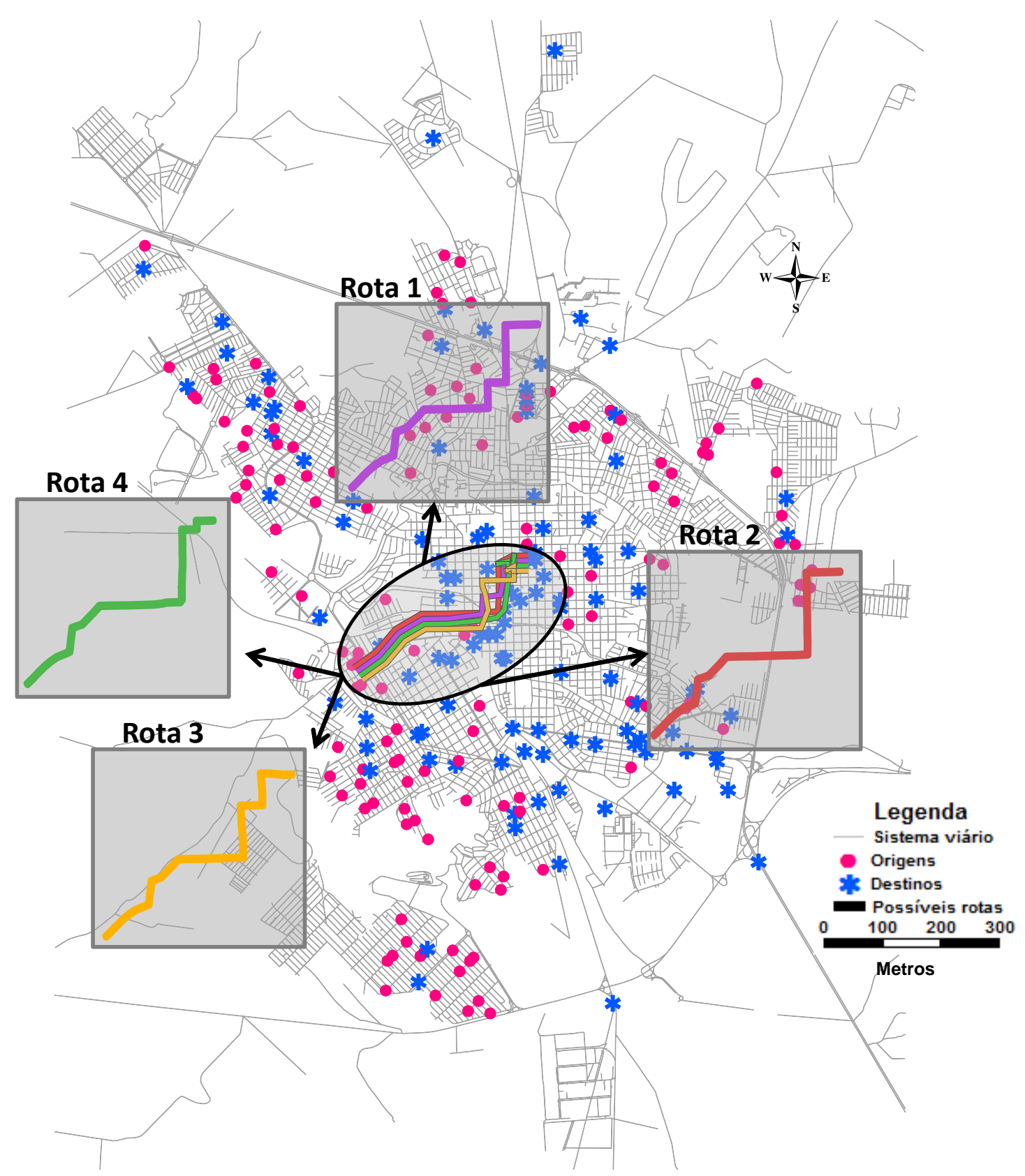

Figura 4.9: Georreferenciamento de origens e destinos das viagens por bicicleta e um exemplo de quatro rotas possíveis a partir de um ponto de origem

Após o traçado das quatro possíveis rotas entre os respectivos pares origem e destino, foi contabilizado o número de possíveis rotas sobrepostas em cada tramo viário, considerando todas as viagens de todos os motivos considerados.

Por exemplo, em um determinado tramo foi verificada a passagem de pelo menos uma possível rota considerando uma viagem gerada entre um par O/D de um 
determinado motivo. Ao realizar o traçado das quatro possíveis rotas para outro par origem-destino de outro motivo diferente, verificou-se no mesmo tramo a passagem de três rotas. Ou seja, somente considerando estas duas viagens geradas, cada uma por um motivo diferente, o mesmo tramo viário contabilizou o total de 4 rotas sobrepostas. O mesmo procedimento foi realizado considerando todas as demais viagens entre dois pares O/D de todos os motivos considerados. Na Figura 4.10 é apresentado um exemplo da contabilização do número de possíveis rotas sobrepostas em cada tramo viário.

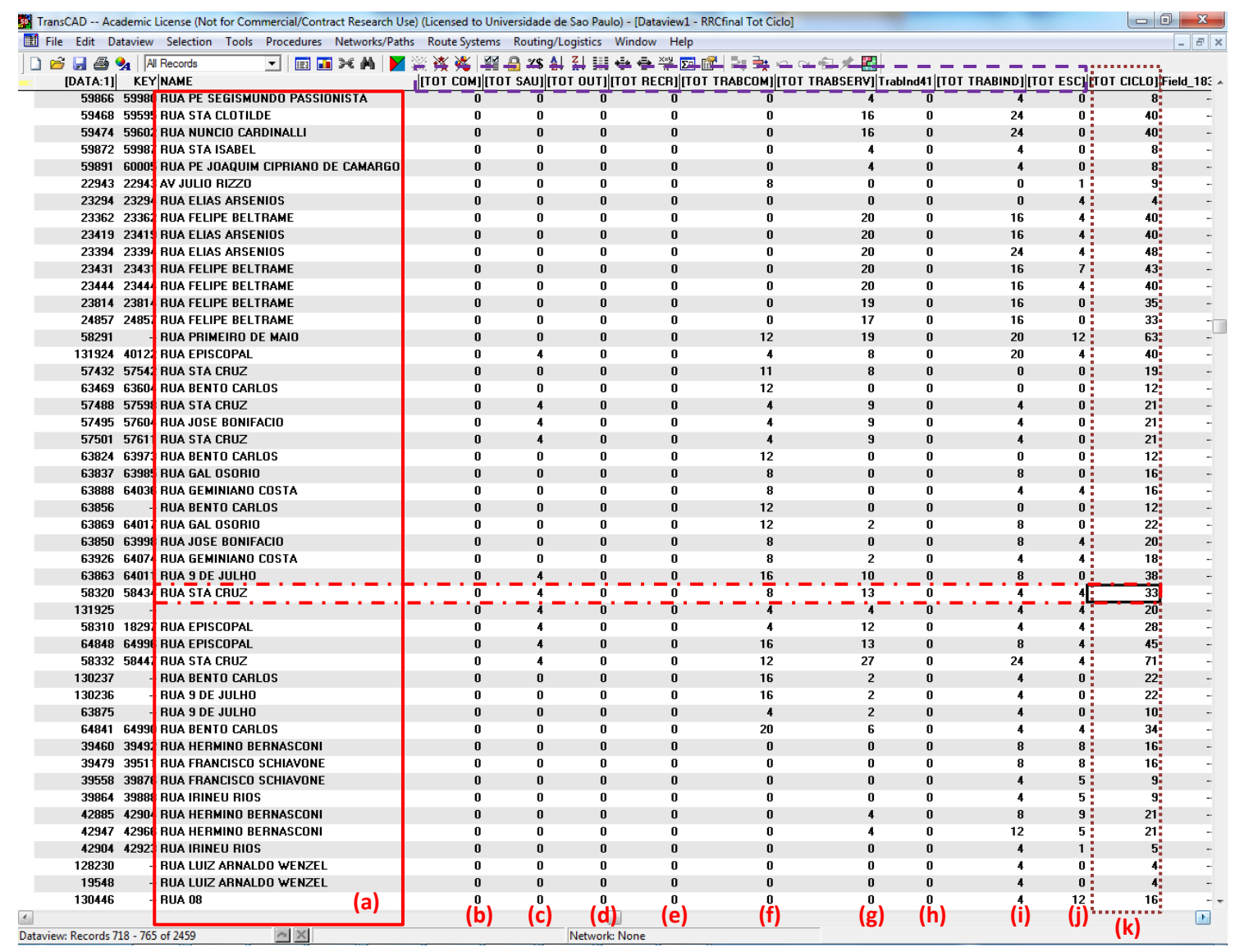

Figura 4.10: Contabilização do número de possíveis rotas sobrepostas em cada tramo viário

Na coluna (a) tem-se cada tramo que dá origem a cada uma das vias da cidade de São Carlos. Das colunas (b) à (j), o total de possíveis rotas sobrepostas em cada tramo, de acordo com o motivo. Por exemplo: o total de rotas em cada tramo devido ao motivo "Compras" está contido na coluna "[TOT COM] (coluna b), devido ao motivo "Saúde" [TOT SAU] (coluna c) e assim por diante. 
A coluna $(\mathrm{k})$ apresenta o total de rotas sobrepostas considerando a soma de todos os motivos. Por exemplo, para o tramo da Rua Sta. Cruz (em destaque na Figura 4.8) é verificado um total de 33 rotas sobrepostas, sendo 4 provenientes do motivo "Saúde", 8 de "Trabalho: Comércio", 13 de "Trabalho: Serviços", 4 de "Trabalho: Indústria" e 4 de "Escola".

De acordo com os resultados obtidos, foram vários os valores obtidos no campo [TOT CICLO], variando entre 3 e 71 rotas sobrepostas. Para evitar que tramos que apresentaram o registro de poucas rotas fossem selecionados, uma vez que não correspondiam às vias que poderiam ser mais utilizadas pelos usuários de bicicleta, fez-se necessário admitir determinados limites de rotas sobrepostas.

Para fins deste estudo foram considerados três valores limites. No primeiro caso, são considerados todos os tramos do sistema viário com mais de 5 rotas sobrepostas, no segundo, com mais de 10 rotas sobrepostas, e no terceiro caso, com mais de 15 rotas sobrepostas, aqui denominadas Rede $5_{+}$, Rede 10+ $_{+}$e Rede ${ }_{15_{+}}$, respectivamente, tal como apresentado na Figura 4.11. Estes traçados também consideraram os volumes e os sentidos dos fluxos de tráfego de automóveis e a topografia das vias. No caso de haver duas ou mais vias com o mesmo número de possíveis rotas sobrepostas (ou valores muito próximos) superior a um dos valores pré-estabelecidos, escolheu-se a que apresentava menor volume de tráfego motorizado e menor elevação do terreno. Além disso, sempre que possível, evitouse definir as redes em sentido contrário ao do fluxo motorizado já estabelecido nas vias existentes.

Especificamente com relação à topografia, em muitas situações a análise do terreno para a definição do traçado da rede cicloviária foi realizada com o auxílio de recursos computacionais, como o programa Google Earth, tal como sugerido por Guerreiro e Rodrigues da Silva (2013) e Guerreiro et al. (2013). Principalmente no caso de haver duas vias com valores de possíveis rotas sobrepostas iguais (ou muito próximos), localizadas a pequena distância entre si (por exemplo, 200 metros), que apresentavam o mesmo sentido das vias e volume de tráfego muito semelhante, foi necessário escolher apenas uma para o traçado da rede cicloviária. Elencar duas vias próximas entre si, com características semelhantes, poderia não agregar 
benefícios ao atendimento dos usuários, além de eventualmente gerar elevado acréscimo do custo de construção, caso viessem a ser executadas.

Um exemplo de aplicação do uso do Google Earth pode ser feito considerando as vias São Joaquim e Rui Barbosa, nos trechos compreendidos entre a Rua Treze de Maio e a Avenida Dr. Carlos Botelho. Tais vias apresentaram várias características semelhantes (por exemplo, sentido das vias e volume de tráfego), inclusive quanto ao traçado de possíveis rotas sobrepostas. Conforme apresentado na Figura 4.11, considerando o tramo viário de cada via localizado entre duas vias pré-determinadas, foi constatado um número igual a 11 rotas sobrepostas para a Rua São Joaquim e 14 para a Rua Rui Barbosa, ou seja, valores próximos.
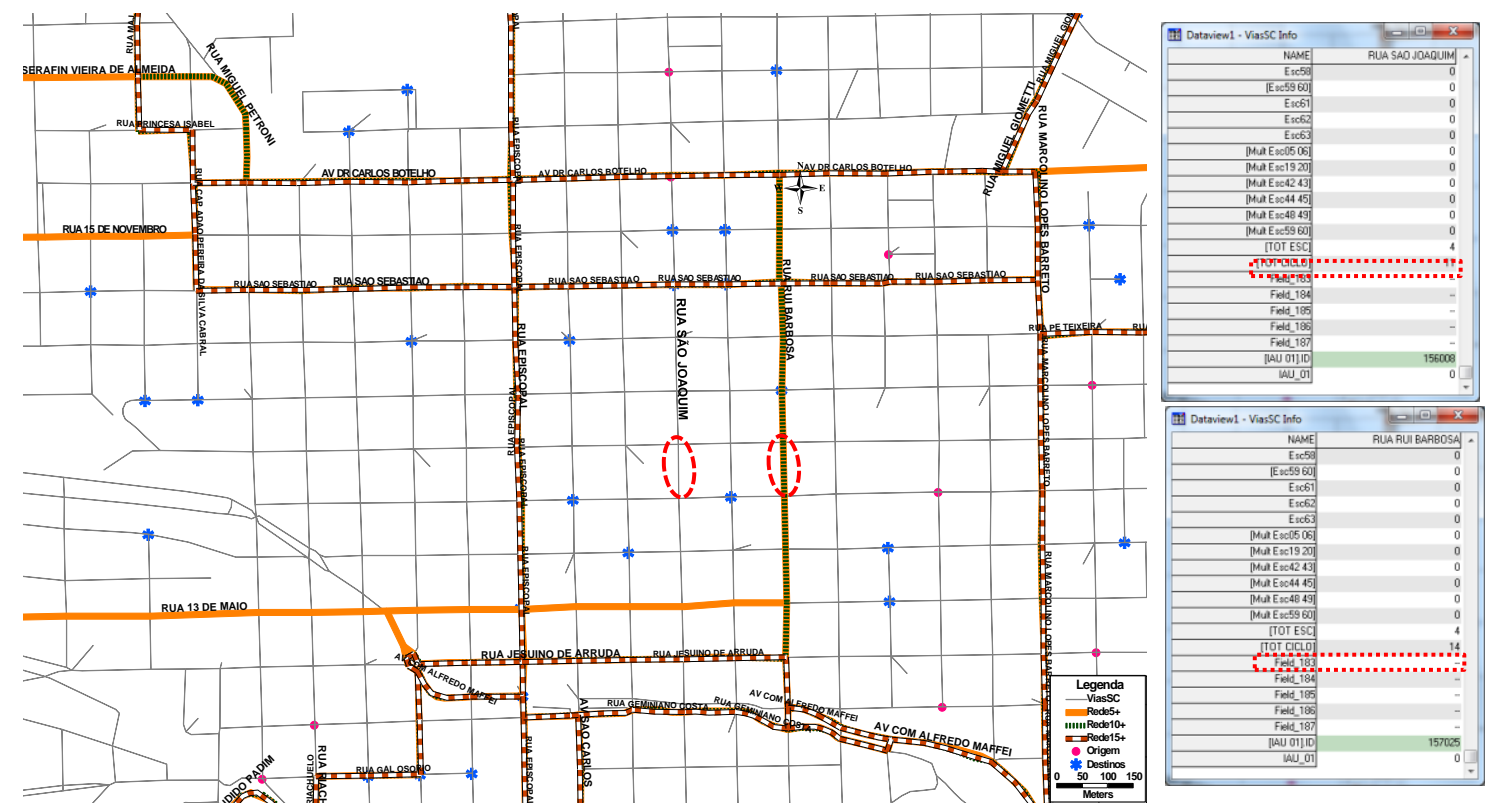

Figura 4.11: Identificação do número de rotas sobrepostas nos tramos viários

Sendo assim, foi necessário avaliar a topografia do trecho em questão, como apresentado na Figura 4.12. Considerando um mesmo ponto no quarteirão considerado, a Rua São Joaquim apresentou valor de aclive igual a 9,9\% e a Rua Rui Barbosa, 8,3\%. Mesmo estes valores sendo superiores a 5,0\% de inclinação, uma vez que eram inerentes às características do trecho em estudo, optou-se pelo menor valor, uma vez que causava menores desconfortos aos usuários de bicicleta. 


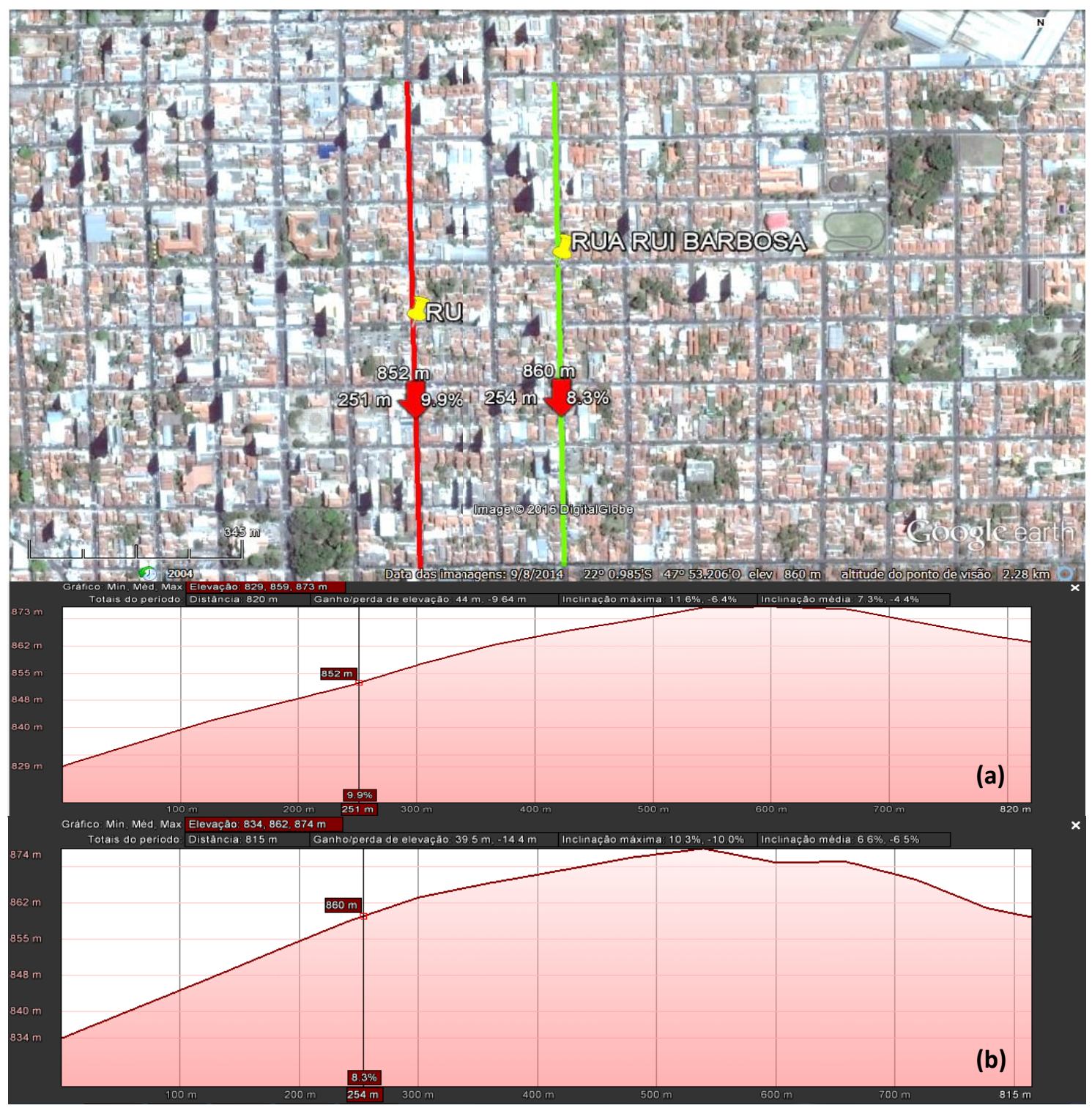

Figura 4.12: Exemplo de avaliação do perfil topográfico - ponto específico no tramo viário

(a) Rua São Joaquim (b) Rua Rui Barbosa

Ainda para o exemplo das ruas São Joaquim e Rui Barbosa, considerando a extensão total de tais vias entre a Rua Treze de Maio e a Avenida Dr. Carlos Botelho, pode-se verificar algumas outras diferenças quanto aos valores de inclinação. A Rua São Joaquim apresentou inclinação máxima igual a 11,6\% e média igual a 7,3\%, enquanto que a Rua Rui Barbosa retornou valores iguais a 10,3\% (inclinação máxima) e 6,6\% (inclinação média). Na Figura 4.13 é apresentado o perfil topográfico da Rua São Joaquim (perfil a) e da Rua Rui Barbosa (perfil b). 


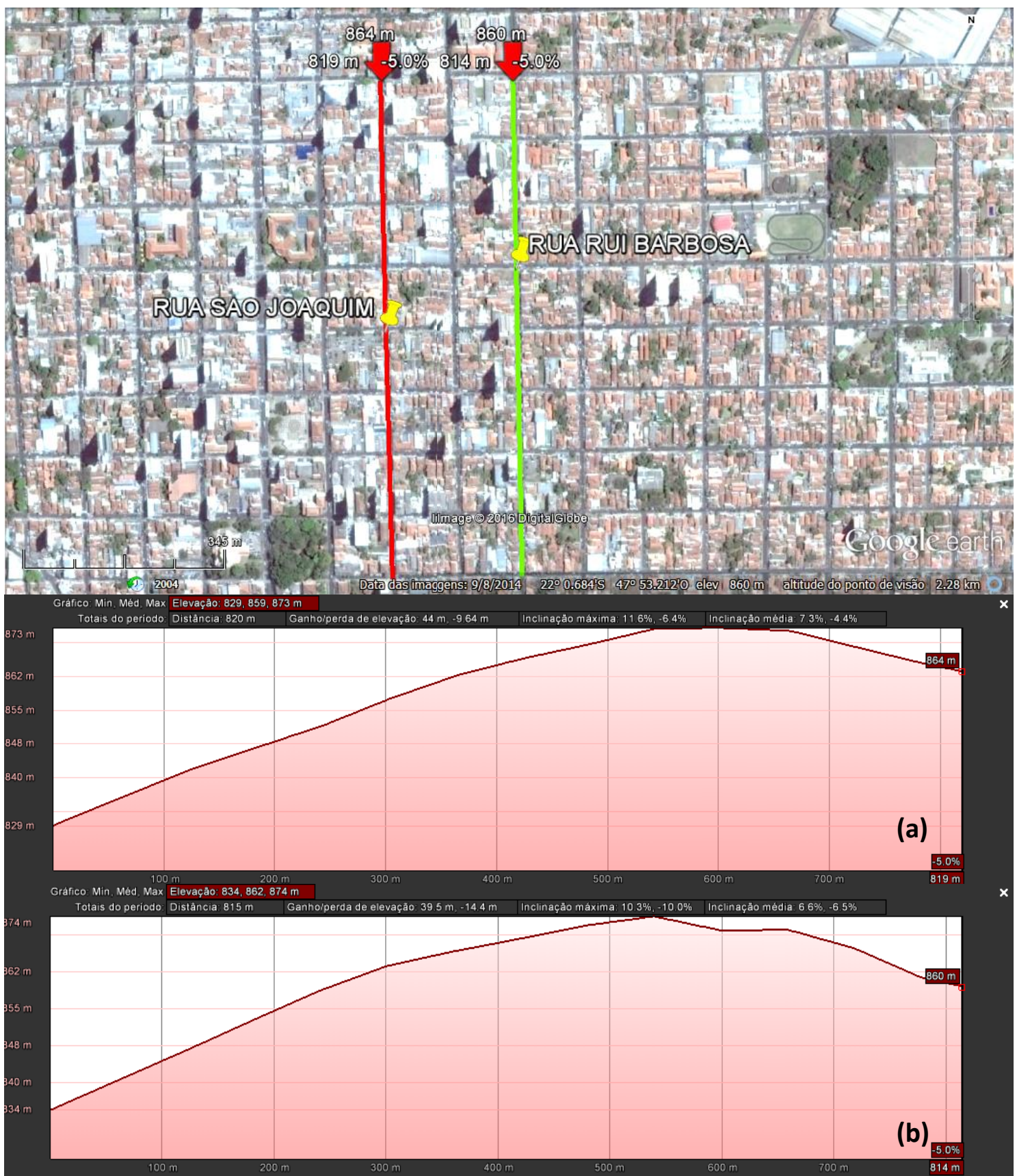

Figura 4.13: Exemplo de avaliação do perfil topográfico - extensão do trecho (a) Rua São Joaquim (b) Rua Rui Barbosa

É importante ressaltar que nem todas as vias elencadas para o traçado das redes apresentaram inclinação superior a 5,0\%. Entretanto, para aquelas que apresentaram e cujas outras características foram semelhantes entre si, optou-se pela via com menor valor de inclinação, tanto máxima como média, como apresentado na Figura 4.13. 
Após as escolhas das vias com menores valores de elevação foi possível propor redes cicloviárias, considerando os três limites admitidos. As redes propostas são apresentadas na Figura 4.14.

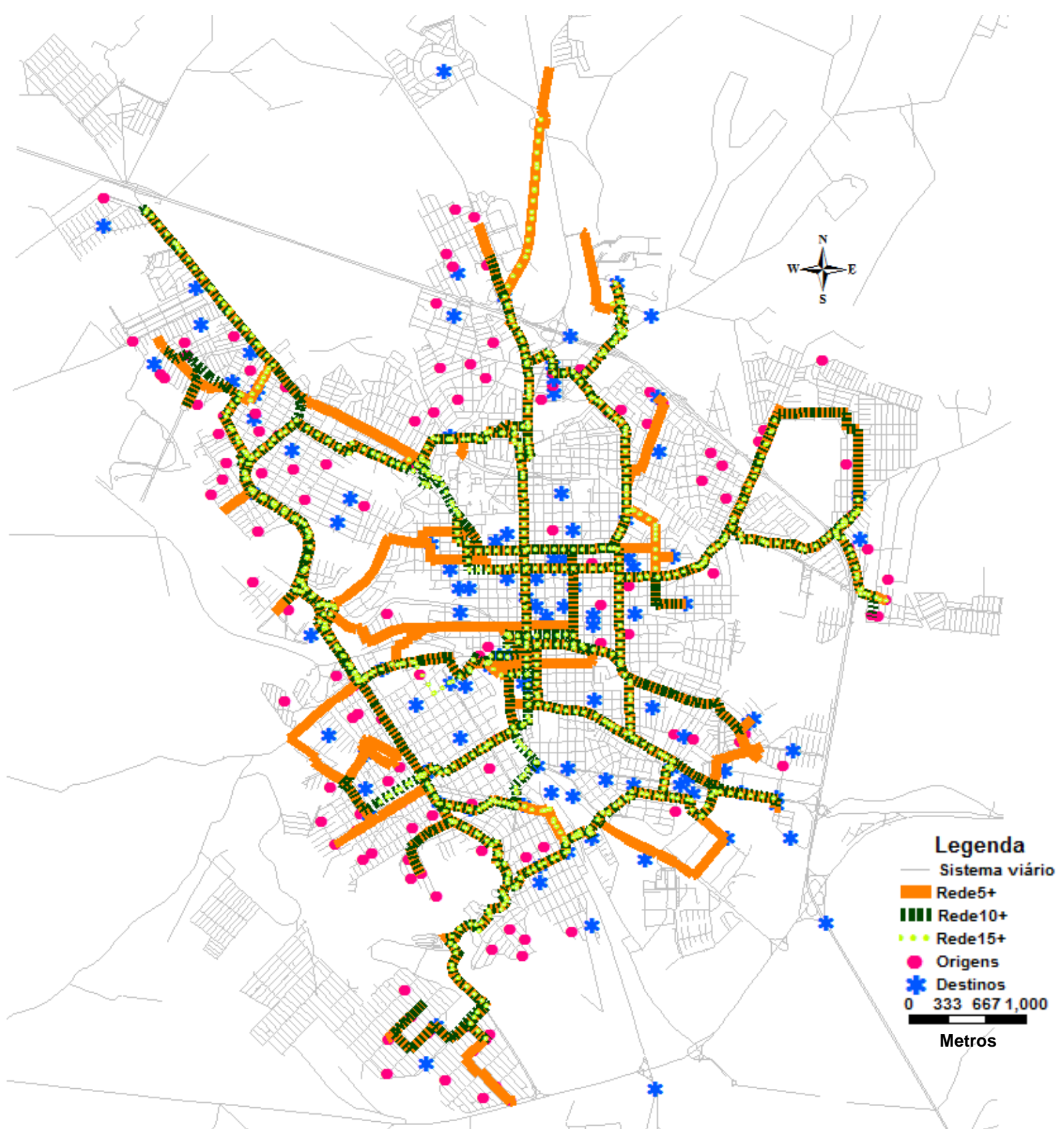

Figura 4.14: Rede de rotas cicloviárias propostas 


\subsection{Comparação entre as redes cicloviárias}

A comparação entre as redes cicloviárias considerou não somente as redes traçadas demonstradas no item anterior (redes propostas), mas também as redes já existentes na cidade de São Carlos (RCE e RCP) e os usuários reais e potenciais, obtidos anteriormente.

Primeiramente com relação às estratégias de avaliação (Avaliação I e Avaliação II), foram contabilizadas 186 viagens para os usuários reais e 258 para os usuários potenciais. A diferença entre estes valores reside no fato de que muitos usuários potenciais realizaram viagens encadeadas, ou seja, o mesmo ponto de destino de uma viagem tornou-se o ponto de origem para a viagem seguinte. Ressalta-se que esta característica da viagem não foi verificada naquelas realizadas pelos usuários reais. Talvez isto possa ser explicado pela possibilidade dos usuários potenciais residirem próximos ao seu local de trabalho/estudo, possibilitando que gastem menos tempo para se locomover, podendo, portanto realizar outras atividades. Outra possibilidade é que os usuários potenciais, por utilizarem outros modos de transporte, tenham maior flexibilidade de locomoção, inclusive conseguindo realizar viagens mais longas ou várias viagens em um curto período de tempo.

Com relação à população urbana total, de acordo com dados do Censo 2010 (IBGE, 2015), foi igual a 212.465 e a extensão total do sistema viário da cidade igual a 1.088,66 km (dados obtidos diretamente na malha viária urbana georreferenciada).

Através da ferramenta "Overlay" do software TransCAD, aplicada à banda de largura igual a 400 metros ao redor de cada uma das redes estudadas, foi possível contabilizar todas as variáveis apresentados nas duas avaliações realizadas. Um exemplo da construção de banda ao redor de uma das redes é apresentado na Figura 4.15, onde se vê também os pontos de origem e destino das viagens. A banda pode também ser mostrada quando sobreposta aos setores censitários, para fins de cálculo da população atendida, como na Figura 4.16. 


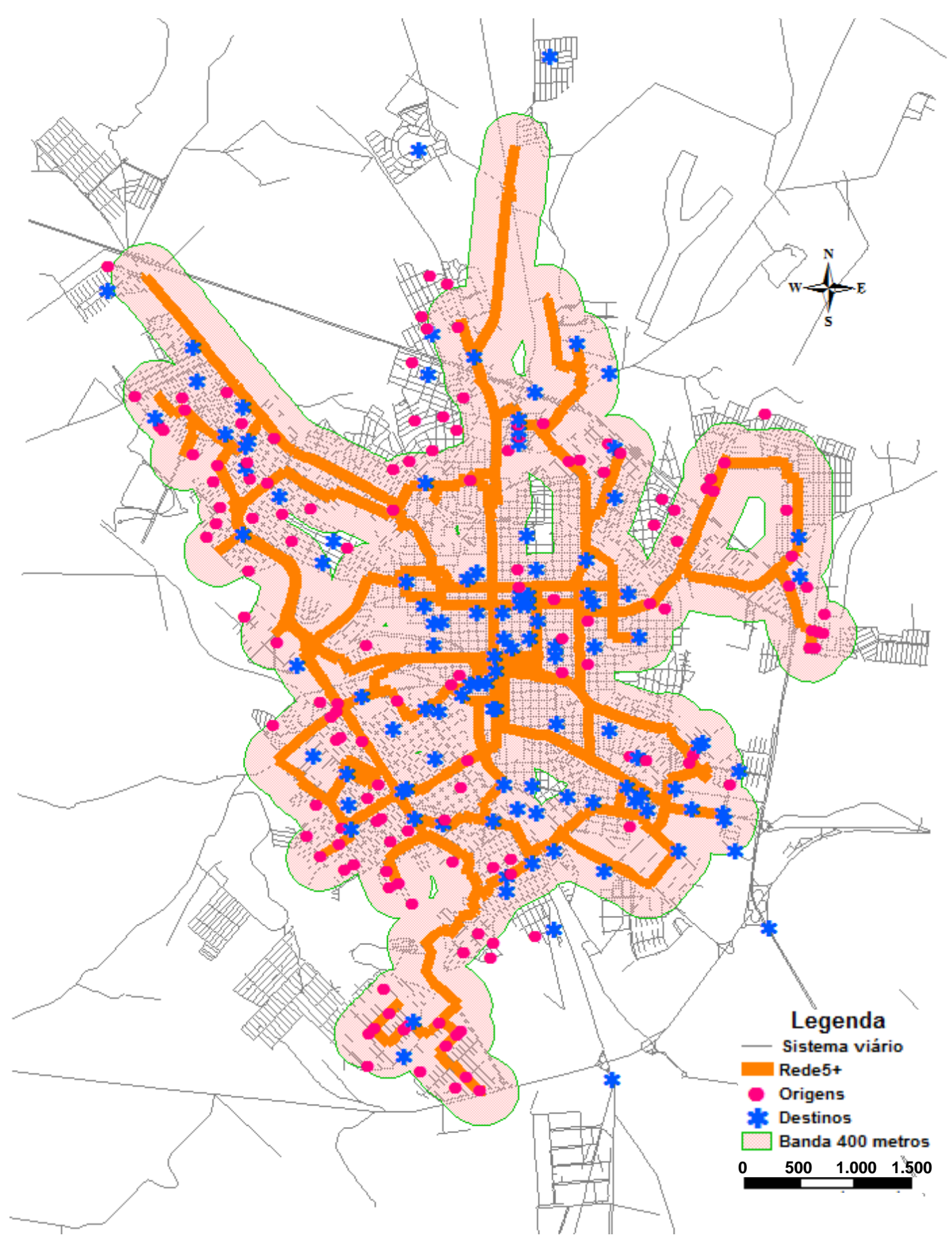

Figura 4.15: Exemplo de construção de banda ao redor de uma rede traçada 


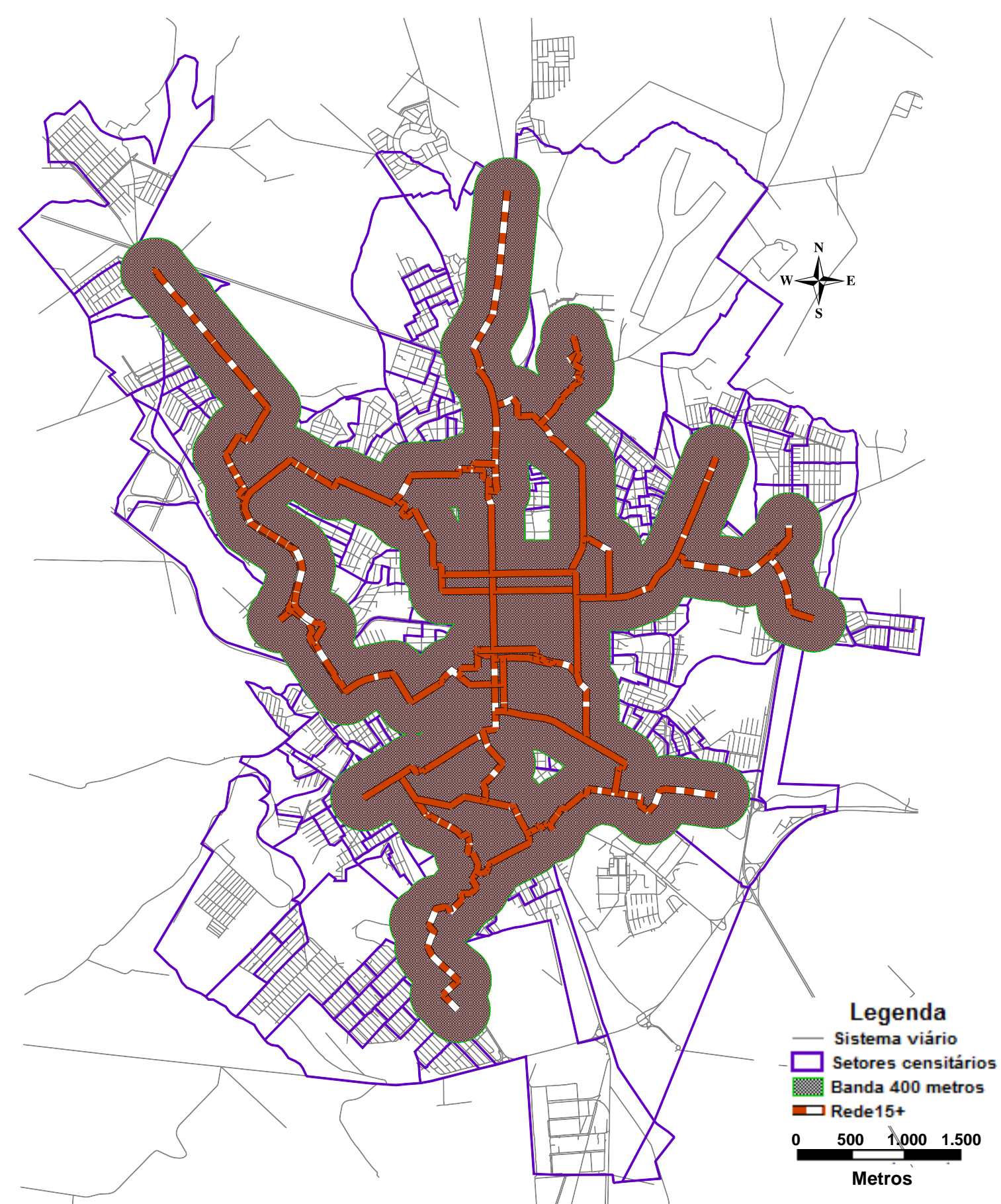

Figura 4.16: Exemplo de construção de banda ao redor de uma das redes traçada, considerando os setores censitários

Os resultados provenientes das estratégias de avaliação são apresentados na Tabela 4.4. 


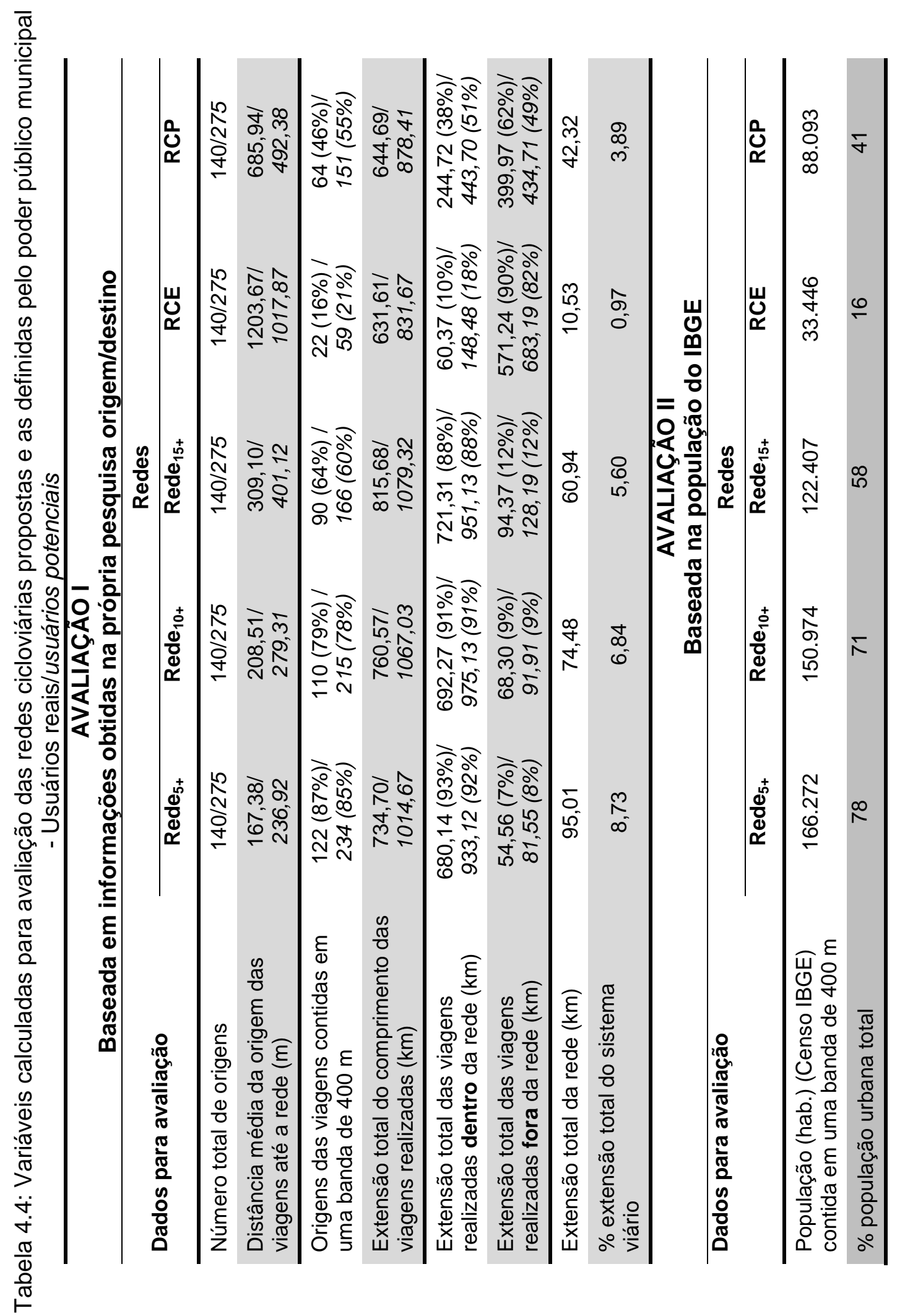


Considerando a Avaliação I (dados desagregados), a rede existente (RCE) foi, em comparação com as redes aqui propostas, a mais distante da origem das viagens dos usuários: para a Rede ${ }_{5+}, 7,0$ vezes mais distante no caso dos usuários reais e 4,5 vezes no caso dos usuários potenciais. Em relação à rede projetada (RCP), esta razão ficou em torno de 2,0 para os dois tipos de usuários. Ressalta-se que quanto mais distante a rede cicloviária estiver da origem das viagens dos usuários, sejam eles reais ou potenciais, maior o tempo de exposição destes às condições de insegurança nas vias até acessarem as redes, podendo elevar o risco de sofrerem acidentes de trânsito. Além disso, a RCE também apresentou o menor valor percentual da extensão das viagens realizadas dentro da rede. Os percentuais de cobertura da RCP para uma banda de 400 metros se mostraram próximos aos obtidos para a $\operatorname{Rede}_{15}$, sobretudo no caso dos usuários potenciais (55\% contra $60 \%$ ), mesmo a rede projetada possuindo uma extensão $31 \%$ menor do que esta rede proposta.

Comparando as redes propostas entre $\mathrm{si}$, embora a Rede ${ }_{15_{+}}$tenha apresentado uma extensão total aproximadamente $20 \%$ menor do que a Rede ${ }_{10+}$, retornou valores de extensão total das viagens realizadas dentro da rede muito próximos, tanto para os usuários reais como para os potenciais ( $88 \%$ no caso da Rede $_{15_{+}}$e $91 \%$ no caso da Rede ${ }_{10+}$ ). Além disso, o maior percentual de cobertura das origens das viagens foi realizado pela $R e{ }_{5_{+}}$, visto sua maior extensão e atendimento às diversas regiões da cidade.

De uma forma geral, os usuários potenciais apresentaram maiores valores de extensão total do comprimento das viagens realizadas (dentro e fora da rede), devido à grande quantidade de viagens encadeadas realizadas pelos mesmos.

Utilizando os dados agregados da população em setores censitários (Avaliação II), tanto no caso dos usuários reais como no dos usuários potenciais, foi possível verificar que a Rede $_{5+}$ retornou a maior porcentagem de atendimento da população $(78 \%)$ em comparação às demais redes, visto sua maior extensão e abrangência. Por outro lado, a RCE retornou o menor percentual de população atendida (16\%), seguida da RCP $(41 \%)$. Entretanto, com esta estratégia de avaliação não é possível obter dados mais específicos acerca da quantidade de 
viagens por motivo que também poderiam ser contempladas, bem como a proximidade ou não dos usuários às redes.

Em seguida foi realizada uma comparação entre as redes, através de uma análise multicritério e considerando os critérios de custos e benefícios apresentados na metodologia e comuns às redes estudadas. Especificamente com relação aos benefícios B4 (percentual de escolas públicas e privadas atendidas pelas redes), B5 (percentual de estabelecimentos comerciais atendidos pelas redes) e B6 (percentual de indústrias atendidas pelas redes), foi necessário obter os dados referentes, georreferenciados dentro da malha viária urbana de São Carlos, tal como apresentado na Figura 4.17. 


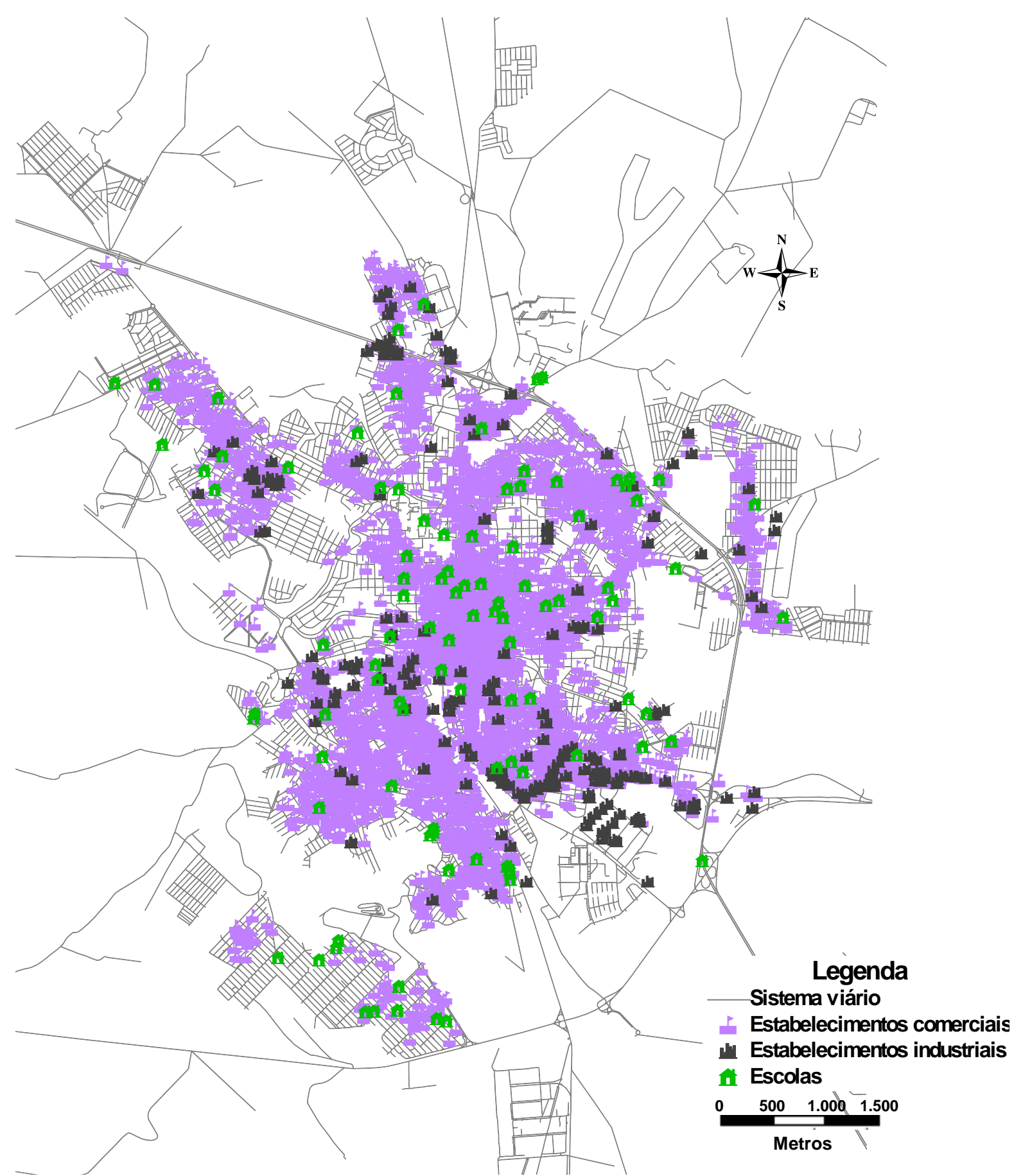

Figura 4.17: Georreferenciamento dos estabelecimentos comerciais e industriais e escolas

Tal como verificado no estudo desenvolvido por Milakis e Athanasopoulos (2014), o estudo aqui apresentado também considera densidade de cruzamentos (dada pelo custo C2), legibilidade (custo C3) e centralidade como alguns dos critérios de avaliação das redes cicloviárias. Especificamente com relação à 
centralidade, Milakis e Athanasopoulos (2014) consideraram polos geradores de viagens contidos dentro de uma banda de 500 metros ao redor das redes estudadas. No estudo aqui desenvolvido optou-se por considerar uma banda igual a 400 metros ao redor das redes, uma vez que corresponde à distância máxima aceitável de acesso até a rota proposta (tal como sugerido por Ferraz e Torres (2004) para o caso dos sistemas de transporte público). Com relação aos demais critérios optou-se por utilizá-los sem alterações, pois poderiam ser um indicativo da eficácia da rede, possibilitando o atendimento de um maior número de usuários.

A comparação considerando os critérios de custos e benefícios e os usuários reais e potenciais é apresentada na Tabela 4.5.

Tabela 4.5: Comparação direta de critérios de custos e benefícios - Usuários reais/usuários potenciais

\begin{tabular}{|c|c|c|c|c|c|c|}
\hline \multirow[b]{2}{*}{$\begin{array}{l}\text { Redes/ } \\
\text { Variáveis }\end{array}$} & \multicolumn{6}{|c|}{ CUSTOS } \\
\hline & $\begin{array}{c}\text { C1 } \\
\text { (Extensão) }\end{array}$ & $\begin{array}{c}\text { C2 } \\
\text { (Interseções) }\end{array}$ & $\begin{array}{c}\text { C3 } \\
\text { (Conversões) }\end{array}$ & $\begin{array}{c}\text { C4 } \\
\text { (Dist. } \\
\text { Escolas) } \\
\end{array}$ & $\begin{array}{c}\text { C5 } \\
\text { (Dist. } \\
\text { Origens) } \\
\end{array}$ & $\begin{array}{c}\text { C6 } \\
\text { (Viagens } \\
\text { fora) }\end{array}$ \\
\hline RCE & 10,53 & 7,69 & 1,14 & 1001,52 & $\begin{array}{c}1203,67 / \\
1017,87\end{array}$ & $\begin{array}{l}90,44 \% / \\
82,15 \%\end{array}$ \\
\hline RCP & 42,32 & 13,52 & 1,56 & 575,12 & $\begin{array}{r}685,94 / \\
492,38\end{array}$ & $\begin{array}{c}62,04 \% / \\
49,49 \%\end{array}$ \\
\hline Rede $_{15+}$ & 60,94 & 18,97 & 6,86 & 310,19 & $\begin{array}{r}309,10 / \\
401,12\end{array}$ & $\begin{array}{r}11,57 \% / \\
11,88 \%\end{array}$ \\
\hline Rede $_{10+}$ & 74,48 & 15,90 & 3,88 & 225,98 & $\begin{array}{c}208,51 / \\
279,31\end{array}$ & $\begin{array}{c}8,98 \% / \\
8,61 \%\end{array}$ \\
\hline Rede $_{5+}$ & 95,01 & 15,65 & 3,48 & 185,84 & $\begin{array}{l}167,38 / \\
236,92 \\
\end{array}$ & $\begin{array}{l}7,43 \% / \\
8,04 \%\end{array}$ \\
\hline \multirow[b]{2}{*}{$\begin{array}{l}\text { Redes/ } \\
\text { Variáveis }\end{array}$} & \multicolumn{6}{|c|}{ BENEFÍCIOS } \\
\hline & $\begin{array}{c}\text { B1 } \\
\text { (Origens) }\end{array}$ & $\begin{array}{c}\text { B2 } \\
\text { (Viagens } \\
\text { dentro) } \\
\end{array}$ & $\begin{array}{c}\text { B3 } \\
\text { (População) }\end{array}$ & $\begin{array}{c}\text { B4 } \\
\text { (Escolas) }\end{array}$ & $\begin{array}{c}\text { B5 } \\
\text { (Comércio) }\end{array}$ & $\begin{array}{c}\text { B6 } \\
\text { (Indústrias) }\end{array}$ \\
\hline RCE & $\begin{array}{l}15,71 \% / \\
21,45 \%\end{array}$ & $\begin{array}{l}9,56 \% / \\
17,85 \%\end{array}$ & $15,74 \%$ & $16,16 \%$ & $17,83 \%$ & $21,40 \%$ \\
\hline $\mathrm{RCP}$ & $\begin{array}{c}45,71 \% / \\
54,91 \%\end{array}$ & $\begin{array}{c}37,96 \% / \\
50,51 \%\end{array}$ & $41,46 \%$ & $42,42 \%$ & $48,92 \%$ & $39,74 \%$ \\
\hline Rede $_{15+}$ & $\begin{array}{c}64,29 \% / \\
60,36 \%\end{array}$ & $\begin{array}{c}88,43 \% / \\
88,12 \%\end{array}$ & $57,61 \%$ & $68,69 \%$ & $88,18 \%$ & $79,04 \%$ \\
\hline Rede $_{10+}$ & $\begin{array}{l}78,57 \% / \\
78,18 \%\end{array}$ & $\begin{array}{l}91,02 \% / \\
91,39 \%\end{array}$ & $71,06 \%$ & $78,79 \%$ & $91,93 \%$ & $84,28 \%$ \\
\hline Rede $_{5+}$ & $\begin{array}{l}87,14 \% / \\
85,09 \%\end{array}$ & $\begin{array}{l}92,57 \% / \\
91,96 \%\end{array}$ & $78,26 \%$ & $83,84 \%$ & $94,03 \%$ & $88,65 \%$ \\
\hline
\end{tabular}

Obs.: Dist. = distância 
Os únicos critérios que diferiram na comparação de usuários reais e potenciais foram os custos $\mathrm{C} 5$ e $\mathrm{C} 6$ e os benefícios B1 e B2. Com relação aos custos, os usuários reais apresentaram maiores valores de C5 para as redes RCE e RCP, e de C6 também para a Rede ${ }_{10+}$. Concomitantemente, os usuários reais apresentaram maiores valores de B1 e B2 para quase todas as redes propostas, enquanto que os usuários potenciais apresentaram percentuais maiores para as redes RCE e RCP.

Assim, para os dados desagregados, tanto para os usuários reais $\mathrm{e}$ potenciais, a Rede $5_{+}$retornou menores valores dos custos C3, C4, C5 e C6, enquanto que a RCE retornou os maiores valores dos três últimos custos. Ainda para esta rede, todos os benefícios apresentados foram inferiores aos apresentados pelas demais redes, notadamente a Rede $_{5_{+}}$, ou seja, a rede com maior extensão e cobertura.

Com relação aos dados referentes à população como um todo (dados agregados), embora a RCP, projetada pelo poder público municipal, tenha apresentado extensão cerca de $31 \%$ menor do que a Rede ${ }_{15}$, atendeu apenas $16 \%$ menos pessoas do que a mesma rede. Já a RCE foi a que possibilitou menor cobertura de atendimento em comparação a todas as demais redes.

Posteriormente foi realizada uma análise de sensibilidade considerando os limites mínimos e máximos de cada critério considerado, como apresentado na Tabela 4.6.

Tabela 4.6: Limites considerados para normalização dos resultados - análise de sensibilidade

\begin{tabular}{ccccccc}
\hline Limites & C1 & C2 & C3 & C4 & C5 & C6 \\
\hline Mínimo & 10 & 5 & 0 & 100 & 100 & $0 \%$ \\
Máximo & 300 & 50 & 20 & 1500 & 1500 & $100 \%$ \\
\hline & $\mathrm{B} 1$ & $\mathrm{~B} 2$ & $\mathrm{~B} 3$ & $\mathrm{~B} 4$ & $\mathrm{~B} 5$ & $\mathrm{~B} 6$ \\
\hline Mínimo & $0 \%$ & $0 \%$ & $0 \%$ & $0 \%$ & 0 & 0 \\
Máximo & $95 \%$ & $95 \%$ & $95 \%$ & $95 \%$ & $95 \%$ & $95 \%$ \\
\hline
\end{tabular}


Para o custo C1 foi admitido o limite mínimo igual a $10 \mathrm{~km}$, ou seja, próximo ao mínimo que a cidade apresenta, enquanto o máximo foi igual a $300 \mathrm{~km}$, que poderia ser considerada uma excelente condição de infraestrutura cicloviária para a cidade de São Carlos.

Foi admitido um mínimo de 5 interseções a cada $1 \mathrm{~km}$, ou seja, 1 interseção a cada 200 metros, e o máximo de 50 interseções a cada 1 km, ou seja, 1 interseção a cada 20 metros (custo C2). O limite mínimo pode ser considerado apropriado aos deslocamentos realizados por bicicleta, uma vez que possibilita a manutenção de uma velocidade constante por um período de tempo maior em comparação ao limite máximo, portanto contribuindo para a rapidez dos deslocamentos. Além disso, um menor número de interseções resulta em menor custo associado à implantação de dispositivos de controle, tais como, o uso de placas "Pare" ou centrais semafóricas contendo programação voltada à travessia de ciclistas.

Com relação ao custo $\mathrm{C} 3$, quanto mais direta for a rede, ou seja, quanto menor o número de conversões ao longo de toda a sua extensão, melhor. Por outro lado, se houver um número maior de conversões ao longo de toda a rota, menor a velocidade desenvolvida, maior a dificuldade de assimilação da rede pelo usuário e menor o uso da rede.

Quanto mais próximas as escolas e as origens das viagens de bicicleta estiverem da rede (respectivamente, custos C4 e C5), menor o tempo de exposição dos indivíduos às condições de insegurança que possam aparecer ao longo do caminho. Sendo assim, caso seja admitida uma velocidade constante do usuário de bicicleta igual a $15 \mathrm{~km} / \mathrm{h}$, se as escolas e os pontos de origem estiverem localizados a 100 metros da rede (limite inferior), os indivíduos ficarão expostos ao tráfego em geral por aproximadamente 24 segundos. No caso de estarem localizados a 1500 metros da rede (limite superior), durante aproximadamente 360 segundos (ou seja, seis minutos a mais).

Considerando o custo C6, o ideal é que nenhuma viagem ocorra fora da rede (limite mínimo) e a pior situação é aquela na qual todas as viagens (100\% do total de 
viagens) ocorram fora da rede (limite superior).Ou seja, na pior situação a rede estudada não atende aos caminhos percorridos pelas viagens consideradas.

Com relação a todos os benefícios, ao admitir um limite mínimo igual a $0 \%$ sugere-se que a rede estudada não atende satisfatoriamente a todas as viagens, origens, à população residente nos setores censitários e às escolas, estabelecimentos comerciais e indústrias. À medida que maiores percentuais são admitidos, por exemplo, 95\% (limite máximo), melhor se torna o atendimento fornecido pela rede.

A normalização foi efetuada considerando o intervalo 0 e 1. Para os custos, quanto menor o valor obtido, melhor a alternativa, e, portanto, foi atribuído o valor 1. Para o maior valor em análise, o valor 0 foi atribuído. Por outro lado, para os benefícios, quanto maiores os percentuais e valores obtidos, melhor a alternativa, ou seja, foi atribuído o valor 1 e, para o menor percentual, o valor 0 .

Considerando o custo $\mathrm{C}$, por exemplo, os limites admitidos na normalização foram 10 (mínimo) e 300 (máximo), ou seja, ao normalizar foi atribuído o valor 1 ao limite mínimo e valor 0 ao limite máximo. Os valores de $C 1$ para as redes consideradas situaram-se entre os limites mínimo e máximo, uma vez que variaram entre 10,53 km e 95,01 km (respectivamente redes RCE e Rede $5_{+}$). Ou seja, foi necessário interpolar os valores de $\mathrm{C} 1$ referentes às redes aqui estudadas, uma vez que apresentaram valores intermediários entre 0 e 1 . Desta forma foi obtido para a $R^{2} \mathrm{de}_{5+}$, por exemplo, o valor 0,71 . O mesmo procedimento foi realizado para os demais custos e todos os benefícios.

Os valores intermediários entre 0 e 1 (referentes às redes propostas e as concebidas pelo poder público municipal) foram obtidos através da interpolação entre os valores extremos. Os resultados desta interpolação e os valores obtidos são apresentados na Figura 4.18 para os usuários reais e na Figura 4.19 para os usuários potenciais. 


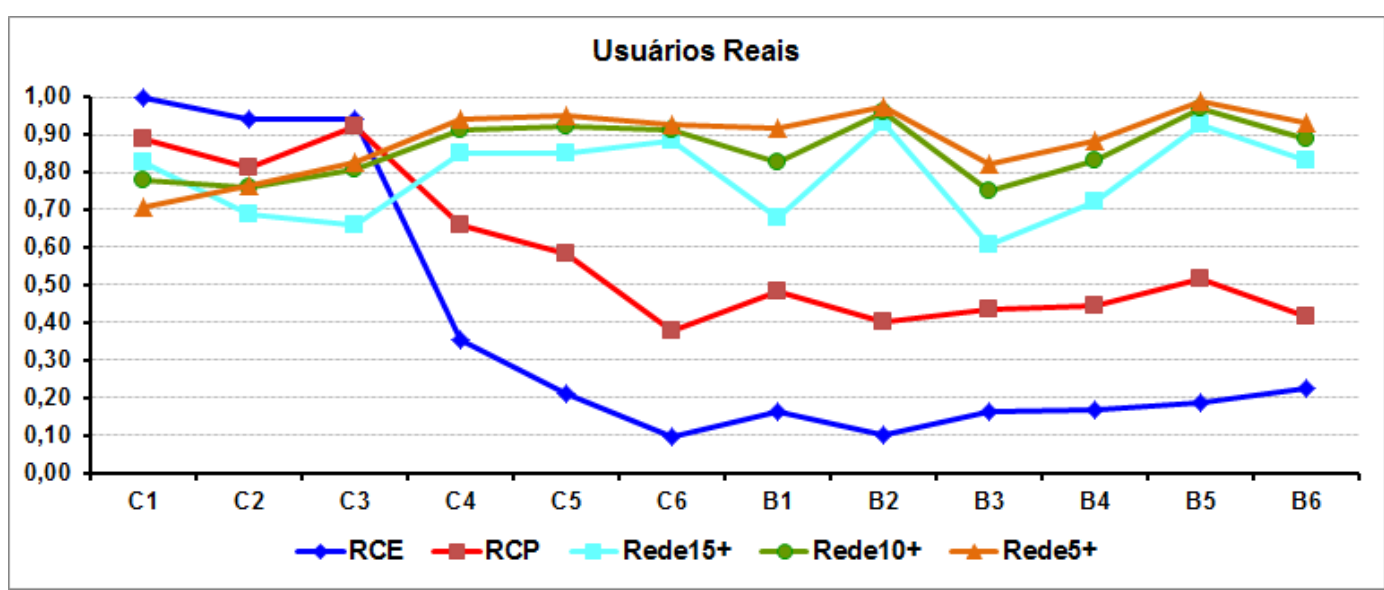

Figura 4.18: Normalização de custos e benefícios das redes estudadas - Usuários reais

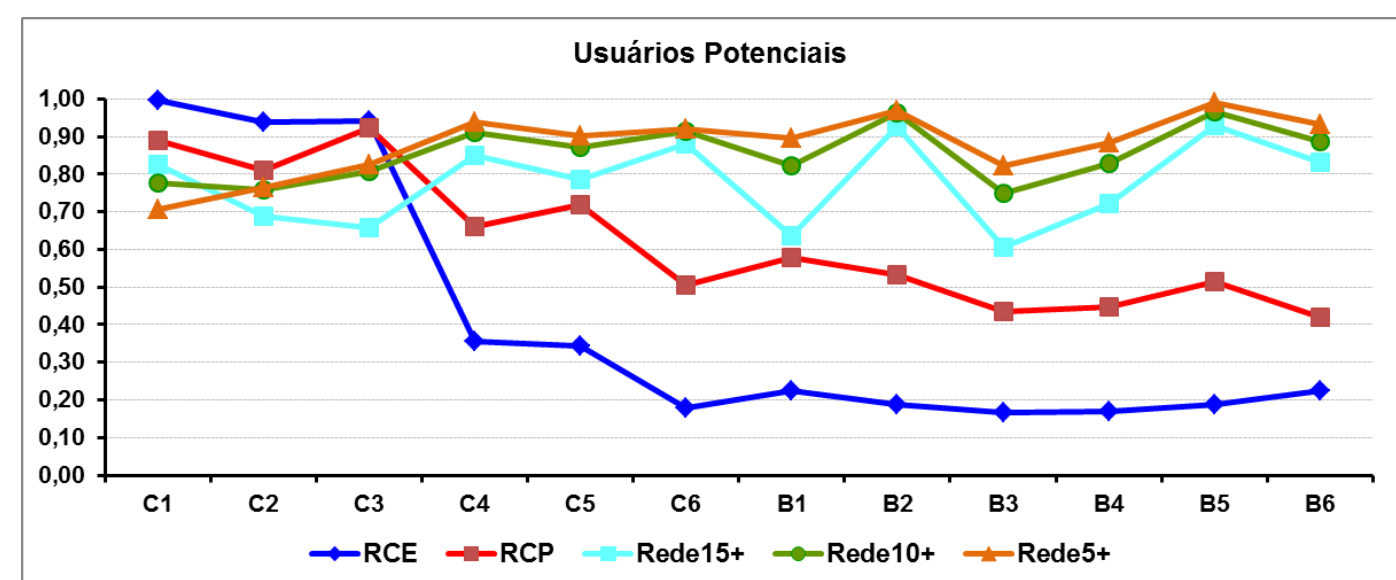

Figura 4.19: Normalização de custos e benefícios das redes estudadas - Usuários potenciais

Analisando o custo $\mathrm{C} 1$ é possível verificar, tanto para os usuários reais como para os potenciais, a estreita relação existente entre os valores normalizados para as redes RCP, Rede $_{5+}$, Rede $_{10+}$ e Rede $_{15_{+}}$. Por outro lado, é possível verificar a melhor condição da RCE, uma vez que apresenta o menor valor do custo $\mathrm{C} 1$.

Em nenhum momento os valores normalizados obtidos para todos os benefícios referentes à RCE mostraram-se superiores aos valores obtidos para qualquer uma das redes aqui estudadas e sim apenas os custos C1, C2 e C3, independente do atendimento ser direcionado aos usuários reais ou potenciais. Isto se deve ao fato da RCE possuir menor cobertura em comparação às demais redes (no caso dos benefícios), como também menor custo de construção $(\mathrm{C} 1)$, menor 
tempo de percurso (C2) e maior facilidade de assimilação da rede (C3), o que pode ser considerado bom para o usuário.

Comparando os usuários potenciais com relação aos reais, a RCP apresentou maior proximidade às origens das viagens $e$, consequentemente, um maior número de origens contidas dentro de uma banda de 400 metros (custo C5 e benefício B1, respectivamente). Com relação às viagens realizadas, a maioria delas foi realizada utilizando a rede, em comparação àquelas realizadas fora da rede (benefício B2 e custo C6, respectivamente). Além disso, considerando somente os usuários potenciais, os valores obtidos do custo $\mathrm{C} 5$ e do benefício $\mathrm{B} 1$ foram muito próximos aos valores obtidos para a Rede ${ }_{15+}$.

Embora a Rede ${ }_{15+}$ tenha um comprimento menor em comparação às demais redes propostas, o número de conversões existentes na mesma é maior do que o verificado na Rede 10+ (331 conversões contra 289, para um comprimento igual a $60,94 \mathrm{~km}$ contra $74,48 \mathrm{~km})$.

Comparando somente as redes propostas entre si e considerando os usuários reais e potenciais, os valores obtidos pelos usuários potenciais apresentaram-se muito próximos aos obtidos pelos usuários reais e, em alguns casos iguais, como por exemplo, para o custo C6 referente à Rede ${ }_{10_{+}}$e à Rede ${ }_{15+}$. 


\section{CONCLUSÕES E RECOMENDAÇÕES}

Este capítulo apresenta as principais conclusões sobre o método e sua aplicação em um estudo de caso. Além disso, também são apresentadas algumas recomendações para trabalhos futuros.

\subsection{0 método}

Este estudo contemplou o desenvolvimento e a aplicação de um método objetivo para o planejamento e comparação de redes cicloviárias, considerando usuários reais e potenciais e dados de uma pesquisa origem-destino (dados desagregados).

O método proposto apresentou-se como uma alternativa aos que utilizam dados agregados (por exemplo, em setores censitários ou zonas de tráfego) e que implicitamente pressupõem uma distribuição homogênea da população no interior das áreas consideradas. Além disto, também foi apresentado um procedimento para a identificação dos potenciais usuários do modo bicicleta e um método de comparação considerando critérios de custo e benefício comuns às redes consideradas. Particularmente com relação às redes no caso estudado, também foram consideradas aquelas definidas por setores da administração pública municipal, a Rede Cicloviária Existente (RCE) e a Rede Cicloviária Proposta (RCP).

Assume-se que o método é objetivo porque foram contabilizados dados de viagens e os critérios de custo e benefício comuns às redes estudadas foram calculados de forma objetiva, numericamente. Embora também possa ser considerado subjetivo, uma vez que há certa subjetividade na escolha das variáveis consideradas importantes para a determinação dos usuários potenciais e para a comparação das redes, isto não é considerado um problema, visto que o método proposto responde às questões relacionadas ao planejamento de redes cicloviárias.

Os dados desagregados continham a exata localização geográfica (latitude e longitude) das origens e dos destinos de cada viagem realizada pelos usuários reais, 
e foram associados às técnicas de mineração de dados (para obtenção dos usuários potenciais), recursos de um Sistema de Informação Geográfica (SIG) (para o planejamento de redes cicloviárias) e análise de vários critérios de custos e benefícios (para uma efetiva comparação entre as redes estudadas).

Ressalta-se que na análise das redes cicloviárias apresentada nesta tese não foram contabilizados os custos e benefícios econômicos das redes estudadas, mas sim custos e benefícios considerando variáveis relacionadas ao uso do solo e às características da localização dos pontos de origem das viagens. Isto ocorre, sobretudo, porque nas redes cicloviárias propostas não foi definido o tipo de infraestrutura a ser implantado (ciclovia, ciclofaixa, espaços compartilhados, etc.), mas apenas o planejamento das mesmas, não sendo possível, portanto, fazer o levantamento dos respectivos custos econômicos.

Além disso, através deste estudo foi possível obter uma visão abrangente da situação atual do sistema cicloviário da cidade de São Carlos. Mesmo estando prevista na revisão do Plano Diretor (ocorrida no ano de 2012), a rede cicloviária existente ainda é muito pequena e ineficaz. Com isto, São Carlos se assemelha a muitas cidades brasileiras no quesito infraestrutura cicloviária, nas quais os ciclistas ainda carecem de redes seguras e condizentes com suas necessidades de deslocamento.

\subsection{Identificação dos usuários potenciais}

A julgar pelos resultados obtidos no estudo de caso, o método utilizado para a identificação dos usuários potenciais do modo cicloviário pode ser considerado uma alternativa válida, sobretudo quando há disponibilidade de dados desagregados de uma pesquisa origem-destino e inexistem pesquisas de preferência declarada ou revelada. Ressalta-se a importância da etapa de tratamento dos dados, através da qual são identificadas e realizadas as correções das inconsistências verificadas. Esta etapa, juntamente com a etapa de escolha das informações a serem inseridas no minerador de dados, caso não sejam realizadas corretamente ou não sejam executadas, podem levar a resultados equivocados, prejudicando a identificação dos usuários potenciais. 
A variável "distância percorrida" não foi considerada importante pelo minerador no processo de obtenção dos usuários potenciais, visto que não foi encontrada nas AD’s geradas. Através de uma investigação mais precisa de seus valores e de sua relação com as demais variáveis, pode ser possível entender o motivo deste não uso pelo minerador. Além disso, uma alteração no número de observações nos nós pai e filhos poderia levar a um melhor entendimento da influência da variável "distância percorrida" nos resultados sobre os usuários potenciais. Para os usuários que foram classificados como pertencentes à classe econômica $\mathrm{C} 2$, a posse de $\mathrm{CNH}$ foi mais importante do que a condição de estudar regularmente, sendo esta a condição mais importante para aqueles indivíduos que foram classificados nas demais classes.

Especificamente neste estudo, além da mineração de dados ter possibilitado a identificação do perfil dos usuários reais de bicicleta, o cálculo de probabilidades de uso da bicicleta referente aos usuários potenciais forneceu subsídios adicionais para identificação dos mesmos. Considerando a amostra de 11.679 viagens, muitas destas se referiram a usuários que apresentaram uma baixa probabilidade do uso de bicicleta nos deslocamentos, ao passo que outros usuários apresentaram uma maior probabilidade.

A realização de viagens encadeadas pelos usuários potenciais poderia ou não ser mantida se os mesmos passassem a utilizar a bicicleta em seus deslocamentos. Isto dependeria muito da decisão dos mesmos e dos tipos de atividades que desenvolvem. De qualquer forma, apresentaram $15 \%$ ou mais de probabilidade de utilizarem a bicicleta, conforme verificado nos resultados provenientes da Árvore de Decisão.

A partir da análise da distribuição destas probabilidades foi possível admitir um valor a partir do qual podiam ser escolhidos os usuários com maior probabilidade de uso da bicicleta em seus deslocamentos. Outros valores limites poderiam ser escolhidos, e neste caso, poderia ser obtido um maior ou menor número de usuários potenciais. Independentemente do número de usuários potenciais identificados e suas respectivas viagens, as informações desagregadas a eles associadas (localização geográfica) permitiram refinar ainda mais os resultados obtidos. 


\subsection{Planejamento de redes cicloviárias}

A formulação de propostas de redes cicloviárias utilizando um conjunto de dados provenientes de uma pesquisa origem-destino e os motivos das viagens correspondentes se mostrou eficaz do ponto de vista de planejamento de uma rede cicloviária. Mesmo não sendo dinâmico, como o método proposto por Lovelace et al. (2015), a utilização de dados precisos de localização dos usuários reais possibilitou traçar rotas mais condizentes com os seus destinos. Este atendimento ao destino dos usuários não poderia ser obtido se fosse considerada, por exemplo, apenas a localização de polos geradores de viagens, tal como realizado nos trabalhos de Yamashita et al. (1998), Kirner (2006), Hsu e Lin (2011), Neri (2012), Milakis e Athanasopoulos (2014) e Sousa e Sanches (2015).

De acordo com a bibliografia consultada, em alguns estudos o caminho mínimo traçado pelo SIG foi diferente do trajeto real realizado pelos ciclistas (Aultman-Hall et al.; 1997; Menghini et al.; 2010; Segadilha, 2014). Apesar disto, em nenhum deles a ferramenta foi considerada inadequada para o traçado de redes cicloviárias, o que evidencia que esta ferramenta pode ser útil para identificação das vias que podem ser utilizadas pelos ciclistas, principalmente quando não há maiores informações adicionais sobre o percurso. Além disso, o traçado de quatro possíveis rotas entre cada par origem-destino utilizando recursos de SIG permite pressupor que pelo menos uma destas rotas poderia se aproximar das condições reais de deslocamento, fornecendo um melhor atendimento aos usuários reais.

A adoção de um número maior de traçado de rotas entre cada par origemdestino poderia fornecer um maior número de possibilidades de percurso entre os pares, no entanto, demandaria maior tempo de análise e escolha dos tramos de vias. Notadamente com relação ao estudo de caso aqui apresentado, o traçado de quatro caminhos mínimo mostrou-se suficiente para o traçado final da rede cicloviária. Em muitas situações, mesmo utilizando quatro alternativas de caminhos mínimos já era verificada a sobreposição entre alguns deles, não sendo necessária portanto a adoção de mais um caminho mínimo. 
Além disso, desde que haja a disponibilidade de dados de pesquisa origemdestino domiciliar georreferenciados e informações referentes ao modo de transporte utilizado pelos usuários entrevistados, o método aqui proposto pode ser empregado em qualquer cidade cujo objetivo seja implantar ou expandir uma rede cicloviária. $\mathrm{O}$ método também pode ser aplicado a grandes polos geradores de viagens, como por exemplo, campi universitários ou shopping centers.

A utilização de recursos computacionais que permitem a visualização da elevação do terreno (como o software Google Earth/Google Street View) mostrou-se satisfatória quando da necessidade de escolha entre dois tramos de via com volume e sentido de tráfego semelhantes, mas com elevações diferentes.

\subsection{Comparação entre as redes cicloviárias}

$\mathrm{Na}$ comparação entre as redes considerando as estratégias de avaliação propostas, a localização exata dos usuários potenciais e seus respectivos destinos possibilitou obter os valores das mesmas variáveis obtidas para os usuários reais. Isso permitiu uma comparação direta entre os mesmos, o que não seria possível caso fossem utilizados somente dados agregados de população. Além disso, com o uso de dados desagregados foi possível mensurar e analisar a proximidade dos usuários às redes, bem como a quantidade de pessoas atendidas, enquanto que com os dados agregados somente foi possível identificar o número de pessoas atendidas, sem nenhuma informação de sua localização e do tipo de usuários atendido (real ou potencial).

Caso os valores obtidos para os critérios de custo e benefício considerando os usuários reais e potenciais fossem muito diferentes entre si, isto poderia ser um indicativo de uma grande diferença na distribuição espacial entre os mesmos, o que consequentemente levaria a um atendimento ruim das redes aos usuários reais e potenciais. Outro indicativo poderia ser quanto à escolha das variáveis utilizadas na mineração dos dados, uma vez que a escolha daquelas consideradas importantes poderia contribuir para a realização das viagens utilizando bicicleta. 
Ainda com relação aos critérios (de custo e benefício) utilizados na avaliação das redes cicloviárias propostas, buscou-se utilizar critérios relacionados não somente com as características físicas das redes (extensão, número de conversões por quilômetro, número de conversões por extensão da rede), mas também com a localização exata dos usuários reais e potenciais e de alguns polos geradores de viagens. Todos os critérios utilizados mostraram-se eficazes (como também verificado no estudo realizado por Milakis e Athanasopoulos, 2014), uma vez que possibilitaram uma comparação direta entre as redes propostas e a infraestrutura existente.

Além disso, a análise de sensibilidade associada à normalização dos valores de custo e benefício obtidos permitiu um melhor entendimento sobre a relação entre todas as redes estudadas, inclusive as redes propostas, sendo claramente possível a verificação da qualidade do atendimento da Rede Cicloviária Existente (RCE) para os usuários reais e potenciais.

Como os valores obtidos para os custos e benefícios não foram originalmente definidos para a mesma escala, a normalização tornou possível uma comparação direta entre os mesmos, possibilitando um melhor entendimento da relação entre as redes propostas e as definidas pelo poder público municipal. Nem sempre uma rede com elevada extensão, embora apresente valores elevados de benefícios, é totalmente benéfica para o usuário de bicicleta. Uma das razões para tal pode estar vinculada às características da malha viária (número de interseções) relacionada à extensão e à legibilidade da rede (facilidade de assimilação da rede pelo usuário). Este conjunto de características pode elevar o tempo de percurso para o usuário, além de necessitar de um projeto de sinalização horizontal, vertical e semafórica mais detalhado, com maiores custos de implantação e manutenção.

Se por um lado a presença de dispositivos de controle de tráfego pode promover maior segurança aos ciclistas nos movimentos de conversão ou ao cruzar as vias, por outro pode contribuir para um maior atraso ao longo do percurso. De qualquer forma, na presença de grandes volumes de tráfego motorizado, os efeitos positivos da implantação de dispositivos de controle de tráfego podem superar os efeitos negativos (Broach et al., 2012). 
De forma geral, tal como verificado na cidade de São Paulo (BBC, 2015), atualmente a cidade de São Carlos apresenta muitos trechos descontínuos da rede cicloviária, o que reflete diretamente nos resultados obtidos com a RCE. Como exemplo pode-se citar a localização das escolas, as quais se encontraram, em média, distantes cerca de 1000 metros da RCE. Este cenário pode gerar um atendimento não plenamente satisfatório para os estudantes que são usuários regulares de bicicleta, além daqueles que poderiam tornar-se, demonstrando claramente que a localização da RCE não está dentro de uma distância aceitável para estes usuários. Acrescenta-se que a descontinuidade da RCE também impacta direta e negativamente no tempo de viagem. Quanto mais fragmentada e descontínua for a rede, maior o tempo de viagem, o que pode desestimular o uso da mesma pelos usuários. Redes cicloviárias diretas e com um pequeno número de paradas contribuem para a atratividade da bicicleta como modo de transporte (Rietveld e Daniel, 2004).

Diante deste cenário e considerando as variáveis utilizadas neste estudo, pode-se afirmar que no estágio atual, esta rede (RCE) atende muito mal aos seus usuários, fornecendo pouca ou nenhuma segurança e rapidez nos deslocamentos.

Uma das razões da presença de trechos descontínuos da RCE pode ser a falta de métodos objetivos para o planejamento da rede, além da falta ou não uso de dados que servem de base para tal, resultando em uma infraestrutura cicloviária que serve eventualmente apenas para fins político-eleitorais. Com a execução da rede projetada (RCP) pode ser que haja uma melhoria no atendimento aos usuários, sobretudo os potenciais, uma vez que os resultados obtidos foram muito próximos a uma das redes propostas. Além disso, com a consolidação de uma rede cicloviária em toda a cidade de São Carlos, muitos dos usuários reais que atualmente utilizam a bicicleta em seus deslocamentos diários podem vir a utilizar mais a infraestrutura a ser executada. Este uso da RCP aconteceria porque o trajeto seria realizado em uma infraestrutura segura e confortável, ainda que os usuários tenham que percorrer distâncias maiores entre suas origens e seus destinos (comparadas às percorridas atualmente), tal como observado no estudo realizado por Dill e Gliebe (2008). 
Cabe salientar que as variáveis consideradas neste estudo não esgotam as possibilidades para avaliar e comparar redes propostas e existentes. Ainda que isto possa indicar uma fragilidade do método, certamente não o invalida. Neste sentido, a adoção de novas variáveis de custo e benefício referentes às características das redes e a atribuição de pesos às mesmas e dadas por diferentes grupos de usuários (por exemplo, usuários que utilizam a bicicleta diariamente, usuários que a utilizam esporadicamente, gestores públicos, etc.), de forma a obter uma análise hierárquica entre todas as variáveis de custos e benefícios, podem contribuir para um melhor entendimento da relação entre as mesmas.

Não só em São Carlos, mas em muitas cidades dos países em desenvolvimento, a partir da conscientização dos gestores públicos acerca da importância de políticas públicas voltadas à inserção da bicicleta nos deslocamentos urbanos, cada vez mais será possível efetivamente fazer uso do espaço urbano, muitas vezes ocioso em decorrência da prioridade dada aos automóveis. Faz-se necessário definir políticas públicas orientadas para ocupação do uso do solo de forma mista, possibilitando maior adensamento e variedade de atividades dentro de uma mesma área, em contraposição ao espalhamento da ocupação do uso do solo. Esta configuração pode contribuir para uma menor distância entre residências e locais de trabalhos, possibilitando maior uso da bicicleta nos deslocamentos diários e menor uso do automóvel, como observado no trabalho realizado por Stinson e Bath (2004).

Além disso, será possível uma maior redução do consumo de energia não renovável e da emissão de poluentes e de ruídos, maior garantia de mobilidade para uma parcela da população que utiliza a bicicleta diariamente, além da economia em obras de infraestrutura voltada à bicicleta. Talvez o maior benefício constatado pela inclusão de uma política urbana voltada à bicicleta seja, no entanto, a igualdade de mobilidade para todos os atores da cidade, independentemente de sua classe socioeconômica. Isto possibilitaria uma cidade não só mais dinâmica, do ponto de vista econômico e social, como também com melhor qualidade de vida para todos que dela compartilham. 


\subsection{Sugestões para trabalhos futuros}

Em face dos resultados obtidos, são apresentadas algumas sugestões para trabalhos futuros considerando as três etapas da metodologia realizada:

- Utilização de um maior número de variáveis (socioeconômicas e referentes às viagens realizadas) para inserção no minerador de dados;

- Adoção de limites diferentes da probabilidade de uso da bicicleta pelos usuários potenciais, com base no conceito de probabilidade condicional;

- Adoção de um número maior de traçado de rotas entre cada par origem-destino;

- Adoção de diferentes valores de rotas sobrepostas em cada tramo viário (acima de 5, 10 e 15 rotas);

- Desenvolvimento de uma metodologia que identifique o valor mais adequado para ser usado como referência de valores de rotas sobrepostas em cada tramo, dado que este é um problema de otimização que envolve custos e benefícios.

- Adoção de valores diferentes de largura de banda ao redor das redes consideradas;

- Adoção de um maior número de variáveis de custo e benefício referentes às características das redes

- Adoção de valores diferentes dos limites dos critérios de custo e benefício considerados;

- Atribuição de pesos às variáveis consideradas por diferentes grupos de usuários (por exemplo, usuários que utilizam a bicicleta diariamente, usuários que a utilizam esporadicamente, gestores públicos, etc.).

- Definição mais precisa do tipo de infraestrutura a ser implantada (ciclovia, ciclofaixa, espaço compartilhado, etc) em cada uma das redes propostas apresentadas neste trabalho.

Tais sugestões podem contribuir para uma melhor compreensão dos níveis de atendimento de redes cicloviárias, sejam elas propostas, existentes ou projetadas. Além disso, mesmo considerando as redes apresentadas neste trabalho, a adoção 
de todas ou de algumas sugestões nele apresentadas podem contribuir para 0 melhor entendimento de como cada uma delas afeta diretamente os resultados obtidos em comparação aos resultados apresentados neste trabalho. 


\section{REFERÊNCIAS BIBILIOGRÁFICAS}

ABEP. (2008) Critério de Classificação Econômica Brasil. Associação Brasileira de Empresas de Pesquisa. São Paulo.

ABRACICLO. (2012) Anuário da indústria brasileira de duas rodas 2012. Associação Brasileira dos Fabricantes de Motocicletas, Ciclomotores, Motonetas, Bicicletas e Similares. São Paulo.

ABRADIBI. (2015) Mercado brasileiro. Associação Brasileira da Indústria, Comércio, Importação e Exportação de Bicicletas, Peças e Acessórios. São Paulo. Disponível em <http://abradibi.com.br/mercado/index.html>. Acesso em 17 de jul. 2015.

AKAR, G.; CLIFTON, K. J. (2009) Influence of individual perceptions and bicycle infrastructure on decision to bike, Transportation Research Record, v. 2140, p. 165 - 172. DOI: $10.3141 / 2140-18$.

ANTP. (2015) Sistema de Informações da Mobilidade Urbana Relatório Comparativo 2003 - 2013. Associação Nacional de Transportes Públicos. São Paulo.

AULTMAN-HALL, L.; HALL, F.L.; BAETZ, B.B. (1997) Analysis of bicycle commuter routes using geographic information systems implications for bicycle planning. Transportation Research Record, v. 1578, p. $102-110$

BBC - British Broadcasting Corporation (2015) Pedal power forges ahead in Sao Paulo's famous Avenida Paulista. Latin America \& Caribbean. Disponível em: http://www.bbc.com/news/world-latin-america-33271772. Acesso em 17 de jul. 2015.

BENICCHIO, T. (2012) Bicicletas transformando a cidade. In: PADOVANO, B. R.; SALA, P. B.; NAMUR, M. (Org). São Paulo: em busca da sustentabilidade. PINI - EDUSP, v. 1, p. 216-230.

BERGSTRÖM, A.; MAGNUSSON, R. (2003) Potential of transferring car trips to bicycle during winter. Transportation Research Part A, v. 37, p. 649 - 666. DOI: 10.1016/S0965-8564(03)00012-0. 
BERTAZZO, Â. B. S.; GALARRAGA, J.; HERZ, M.; JACQUES, M. A. P. (2012) Estabelecimentos de Ensino. In: PORTUGAL, L. S. (Org.). Polos geradores de viagens orientados à qualidade de vida e ambiental: Modelos e taxas de geração de viagens. $1^{\underline{a}}$ ed. Interciência, Cap. 10, p. 287-327.

BHTRANS. (2012) Plano de mobilidade urbana de Belo Horizonte. Empresa de Transportes e Trânsito de Belo Horizonte. Belo Horizonte. Disponível em: http://www.bhtrans.pbh.gov.br/portal/pls/portal/!PORTAL.wwpob_page.show?_d ocname=9604263.PDF. Acesso em 25 de jul. 2015.

BICYCLE NETWORK. (2014) Active paths. Disponível em <https://www.bicyclenetw ork.com.au/general/programs/358/> Acesso em 10 de set. 2014.

BISPO, C.A.F. (1998) Uma análise de nova geração de sistemas de apoio à decisão. Dissertação (Mestrado) - Escola de Engenharia de São Carlos, Universidade de São Paulo, São Carlos, 1998.

BORGES, F.A.S. (2013) Extração de características combinadas com árvore de decisão para detecção e classificação dos distúrbios de qualidade da energia elétrica. Dissertação (Mestrado) - Escola de Engenharia de São Carlos, Universidade de São Paulo, São Carlos.

BOUSSAUW, K.; VAN MEETEREN, M.; WITLOX, F. (2014) Short trips and central places: The home-school distances in the Flemish primary education system (Belgium). Applied Geography, v. 53, p. 311 - 322.

BRASIL. (1997) Lei no 9.503, de 23 de setembro de 1997. Institui o Código de Trânsito Brasileiro. Brasília.

(2001) Lei no 10.257, de 10 de julho de 2001. Estatuto da Cidade. Brasília.

(2009) Projeto de Lei no 6474/2009. Institui o Programa Bicicleta Brasil, para incentivar o uso da bicicleta visando a melhoria das condições de mobilidade urbana. Texto Original. Brasília. Disponível em < http://www.camara.gov.br/prop osicoesWeb/prop_mostrarintegra?codteor $=717079$ \&filename $=P L+6474 / 2009>$ Acesso em 16 de jul. 2015.

(2012) Lei no 12.587, de 03 de janeiro de 2012. Institui as diretrizes da Política Nacional de Mobilidade Urbana e dá outras providências. Brasília. 
(2013) Projeto de Lei no 4997/2013. Dispõe sobre o IPI - Imposto sobre Produtos Industrializados, fixando alíquota de zero por cento para as bicicletas (item 8712.00.10 da NCM - Nomenclatura Comum do Mercosul), suas partes e acessórios. Texto Original. Disponível em < http://www.camara.gov.br/proposicoesWeb/fichadetr amitacao?idProposicao=565266. Acesso em 16 de jul. 2015.

(2013) Projeto de Lei $n^{\circ}$ 6418/2013. Altera a Lei $n^{\circ}$ 7.418, de 16 de dezembro de 1985, para permitir que o vale-transporte seja utilizado para 0 custeio de transporte do empregado por meio de bicicletas. Texto Original. Disponível em <http://www.camara.gov.br/proposicoesWeb/prop_mostrarintegra?codteor $=114$ 2479\&filename=PL+6418/2013> Acesso em 16 de jul. 2015.

(2013) Projeto de Lei no 6724/2013. Acrescenta artigo à Lei no 7.418, de 16 de dezembro de 1985, para instituir o "Vale-Bicicleta". Texto Original. Disponível em<http://www.camara.gov.br/proposicoesWeb/prop_mostrarintegr a?codteor=1176752\&filename=PL+6724/2013> Acesso em 16 de jul. 2015.

BRASÍLIA (2010). Plano Diretor de Transporte Urbano e Mobilidade do Distrito Federal e Entorno - PDTU/DF. Relatório Final. Governo do Distrito Federal.

BREIMAN, L.; FRIEDMAN, J. H.; OLSHEN, R. A.; STONE, C.J. (1984) Classification and Regression Trees. California: Wadsworth International Group. 368 p.

BROACH, J.; DILL, J.; GLIEBE, J. (2012) Where do cyclists ride? A route choice model developed with revealed preference GPS data. Transportation Research Part A, v. 46, p. 1730 - 1740. DOI: 10.1016/j.tra.2012.07.005.

CABALleRO, D.; CARO, A.; RODRÍGUEZ, P. G.; DURAN, M. L.; AVILA, M. M.; PALACIOS, R.; ANTEQUERA, T.; PEREZ-PALACIOS, T. (2016). Modeling salt diffusion in Iberian ham by applying MRI and data mining. Journal of Food Engineering, v. 189, p. 115 - 122. DOI: 10.1016/j.jfoodeng.2016.06.003.

CÂMARA DOS DEPUTADOS. (2014) Comissões vão avaliar regras tributárias para bicicletas. Câmara Notícias, 2014. Disponível em: <http://www2.camara.leg.br/camaranoticias/noticias/TRANSPORTE-ETRANSITO/467797-COMISSOES-VAO-AVALIAR-REGRAS-TRIBUTARIASPARA-BICICLETAS.html. Acesso em 16 de jul. de 2015. Brasília, DF.

CASTILLO-MANZANO, J. I.; LÓPEZ-VALPUESTA, L.; SÁNCHEZ-BRAZA, A. (2016) Going a long way? On your bike! Comparing the distances for which public 
bicycle sharing system and private bicycles are used. Applied Geography, v. 71, p. 95 - 105. DOI: 10.1016/j.apgeog.2016.04.003.

CBN CURITIBA. (2016) Ippuc realiza pesquisa "Origem-Destino" em Curitiba e região. Central Brasileira de Notícias Curitiba. Disponível em < https://cbncuritiba.com/2016/04/25/ippuc-realiza-pesquisa-origem-destino-emcuritiba-e-regiao/> Acesso em 03 de ago. 2016.

CEARÁ AGORA (2016). Prefeitura de Fortaleza entrega ciclofaixas no Conjunto Ceará. Disponível em: http://www.cearaagora.com.br/site/2016/08/prefeiturade-fortaleza-entrega-ciclofaixas-no-conjunto-ceara/. Acesso em 04 de set. de 2016.

CENTER FOR URBAN TRANSPORTATION RESEARCH. (1995) Bikes-On-Bus Service Delivery in Dade County: Suitability and Feasibility. Metro-Dade Transit Agency, Miami, Florida.

CERVERO, R. (1996) Mixed land-uses and commuting: evidence from the American housing survey. Transportation Research Part A, v. 30, n. 5, p. 361 - 377. DOI: 10.1016/0965-8564(95)00033-X.

COSTA, A. S. G. (2013) Proposta de um método para estimação de escolha modal através da Geoestatística. Dissertação (Mestrado) - Universidade Federal da Bahia, Escola Politécnica, Salvador, 2013.

CROW, E. (2007) Design manual for bicycle traffic. Record n. 25. Ede. The Netherlands, $388 \mathrm{p}$.

DENATRAN. (2008) Sinalização de áreas escolares. Departamento Nacional de Trânsito. Brasília. Disponível em <http://www.denatran.gov.br/publicacoes/ download/AreasEscolares.pdf>. Acesso em 09 set. de 2014.

DENATRAN. (2015) Frota de veículos. Departamento Nacional de Trânsito. Brasília. Disponível em <http://www.denatran.gov.br/frota.htm>. Acesso em 17 de jul. 2015.

DEPARTMENT OF ENVIRONMENTAL RESOURCES. (1996) North Central Texas Council of Governments. Draft Bicycle Needs Index, 1996. Disponível em <http://www.nctcog.tx.us/envir/bikeped/draftbni.pdf> Acesso em 30 de ago. 2016. 
DILL, J.; CARR, T. (2003) Bicycle commuting and facilities in major U.S. cities: if you build them, commuters will use them. Transportation Research Record, n. 1828, p. $116-123$.

DILL, J.; GLIEBE, J. (2008) Understanding and measuring bicycling behavior: a focus on travel time and route choice. Final report OTREC-RR-08-03 prepared for Oregon Transportation Research and Education Consortium (OTREC).

DILL, J., VOROS, K. (2007) Factors affecting bicycling demand initial survey findings from the Portland, Oregon, Region. Transportation Research Record, v. 2031, p. 9 - 17. DOI: 10.3141/2031-02.

DIXON, L.B. (1996) Bicycle and pedestrian level of service performance measures and standards for congestion management systems. Transportation Research Record, v. 1538, p. $01-09$.

DUBOSE, B. (2011) Physically separated bikeways: A game changer for bicycle mode split? ITE Journal, v. 81, n. 4, p. 54.

EL NAQA, I.; DEASY, J. O.; MU, Y.; HUANG, E.; HOPE, A. J.; LINDSAY, P. E.; APTE, A.; ALALY, J.; BRADLEY, J. D. (2010) Datamining approaches for modeling tumor control probability. Acta Oncologica, v. 49, p. 1363 - 1373. DOI: 10.3109/02841861003649224.

ENGLUND, C.; NILSSON, M.; VORONOV, A. (2016) The application of data mining techniques to model visual distraction of bicyclists. Expert Systems With $\begin{array}{llllll}\text { Applications, } & \text { v. } & 52, & \text { p. } & 99-107 . & \text { DOI: }\end{array}$ http://dx.doi.org/10.1016/j.eswa.2016.01.006.

EPPERSON, B.; HENDRICKS, S. J.; YORK, M. (1995) Estimation of Bicycle Transportation Demand from Limited Data. In: 1995 Compendium of Technical Papers. Presented at the $65^{\text {th }}$ Annual Meeting of the Institute of Transportation Engineers. Denver, Colorado, pp. 436-440.

FERNÁNDEZ-HEREDIA, A.; JARA-DÍAZ, S.; MONZÓN, A. (2016) Modelling bicycle use intention: the role of perceptions. Transportation, v. 43, p. 1-23. DOI 10.1007/s11116-014-9559-9.

FERRARI, R. (2008) Plano diretor cicloviário integrado de Porto Alegre - a questão da institucionalização. In: XXIII ANPET - Congresso de Pesquisa e Ensino em Transportes, 2008. Fortaleza, ANPET. 
FERREIRA, C. A.; SOARES, J. F.; CRUZ, F. R. B. (2001) Reconhecimento de Padrões em Estatística: Uma Abordagem Comparativa. In: Proceedings of the $\checkmark$ Brazilian Conference on Neural Networks - V Congresso Brasileiro de Redes Neurais, p. 409 - 414, Rio de Janeiro.

FHWA. (1992) Reasons why bicycling and walking are not being used more extensively as travel modes: case study no 1. Federal Highway Administration, 1992. Oxford: US Department of Transportation.

FHWA (1999) Guidebook on methods to estimate non-motorized travel: overview of methods. Federal Highway Administration, 1999. Washington: US Department of Transportation.

FLÜGEL, S.; RAMJERDI, F.; VEISTEN, K.; KILLI, M.; ELVIK, R. (2015) Valuation of cycling facilities with and without controlling for casualty risk. International Journal of Sustainable Transportation, v. 9:5, p. 364-376, DOI: 10.1080/15568318.2013.798749.

GÄRLING, T.; BOE, O.; GOLLEDGE, R.G. (2000) Determinants of distance thresholds for driving. Transportation. Research Record, v. 1718, p. 68 - 72.

GATERSLEBEN, B.; APPLETON, K. M. (2007) Contemplating cycling to work: Attitudes and perceptions in different stages of change. Transportation Research Part A, v. 41, p. 302 - 312. DOI: 10.1016/j.tra.2006.09.002.

GEIPOT. (2001) Manual de Planejamento Cicloviário. Empresa Brasileira de Planejamento de Transportes, 2001. Brasília.

GOLDSMITH, S. [19--]. Estimating the effect of bicycle facilities on VMT and emissions. Seattle Engineering Department, Seattle, Washington.

GONZALEZ, M. P.; LORES, J.; GRANOLLERS, A. (2008) Enhancing usability testing through datamining techniques: A novel approach to detecting usability problem patterns for a context of use. Information and Software Technology, v. 50, p. 547 - 568. DOI: 10.1016/j.infsof.2007.06.001.

GÖSSLING, S.; CHOI, A. S. (2015) Transport transitions in Copenhagen: Comparing the cost of cars and bicycles. Ecological Economics, v. 113, p. $106-113$. 
GRAU, R. I. (2015) Mobilidade cicloviária em viagens a campi universitários - estudo de caso: UFSCar, São Carlos, SP. Dissertação (Mestrado) - Universidade Federal de São Carlos, São Carlos, 2015.

GUERREIRO, T. C. M.; RODRIGUES DA SILVA, A. N. (2013) A computer-aided approach for planning sustainable trips to large trip generators: the case of cycling routes serving university Campuses. In: GEERTMAN, S.; TOPPEN, F.; STILLWELL, J. (Org.). Lecture Notes in Geoinformation and Cartography. $1^{\text {a }}$ ed. Springer Berlin Heidelberg, p. 297 - 308. DOI: 10.1007/978-3-642-375330_17

GUERREIRO, T. C. M.; STEIN, P. P.; RODRIGUES DA SILVA, A. N. (2013) Potencial de uma infraestrutura cicloviária para diferentes usuários de um polo gerador de viagens: o caso de um campus universitário. In: XXVII ANPET Congresso de Pesquisa e Ensino em Transportes, 2013, Belém. ANPET.

GUERREIRO, T. C. M.; RODRIGUES DA SILVA, A. N.; RAMOS, R. A. R. (2017) Explorando dados de pesquisas origem-destino para o planejamento de novas redes cicloviárias. Revista dos Transportes Públicos. No prelo.

HABIB, K. N.; MANN, J.; MAHMOUD, M.; WEISS, A. (2014) Synopsis of bicycle demand in the City of Toronto: Investigating the effects of perception, consciousness and comfortability on the purpose of biking and bike ownership. Transportation Research Part $A$, v. 70, p. 67-80. DOI: 10.1016/j.tra.2014.09.012.

HAMER, L. J.; ALMEIDA, C. F.; ANDRADE, K. (2015) Contribuição para definição de diretrizes para implantação de ciclovias com base na identificação do perfil do usuário em potencial de bicicleta: um estudo no corredor universitário em Goiânia. In: XXIX ANPET - Congresso de Pesquisa e Ensino em Transportes, 2015, Ouro Preto. ANPET, p. 2081 - 2092.

HEINEN, E.; K. MAAT; VAN WEE, B. (2011) The role of attitudes toward characteristics of bicycle commuting on the choice to cycle to work over various distances. Transportation Research Part D, v. 16, n. 2, p. 102-109.

HOPKINSON, P.; WARDMAN, M. (1996) Evaluating the demand for new cycle facilities. Transport Policy, v. 3, n. 4, p. 241 - 249.

HSU, T.P.; LIN, Y. T. A model for planning a bicycle network with multi-criteria suitability evaluation using GIS. In: Brebbia, C.A; Zubir, S. S (Org). Management of Natural Resources, Sustainable Development and Ecological 
Hazards III. Southampton: WIT Press, 2012, Section 4: Planning and development, p. 243 - 252.

HUANG, Y.; YE, G. (1995) Selecting bicycle commuting routes using GIS. Berkeley Planning Journal, v. 10, n. 1, p.75 - 90.

HUI, E. C. M. ; ZUO, W. ; HU, L. (2011) Examining the relationship between real estate and stock markets in Hong Kong and the united kingdom through datamining. International Journal of Strategic Property Management, v. 15, p. 26 - 34. DOI: 10.3846/1648715x.2011.565867.

HYODO, T.; SUZUKI, N.; TAKAHASHI, K. (2000) Modeling of bicycle route and destination choice behavior for bicycle road network plan. Transportation Research Record 1705, p. 70-76.

IBGE. (2010) Pesquisa Nacional por Amostra de Domicílios 2009. Instituto Brasileiro de Geografia e Estatística. Rio de Janeiro. Disponível em < http://www.ibge.gov.br/home/estatistica/populacao/trabalhoerendimento/pnad20 09/>. Acesso em 17 de jul. 2015.

(2015) Projeção da população das unidades da federação por sexo e idade: 2000 -2030. Instituto Brasileiro de Geografia e Estatística. Disponível em: http://www.ibge.gov.br/home/estatistica/populacao/projecao_da_populacao/201 3/default_tab.shtm. Acesso em 17 de jul. 2015.

(2016) Cidades - São Carlos. Instituto Brasileiro de Geografia e Estatística. Disponível em: < http://www.cidades.ibge.gov.br/xtras/perfil.php?lan $g=\&$ codmun=354890\&search=sao-paulo|sao-carlos $>$. Acesso em 11 de fev. 2016.

IBM Corporation. (2016) IBM SPSS Decision Trees 24. Disponível em: <ftp://public.dhe.ibm.com/software/analytics/spss/documentation/statistics/24.0/ pt-BR/client/Manuals/IBM_SPSS_Decision_Trees.pdf>. Acesso em $10 \mathrm{fev}$. 2016.

IDU. (2014) Plan Maestro de Ciclo Rutas. Instituto de Desarrollo Urbano. Bogotá. Disponível em <https://www.idu.gov.co/atencion-al-ciudadano/infraestructuracicloinclusiva/plan-maestro-de-ciclorutas>. Acesso em 13 de jul. 2015.

IMPLAN. (2012) Plan de desarrollo urbano municipal de San Pedro Garza García, N.L. 2030 - Versión para consulta pública. Instituto Municipal de Planeación 
Urbana San Pedro Garza García. San Pedro Garza García. Disponível em: <https://www.sanpedro.gob.mx/Gobierno/Plan2030/PlanDesarrolloUrbano2030. pdf>. Acesso em 13 de jul. 2015.

INFRAESTRUTURA URBANA (2014) Recife lança plano diretor cicloviário: Documento estabelece diretrizes para criar mais de $240 \mathrm{~km}$ de ciclovias interligando 14 municípios. Disponível em < http://infraestruturaurbana.pini.com .br/solucoes-tecnicas/41/artigo319512-1.aspx> Acesso em 04 de set. de 2016.

IPEA. (2012) Situação social brasileira - monitoramento das condições de vida 2. Instituto de Pesquisa Econômica Aplicada. Brasília. Disponível em < http://www.ipea.gov.br/portal/index.php?option=com_content\&view=article\&id=1 5429> Acesso em 20 de ago. 2015.

IPEA (2015) Estimativa dos custos dos acidentes de trânsito no Brasil com base na atualização simplificada das pesquisas anteriores do Ipea. Disponível em $<$ http://www.en.ipea.gov.br/agencia/images/stories/PDFs/relatoriopesquisa/160 516_relatorio_estimativas.pdf> Acesso em 20 de ago. 2015.

IPPUC. (2013) Plano estratégico cicloviário de Curitiba. Instituto de Pesquisa e Planejamento Urbano de Curitiba. Curitiba. Disponível em < http://ippuc.org.br/mostrarPagina.php?pagina=313\&idioma $=1$ \&titulo=> Acesso em 13 de jul. 2015.

ISLER, C. A.; PITOMBO, C. S. (2014) Avaliação da escolha modal para o transporte ferroviário de passageiros na região sudeste através de Árvores de Decisão. In: XXVIII ANPET - Congresso de Pesquisa e Ensino em Transportes, 2014, Curitiba. ANPET.

KASS, G. V. (1980) An exploratory technique for investigating large quantities of categorical data. Applied Statistics, v. 29, p. $119-127$.

KHAN, M.; KOCKELMAN, K. M.; XIONG, X. (2014) Models for anticipating nonmotorized travel choices, and the role of the built environment. Transport Policy, v. 35, p. 117 - 12.6. DOI: 10.1016/j.tranpol.2014.05.008.

KHEIR, R. B.; CHOROWICZ, J.; ABDALLAH, C.; DHONT, D. (2008) Soil and bedrock distribution estimated from gully form and frequency: A GIS-based decision-tree model for Lebanon. Geomorphology, v. 93, p. 482-492. DOI:10.1016/j.geomorph.2007.03.010. 
KIRNER, J. (2006) Proposta de um método para definição de rotas cicláveis em áreas urbanas. Dissertação (Mestrado) - Universidade Federal de São Carlos, São Carlos, 2006.

LANDIS, B. (1996) Using the Latent Demand Score Model to estimate use. In: Pro Bike/Pro Walk 96 Resource Book. Presented at the Ninth International Conference on Bicycle and Pedestrian Programs, Portland, Maine. p. 320-325.

LARSEN, J.; PATTERSON, Z.; EL-GENEIDY, A. (2013) Build it. But where? The use of Geographic Information Systems in identifying locations for new cycling infrastructure. International Journal of Sustainable Transportation, v. 7, p. 299 317.DOI: 10.1080/15568318.2011.631098.

LIN, J.; YU, C. (2013) A bikeway network design model for urban areas. Transportation, v. 40, p. 45 - 68. DOI 10.1007/s11116-012-9409-6.

LINDNER, A.; PITOMBO, C. S.; CUNHA, A. L. (2017) Estimating motorized travel mode choice using classifiers: An application for high-dimensional multicollinear data. Travel Behaviour and Society, v. 6, p. 100-109.

LITMAN T.; BLAIR, R; DEMOPOULOS, B.; EDDY, N.; FRITZEL, A.; LAIDLAW, D.; MADDOX, H.; FORSTER, K. (2002) Pedestrian and bicycle planning: a guide to best practices. Victoria Transport Policy Institute, Canadá. Disponível em: <http://www.vtpi.org/nmtguide.doc>. Acesso em out. de 2012.

LOUKOPOULOS, P.; GÄRLING, T. (2005) Are car users too lazy to walk? The relationship of distance thresholds for driving to the perceived effort of walking. Transportation Research Record, v. 1926, p. 206 - 211.

LOUVIERE, J.J.; HENSHER, D.A.; SWAIT, J.D. (2000) Stated choice methods analysis and aplication. Cambridge: Cambridge University Press, $30 \mathrm{p}$.

LOVELACE, R.; GOODMAN, A.; ALDRED, R.; BERKOFF, N; ABBAS, A.; WOODCOCK, J. (2015) The Propensity to Cycle Tool: An open source online system for sustainable transport planning. Disponível em: <http://arxiv.org/abs/1509.04425>. Acesso em jan. de 2015.

LTSA - Land Transport Safety Authority. (2004) Cycle network and route planning guide. Nova Zelândia: LTSA. 92 p. 
MACKETT, R.L. (2001) Policies to attract drivers out of their cars for short trips. Transportation Research Policy, v. 8, edição 4, p. 295 - 306.

MAIA, L. H.; SOUSA, G. M.; FERNANDES, M. C. (2016) Uso de mineração de dados para mapeamento da cobertura da terra em imagem Landsat 8 no Parque Nacional do Itatiaia, Revista Continentes (UFRRJ), ano 5, n. 8, p. 63-74 (ISSN 2317-8825).

MALAGUTI, R.; MICHALKA, Jr. C. (2012) As denominadas ciclovias cariocas: uma avaliação à luz da legislação federal e das recomendações técnicas. In: III SIMPGEU - Simpósio de Pós Graduação em Engenharia Urbana, Maringá. SIMPGEU. 2012.

MARINS, K. R. C. C.; PIOCHI, M. M. P.; TORRETTA, I. P.; CARVALHO, A. F.; LOPES, M. P. (2015) Estudo de viabilidade para implantação de sistema cicloviário no Campus da USP em São Paulo. In: 20ํㅡㄹ Congresso Brasileiro de Transporte e Trânsito, 2015, Santos. ANTP.

MEDEIROS, R. M.; DUARTE, F. (2013) Policy to promote bicycle use or bicycle to promote politicians? Bicycles in the imagery of urban mobility in Brazil. Urban, Planning and Transport Research: An Open Access Journal, n. 1, p. 28 - 44. DOI:10.1080/21650020.2013.866875.

MENGHINI, G.; CARRASCO, N.; SCHÜSSLER, N.; AXHAUSEN, N. (2010) Route choice of cyclists in Zurich. Transportation Research Part A, v. 44, p. 754 - 765. DOI:10.1016/j.tra.2010.07.008.

MESBAH, M.; THOMPSON, R.; MORIDPOUR, S. (2012) Bilevel optimization approach to design of network of bike lanes. Transportation Research Record, v. 2284, p. 21 - 28. DOI: 10.3141/2284-03.

MILAKIS, D.; ATHANASOPOULOS, K. (2014) What about people in cycle network planning? Applying participative multicriteria GIS analysis in the case of the Athens metropolitan cycle network. Journal of Transport Geography, v. 35, p. $120-129$.

MINISTÉRIO DAS CIDADES. (2007) Coleção Bicicleta Brasil: Programa Brasileiro de Mobilidade por Bicicleta. Ministério das Cidades: Brasilia. 
MONTEIRO, F. B.; CAMPOS, V. B. G. (2012) A proposal of indicators for evaluation of the urban space for pedestrians and cyclists in access to mass transit station. Procedia - Social and Behavioral Sciences, v. 54, p. 637 - 645.

MORAIS, M. P.; CARVALHO, C. H.; REGO, P A. (2012) Condições de moradia, saneamento básico e mobilidade urbana no Brasil: evidências a partir da PNAD 2009. In: CASTRO, J. A; ARAÚJO, H. E. (org.) Situação social brasileira: monitoramento das condições de vida 2. Instituto de Pesquisas Econômicas Aplicadas; 2012, Cap. 8, p.139 - 59.

MOUDON, A.V.; LEE, C.; CHEADLE, A.D.; COLLIER, C.W.; JOHNSON, D.; SCHMID, T.L.; WEATHER, R.D. (2005) Cycling and the built environment, a US perspective. Transportation Research Part D, v. 10, p. 245-261. DOI:10.1016/j.trd.2005.04.001.

MUTRIE, N.; CARNEY, C.; BLAMEY, A.; CRAWFORD, F.; AITCHISON, T.; WHITELAW, A (2002) Walk in to Work Out: a randomised controlled trial of a self help intervention to promote active commuting. Journal of Epidemiology and Community Health, v. 56, p. 407 - 412.

NCHRP (2006) Guidelines for Analysis of Investments in Bicycle Facilities. NCHRP Report 552, Transportation Research Board, Washington, D.C. Disponível em: http://onlinepubs.trb.org/onlinepubs/nchrp/nchrp_ rpt_552.pdf. Acesso em: 20 de mar. 2012.

NERI, T. B. (2012) Proposta metodológica para definição de rede cicloviária: um estudo de caso de Maringá. Dissertação (Mestrado) - Universidade Estadual de Maringá, Maringá, 2012.

NKURUNZIZA, A.; ZUIDGEEST, M.; BRUSSEL, M.; MAARSEVEEN, M. V. (2012) Examining the potential for modal change: Motivators and barriers for bicycle commuting in Dar-es-Salaam. Transport Policy, v. 24, p. 249 -259. DOI: 10.1016/j.tranpol.2012.09.002.

ORTÚZAR, J. D.; IACOBELLI, A.; VALEZE, C. (2000) Estimating demand for a cycleway network. Transportation Research Part A, v. 34, p. 353-373.

ORTÚZAR, J. D.; WILLUMSEN, L. G. (2011) Modelling transport (4ª ed.). Chichester: John Wiley \& Sons Ltd. 607 p. 
PARKES, S. D.; JOPSON, A.; MARSDEN, G. (2016) Understanding travel behaviour change during mega-events: Lessons from the London 2012 Games. Transportation Research Part A, v. 92, p. 104-119. DOI: 10.1016/j.tra.2016.07.006.

PERU (2014) Plan Metropolitano de Desarrollo Urbano de Lima - Callao (PLAM). Disponível em < http://www.transitemos.org/aprende-de-movilidad/plam-lima-ycallao-2035/> Acesso em 30 ago. 2016.

PEZZUTO, C. C.; SANCHES, S. P. (2004) Identificação dos fatores que influenciam no uso da bicicleta. In: XVII ANPET - Congresso de Pesquisa e Ensino em Transportes, 2004, Florianópolis. ANPET.

PLATAFORMA URBANA (2015). Los planes de ciclovías para el Gran Santiago hasta 2032. Disponível em: http://www.plataformaurbana.cl/archive/2015/02/03/ los-planes-de-ciclovias-para-el-gran-santiago-hasta-2032/. Acesso em 13 de jul. 2015.

PITOMBO, C. S. (2007) Estudo de relações entre variáveis socioeconômicas, de uso do solo, participação em atividades e padrões de viagens encadeadas urbanas. Tese (Doutorado) - Escola de Engenharia de São Carlos, Universidade de São Paulo, São Carlos, 2007.

PITOMBO, C. S.; COSTA, A. S. G. (2015) Aplicação conjunta de modelos não paramétricos e paramétricos para previsão de escolha modal. Journal of Transport Literature, v. 9, p. 30-34, 2015.

PITOMBO, C. S.; GUIMARÃES, H. S. (2016) Uso de técnica de mineração de dados no auxílio à modelagem de distribuição de viagens intermunicipais. Revista Engenharia Civil, n. 52.

POURTAGHI, Z. S.; POURGHASEMI, H. R.; ARETANO, R.; SEMERARO, T. (2016) Investigation of general indicators influencing on forest fire and its susceptibility modeling using different data mining techniques. Ecological Indicators, v. 64, p. 72 - 84. DOI:10.1016/j.ecolind.2015.12.030.

PREFEITURA DO MUNICÍPIO DE SÃO PAULO (2015) Plano de mobilidade de São Paulo Modo bicicleta. Disponível em <http://www.prefeitura.sp.gov.br/cidade/se cretarias/upload/chamadas/planmobsp-rev002_1428005731.pdf>. Acesso em 14 de jul. 2015. 
PROCHASKA, J. O.; DI CLEMENTE, C. C. (1982) Transtheoretical therapy: Toward a more integrative model of change. Psychotherapy: theory, research \& practice, v. 19, n. 3, p. $276-288$.

PROCHASKA, J.; DI CLEMENTE, C. (1983) Stages and processes of self-change of smoking: Toward an integrative model of change. Journal of Consulting and Clinical Psychology, v. 51, p. 390 - 395.

PROCHASKA, J. O.; DI CLEMENTE, C. C. (1984) The transtheoretical approach: crossing traditional boundaries of change. Dow Jones/Irwin, Homewood, IL. 193 p.

PROVIDELO, J. K.; SANCHES, S. P (2010) Percepções de indivíduos acerca do uso da bicicleta como modo de transporte. TRANSPORTES, v. XVIII, n. 2, p. 53 61.

PROVIDELO, J. K.; SANCHES, S. P. (2011) Roadway and traffic characteristics for bicycling. Transportation, v. 38, p. $765-777$. DOI 10.1007/s11116-011-9353-x.

QUINLAN, J. R. C4.5: (1993) Programs for machine learning. San Mateo, California: Morgan Kaufmann Publishers. $302 \mathrm{p}$.

RASOULI, S.; TIMMERMANS, H. J. P. (2014) Using ensembles of decision trees to predict transport mode choice decisions: Effects on predictive success and uncertainty estimates. European Journal of Transport and Infrastructure Research, v. 14, n. 4, p. 412 - 424.

RASTOGI, R. (2010). Willingness to shift to walking or bicycling to access suburban rail: case study of Mumbai, India. Journal of Urban Planning and Development, v. 136, p. $3-10$.

RHODE ISLAND. (1982) Providence-Bristol Bicycle Facility Trip Estimates. Rhode Island Department of Transportation, Planning Division. Providence.

RIBEIRO, R. A. (2011) Modelo baseado em agentes para estimar a geração e a distribuição de viagens intraurbanas. Tese (Doutorado) - Escola de Engenharia de São Carlos, Universidade de São Paulo, São Carlos, 2011.

RIDGWAY, M. D. (1995) Projecting bicycle demand: an application of travel demand modeling techniques to bicycles. In: 1995 Compendium of Technical Papers. 
Presented at the $65^{\text {th }}$ Annual Meeting of the Institute of Transportation Engineers, 1995, Denver, p. $755-761$.

RIETVELD, P.; DANIEL, V. (2004) Determinants of bicycle use: do municipal policies matter? Transportation Research Part A, v. 38, p. 531-550. DOI:10.1016/j.tra.2004.05.003

RISTOSKI, P.; PAULHEIM, H. (2016) Semantic Web in data mining and knowledge discovery: A comprehensive survey. Web Semantics: Science, Services and Agents on the World Wide Web, v. 36, p. 1-22. DOI:10.1016/j.websem.2016.01.001.

RODRÍGUEZ, D. A.; JOO, J. (2004) The relationship between non-motorized mode choice and the local physical environment. Transportation Research Part $D$, v. 9, n. 2, p. $151-173$.

RODRIGUES, V. C.; VIEIRA, F. M. C.; SILVA, I. J. O. (2013). Data-mining for preslaughter mortality preview of broilers. Archivos de Zootecnia, v. 62, p. 469 472. DOI: 10.4321/s0004-05922013000300015.

RODRIGUES DA SILVA, A. N. (2008) Pesquisa Origem-Destino da Cidade de São Carlos. Relatório do projeto de pesquisa FAPESP (Fundação de Amparo à Pesquisa do Estado de São Paulo) número 04/15843-4. São Carlos.

RODRIGUES DA SILVA, A. N.; RIBEIRO, A. S. N.; PINHEIRO, E. A.; CORREIA, G. H. A. R.; GUERREIRO, T. C. M.; CRUZ, I.; FRADE, I.; CAMPOS, V. B. G. (2012) Viagens por bicicletas. In: PORTUGAL, L.S. (Org.). Polos geradores de viagens orientados à qualidade de vida e ambiental: Modelos e taxas de geração de viagens. $1^{\text {a }}$ ed. Interciência, Cap. 15, p. 497 - 529.

ROSE, G.; MARFURT, H. (2007) Travel behaviour change impacts of a major ride to work day event. Transportation Research Part A, v. 41, p. 351 -364. DOI: 10.1016/j.tra.2006.10.001.

RUIZ, T.; BARNABÉ, J. C. (2014) Measuring factors influencing valuation of nonmotorized improvement measures. Transportation Research Part A, v. 67, p. 195 - 211. DOI: 10.1016/j.tra.2014.06.008.

RYBARCZYK, G.; WU, C. (2010) Bicycle facility planning using GIS and multi-criteria decision analysis. Applied Geography, v. 30, p. 282 - 293. 
SAFAVIAN, S.R.; LANDGREBE, D. (1991) A survey of decision tree classifier methodology. IEEE Transactions on Systems, Man, and Cybernetics, v. 21, n. 3, p.660 - 674.

SANTOS, M. C. S. (2015) Explorando técnicas para modelagem de dados agregados de óbitos provenientes de acidentes por automóvel. Dissertação (Mestrado) - Escola de Engenharia de São Carlos, Universidade de São Paulo, São Carlos, 2015.

SÃO CARLOS. (2005) Lei no 13.691, de 25 de novembro de 2005. Institui o Plano Diretor do Município de São Carlos e dá outras providências. Texto Original. Disponível em < http://www.saocarlos.sp.gov.br/images/stories/pdf/Lei_13691_05_Plano_ Diretor.pdf>. Acesso em 11 de fev. 2016.

(2011) Revisão do Plano Diretor do Município de São Carlos. Produto I: Atualização da leitura técnica do município. Contrato no40/11 - PMSC/FUSP. São Carlos. 141 p.

(2012) Revisão do Plano Diretor do Município de São Carlos. Etapa 4: Propostas para a revisão do plano diretor do município de São Carlos. Contrato no-40/11 - PMSC/FUSP. São Carlos. 46 p.

SÃO PAULO (Estado) (2014) Lei no 15.318, de 13 de fevereiro de 2014. Institui a política de mobilidade sustentável e de incentivo ao uso da bicicleta no âmbito do estado de São Paulo e dá outras providências. São Paulo.

SCHUH, M. A.; ANGRYK, R. A.; Martens, P. C. (2015) Solar image parameter data from the SDO: Long-term curation and data mining. Astronomy and Computing, v. 13, p. 86 - 98. DOI: 10.1016/j.ascom.2015.10.004.

SEGADILHA, A.B.P. (2014) Identificação dos fatores que influenciam na escolha da rota pelos ciclistas: estudo de caso da cidade de São Carlos. Dissertação (Mestrado) - Universidade Federal de São Carlos, São Carlos, 2014.

SENER, I. N.; ELURU, N.; BHAT, C. R. (2009) An analysis of bicycle route choice preferences in Texas, US. Transportation, v. 36, p. 511-539. DOI 10.1007/s11116-009-9201-4. 
SHANNON, T.; GILES-CORTI, B.; PIKORA, T.; BULSARA, M.; SHILTON, T.; BULL, $F$. (2006) Active commuting in a university setting: Assessing commuting habits and potential for modal change. Transport Policy, v. 13, p. $240-253$. DOI: 10.1016/j.tranpol.2005.11.002.

SILVA, C. O. (2015) Corrida cicloviária: uma avaliação da rede de ciclovias implantada no Distrito Federal. In: XVI ENANPUR - Encontro Nacional da Associação Nacional de Pós-Graduação e Pesquisa em Planejamento Urbano e Regional, 2015, Belo Horizonte. ENANPUR.

SILVA, M. A. (2006) Verificação da aplicabilidade da técnica de mineração de dados na previsão de demanda por transporte de passageiros urbanos usando dados da região metropolitana de São Paulo. Dissertação (Mestrado) - Escola de Engenharia de São Carlos, Universidade de São Paulo, São Carlos, 2006.

SOUSA, I. C. N.; SANCHES, S. P. (2015) Proposta de procedimentos para a definição de redes cicloviárias em cidades de porte médio. In: XXIX ANPET Congresso de Pesquisa e Ensino em Transportes, 2015, Ouro Preto. ANPET, p. $1682-1685$.

SOUZA, P. B. (2012) Análise de fatores que influem no uso da bicicleta para fins de planejamento cicloviário. Tese (Doutorado) - Escola de Engenharia de São Carlos, Universidade de São Paulo, São Carlos, 2012.

SMAC. (2010) Programas cicloviários - Rio, capital da bicicleta. Secretaria Municipal de Meio Ambiente. Disponível em <http://www.rio.rj.gov.br/web/smac/riocapital-da-bicileta> Acesso em 14 de jul. 2015.

STEIN, P. P. (2013) Barreiras, motivações e estratégias para mobilidade sustentável no campus São Carlos da USP. Dissertação (Mestrado) - Escola de Engenharia de São Carlos, Universidade de São Paulo, São Carlos, 2013.

STINSON, M. A.; BHAT, C. R. (2003) Commuter bicyclist route choice - analysis using a stated preference survey. Transportation Research Record 1828, p. 107 $-115$.

STOJANOVA, D.; PANOV, P.; KOBLER, A.; DŽEROSKI, S.; TAŠKOVA, K. (2006) Learning to predict forest fires with different data mining techniques. In: Proceedings of the $9^{\text {th }}$ International multi conference Information Society IS. Jožef Stefan Institute, Ljubljana. 
TEOH, S. T.; KITAMURA, M.; NAKAYAMA, Y.; PUTRI, S.; MUKAI,Y.; FUKUSAKI, E. (2016). Random sample consensus combined with partial least squares regression (RANSAC-PLS) for microbial metabolomics data mining and phenotype improvement. Journal of Bioscience and Bioengineering, v. 122, p. 168 - 175. DOI: doi:10.1016/j.jbiosc.2016.01.007.

THIESEN, S.; VIEIRA, D. M. (2013) Análise e otimização por programação linear da distribuição de bicicletas na região universitária de Florianópolis/SC. In: XXVII ANPET - Congresso de Pesquisa e Ensino em Transportes, 2013, Belém. ANPET.

THIGPEN, C. G; DRILLER, B. K.; HANDY, S. L. (2015) Using a stages of change approach to explore opportunities for increasing bicycle commuting. Transportation Research Part D, v. 39, p. $44-55 . \quad$ DOI: 10.1016/j.trd.2015.05.005.

TURNER, S.; HOTTENSTEIN, A.; SHUNK, G. (1997) Bicycle and Pedestrian Travel Demand Forecasting Literature Review. Publication 1723-1. Texas Transportation Institute, Texas A\&M University, and Texas Department of Transportation.

UNDERWOOD, S. K.; HANDY, S. L.; PATERNITI, D. A.; LEE, A. E. (2014) Why do teens abandon bicycling? A retrospective look at attitudes and behaviors. Journal of Transport \& Health, v. 1, p. 17 - 24. DOI:/10.1016/j.jth.2013.12.002.

VÁ DE BIKE. (2014) Reduzir impostos da bicicleta aumentaria a arrecadação (além de deixá-la mais barata). Disponível em <http://vadebike.org/2013/11/bicicletapara-todos-reducao-impostos/> Acesso em 16 de jul. de 2015.

VERMA, M.; RAHUL, T. M.; REDDY, P. V.; VERMA, A. (2016) The factors influencing bicycling in the Bangalore city. Transportation Research Part $A, \mathrm{v}$. 89, p. 29 - 40. DOI: 10.1016/j.tra.2016.04.006.

WALCYNG. (1997) How to enhance walking and cycling instead of shorter car trips and to make these modes safer. Disponível em < http://cordis.europa.eu/transport/src/walcyng.htm> Acesso em 20 de ago. 2016.

WANG, J.Y.T.; MIRZA, L.; CHEUNG, A.K.L.; MORADI, S. (2014) Understanding factors influencing choices of cyclists and potential cyclists: A case study at the University of Auckland. Road \& Transport Research, v. 23, 3ª edição, p. 37 - 51. 
WARDMAN, M.; TIGHT, M.; PAGE, M. (2007) Factors influencing the propensity to cycle to work. Transportation Research Part A, v. 41, p. $339-350$. DOI:10.1016/j.tra.2006.09.011.

WILLIAMSON, R. I.; FIELD, J. G.; SHILLINGTON, F. A.; JARRE, A.; POTGIETER, A. (2015) Combining shipboard in situ data with satellite data to estimate daily primary production in a coastal upwelling system: A data mining approach. Progress in Oceanography, v. 138, p. $58-76$. DOI: 10.1016/j.pocean.2015.09.004.

WOOLISCROFT, B.; GANGLMAIR-WOOLISCROFT, A. (2014) Improving conditions for potential New Zealand cyclists: An application of conjoint analysis. Transportation Research Part $A$, v. 69, p. 11-19. DOI: 10.1016/j.tra.2014.08.005.

WUERZER, T.; MASON, S. G. (2015) Cycling willingness: investigating distance as a dependent variable in cycling behavior among college students. Applied Geography, v. 60, p. 95 - 106. DOI:10.1016/j.apgeog. 2015.03.009

XIE, C.; JINYANG, L.; PARKANY, E. (2003) Work travel mode choice modeling with data mining: decision trees and neural networks. Transportation Research Record, v. 1854, p. 50 - 61. DOI: 10.3141/1854-06

YAMASHITA, Y.; DANTAS, A.; TACO, P.; YAMAMOTO, K. (1998) Geographical Information System \& Remote Sensing in bicycle planning. In: Proceedings of 21th Annual Infrastructure Planning Conference, p. 295 - 298, Shiga, Japan.

YI, M.; FEENEY, K.; ADAMS, D.; GARCIA, C.; CHANDRA, P. (2011) Valuing cycling - Evaluating the economic benefits of providing dedicated cycle ways at a strategic network level. In: Proceedings of Australasian Transport Research Forum 2011. Adelaide, Austrália.

ZAHRAN, S.; BRODY, S. D.; MAGHELAL, P.; PRELOG, A.; LACY, M. (2008) Cycling and walking: explaining the spatial distribution of healthy modes of transportation in the United States. Transportation Research Part D, v. 13, n. 7, p. 462 - 470. 